CARLOS MARTINS AGRA

\title{
AVALIAÇÃO QUANTITATIVA E QUALITATIVA DE DUAS CERÂMICAS FRENTE A DIFERENTES TRATAMENTOS DE SUPERFÍCIE
}

Tese apresentada à Faculdade de Odontologia da Universidade de São Paulo, para obter o Título de Doutor, pelo Programa de PósGraduação em Odontologia.

Área de Concentração: Dentística

Orientador: Prof. Dr. Glauco Fioranelli Vieira

São Paulo

2005 
Catalogação-na-Publicação

Serviço de Documentação Odontológica

Faculdade de Odontologia da Universidade de São Paulo

Agra, Carlos Martins

Avaliação quantitativa e qualitativa de duas cerâmicas frente a diferentes tratamentos de superfície / Carlos Martins Agra; orientador Glauco Fioranelli Vieira.

-- São Paulo, 2005.

135p. : fig., tab., graf., $30 \mathrm{~cm}$.

Tese (Doutorado - Programa de Pós-Graduação em Odontologia. Área de Concentração: Dentística) -- Faculdade de Odontologia da Universidade de São Paulo.

1. Sistemas cerâmicos - Desgaste dos materiais - Avaliação 2. Tratamento de superfícies - Cerâmica 3 . Dentística

AUTORIZO A REPRODUÇÃO E DIVULGAÇÃO TOTAL OU PARCIAL DESTE TRABALHO, POR QUALQUER MEIO CONVENCIONAL OU ELETRÔNICO, PARA FINS DE ESTUDO E PESQUISA, DESDE QUE CITADA A FONTE E COMUNICADO AO AUTOR A REFERÊNCIA DA CITAÇÃO.

São Paulo,

Assinatura:

E-mail: 


\section{FOLHA DE APROVAÇÃO}

Agra CM. Avaliação quantitativa e qualitativa de duas cerâmicas frente a diferentes tratamentos de superfície [Tese Doutorado]. São Paulo: Faculdade de Odontologia da USP; 2005.

São Paulo, / /2005.

\section{Banca Examinadora}

1) $\operatorname{Prof}(a) . \operatorname{Dr} .(a)$

Titulação:

Julgamento:

Assinatura

2) $\operatorname{Prof}(a)$. Dr.(a)

Titulação:

Julgamento:

Assinatura

3) Prof(a). Dr.(a)

Titulação:

Julgamento:

Assinatura

4) $\operatorname{Prof}(a)$. Dr.(a)

Titulação:

Julgamento:

Assinatura

5) Prof(a). Dr.(a)

Titulação:

Julgamento:

Assinatura 


\section{DEDICATÓRIA}

À Simone, Pedro e Isabela.

Ao meu mestre e amigo, Prof. Glauco. 
Agra CM. Avaliação quantitativa e qualitativa de duas cerâmicas frente a diferentes tratamentos de superfície [Tese Doutorado]. São Paulo: Faculdade de Odontologia da USP; 2005.

\section{RESUMO}

A característica de superfície representa um fator importante na previsibilidade do comportamento dos materiais cerâmicos quanto ao desgaste. A rugosidade superficial de duas cerâmicas (Duceram Plus e Duceragold) foi avaliada através de dois métodos - análise quantitativa e qualitativa - após diferentes tratamentos. Foram confeccionados 36 corpos de prova de prova para a análise ao rugosímetro, e 24 corpos de prova para a análise ao MEV. Os resultados destas análises demonstraram o comportamento distinto entre os diferentes tratamentos. A análise com o rugosímetro demonstrou que a ação dos polidores EDENTA foi a mais efetiva para devolver lisura à superfície após a realização de desgaste com instrumento abrasivo diamantado rotatório. Todas as técnicas de polimento acarretaram em valores de rugosidade menores que os observados nos espécimes que foram submetidos apenas ao "glaze". Entre as cerâmicas avaliadas, a Duceragold apresentou valores médios de rugosidade inferiores aos observados na porcelana Duceram Plus na maioria dos tratamentos pesquisados. Pela análise ao MEV não foi possível distinguir diferenças entre as cerâmicas ou entre os corpos de prova polidos ou submetidos apenas ao "glaze".

Palavras-Chave: Cerâmica Dental - Parâmetros de Rugosidade - Análise Quantitativa - Análise Qualitativa 
Agra CM. Avaliação quantitativa e qualitativa de duas cerâmicas frente a diferentes tratamentos de superfície [Tese Doutorado]. São Paulo: Faculdade de Odontologia da USP; 2005.

\begin{abstract}
The surface characteristic of ceramic material is an important factor to predict its wear behavior. The surface roughness of two ceramics (Duceram Plus e Duceragold) was evaluated trough qualitative and quantitative methods after different treatments. 36 specimens were fabricated for the analysis utilizing a surface profiling instrument, and 24 for the SEM analysis. The results determined different behavior between the two ceramics evaluated due the treatment executed. The analysis utilizing a surface profiling instrument showed that the treatment using the EDENTA polishers was the most effective technique to provide the smoothest surface after trimming. All polishing techniques resulted in better surface properties when compared to the treatment glaze. The Duceragold ceramic presented lower roughness values in most treatments executed when compared to Duceram Plus. The perception trough the SEM analysis of significant differences between treatments or between the two ceramics was not achievable.
\end{abstract}

Keywords: Dental ceramics, roughness parameters, quantitative analysis, qualitative analysis 


\section{LISTA DE ILUSTRAÇÕES}

Figura 2.1 - A maior parte das diferentes técnicas de confecção vale-se do processo de cocção para a obtenção do aspecto final da restauração, seja pela queima de pigmentos na superfície do material, ou pelo acréscimo de porcelanas de revestimento .28

Figura 2.2 - Diferentes possibilidades de prover reforço à porcelana feldspática.

Figura $4.1-$ Pastilhas de porcelana antes da sinterização 64

Figura 4.2 - Pastilhas de porcelana depositadas sobre lâmina de vidro e posicionadas sob a mufla do forno de porcelana. 64

Figura 4.3 - Representação gráfica do esquema de queima das cerâmicas .66

Figura 4.4 - $\quad$ Representação da ação do filtro elétrico e seus diferentes valores de $\lambda c$ sobre a "percepção" da rugosidade da superfície. 68

Figura 4.5 - Percurso da sonda apalpadora sobre a superfície. $\lambda c$ comprimento de amostragem; Iv - percurso para calibragem; Im percurso de medição; It - percurso total, $\mathrm{IV}+\mathrm{Im}$. .70

Figura 4.6 - Parâmetro Ra: Soma dos valores absolutos das ordenadas $(Y)$ em relação à linha média (LM), dividida pelo número de ordenadas (n). 
Rz - média das distâncias verticais entre a maior protusão e a maior depressão em cada um dos cinco comprimentos de amostragem. Rz - média das distâncias verticais entre a maior protusão e a maior depressão em cada um dos cinco comprimentos de

amostragem 74

Figura 4.7 - $\quad$ Esquematização de duas superfícies diferentes que apresentam rugosidade média

igual. .75

Figura 4.8 - $\quad$ Roda EXA-CERAPOL 0301UM para pré-polimento (cinza), roda EXA-CERAPOL 0306UM para polimento (rosa) e CERAPOL SUPER 0374PM para polimento final (cinza escuro) .77

Figura 4.9 - $\quad$ Roda de granulosidade média (EVE KERAMIK R22VK - cinza), de granulosidade fina (EVE KERAMIK R22NK - rosa), roda de feltro e pasta contendo partículas de diamante (Crystar

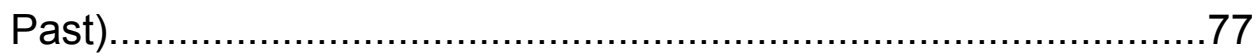

Figura 4.10 - $\quad$ Corpos de prova colados aos "stubs" e com a camada condutora já aplicada

("sputtering"). .80

Figura 4.11 - Detalhe dos corpos de prova após a

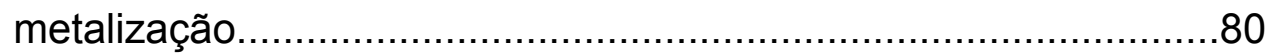

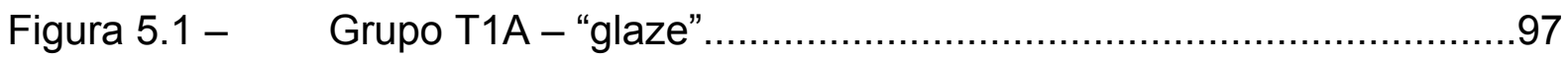

Figura 5.2 - $\quad$ Grupo T2A - "glaze"+ polimento com roda EVE R22NK..............97

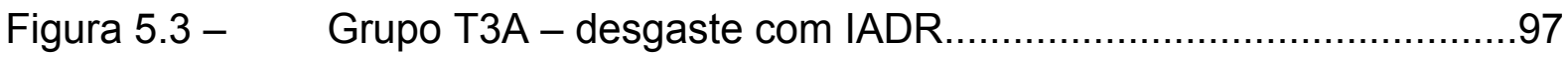


Figura 5.4 - $\quad$ Grupo T4A - ação dos polidores EDENTA ................................97

Figura 5.5 - $\quad$ T5A - polidores EVE Keramik ...............................................

Figura 5.6 - Grupo T6A - polidores EVE Keramik + pasta CrystarPast............97

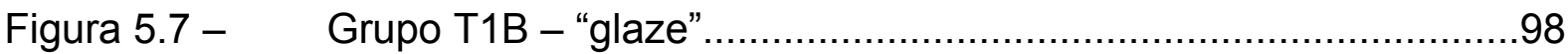

Figura 5.8 - $\quad$ Grupo T2B - "glaze"+ polimento com roda EVE R22NK..............98

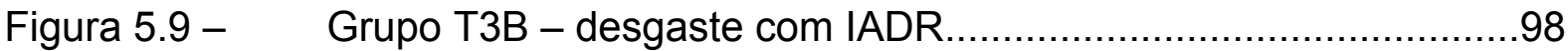

Figura 5.10 - G Gupo T4B - ação dos polidores EDENTA $\quad$ G.............................98

Figura 5.11 - $\quad$ T5B - polidores EVE Keramik ..........................................98

Figura 5.12 - Grupo T6B - polidores EVE Keramik + pasta CrystarPast...........98

Figura 6.1 - $\quad$ Corpo de prova da cerâmica Duceragold. A metade superior da superfície foi mantida desgastada enquanto a inferior foi polida com os polidores EDENTA ....................................................... 107

Figura 6.2 - Ampliação da superfície do IADR onde observa-se o aspecto irregular das partículas de diamante. .107

Gráfico 5.1 - V Valores médios dos postos obtidos com o teste Kruskal-Wallis para o parâmetro Ra 86

Gráfico 5.2 - V Valores médios dos postos obtidos com o teste Kruskal-Wallis para o parâmetro Rz .88

Gráfico 5.3 - V Valores médios dos postos obtidos com o teste Kruskal-Wallis para o parâmetro Rp. .90

Gráfico 5.4 - V Valores médios dos postos obtidos com o teste Kruskal-Wallis para o coeficiente Rp/Rz. .92 


\section{LISTA DE TABELAS}

Tabela 2.1 - Métodos de confecção das restaurações cerâmicas. .23

Tabela 4.1 - Etapas e temperaturas de queima realizadas na confecção dos corpos de prova das porcelanas Duceram Plus e DuceraGold. .65

Tabela 4.2 - Valores mínimos de comprimento de amostragem em função da rugosidade média $(\mathrm{Ra})$

Tabela 4.3 - . Exemplos de parâmetros para avaliação da rugosidade superficial..71

Tabela 4.4 - Número de corpos de prova, tratamentos e especificações da análise quantitativa 78

Tabela 5.1 - Valores médios de rugosidade dos parâmetros Ra e Rz. Desvio padrão e valores máximos e mínimos apurados

Tabela 5.2 - Valores médios de rugosidade do parâmetros $\mathrm{Rp}$ e do coeficiente Rp/Rz. Desvio padrão e valores máximos e mínimos apurados.

Tabela 5.3 - Valores médios dos postos obtidos com o teste KruskalWallis 84

Tabela 5.4 - Resultado do teste Kruskal-Wallis para a variável de agrupamento TRATAMENTO (T1A à T6B). .84

Tabela 5.5 - Resultado do teste Mann-Whitney para o parâmetro Ra, comparando os diferentes grupos e verificando diferenças significativas entre os mesmos. 
Tabela 5.6 - Resultado do teste Mann-Whitney para o parâmetro Rz, comparando os diferentes grupos e verificando diferenças significativas entre os mesmos.

Tabela 5.7 - Resultado do teste Mann-Whitney para o parâmetro Rp, comparando os diferentes grupos e verificando diferenças significativas entre os mesmos.

Tabela 5.8 - Resultado do teste Mann-Whitney para o coeficiente Rp/Rz, comparando os diferentes grupos e verificando diferenças significativas entre os mesmos 91

Tabela 5.9 - Teste de correlação não-paramétrica de Spearman .95

Tabela 5.10 Teste de correlação não-paramétrica de Spearman. .96

Tabela 5.11 - Valores médios dos parâmetros em função dos tratamentos aplicados .99

Tabela 6.1 - Resultado do teste Mann-Whitney para o parâmetro Rp, comparando os diferentes grupos e verificando diferenças significativas, mas considerando o coeficeinte Rp/Rz para distinguir grupos sem diferença significativa 105 


\section{LISTA DE ABREVIATURAS E SIGLAS}

MEV microscópio eletrônico de varredura

CAD/CAM "computer assisted design / computer assisted manufacturing"

ABNT Associação Brasileira de Normas Técnicas

TPD Técnico em Prótese Dental 


\section{LISTA DE SÍMBOLOS}

It percurso de apalpamento

Iv percurso inicial

Im percurso de medição

$\lambda c \quad$ "cut off", ou comprimento de amostragem quando um filtro elétrico é empregado

LM linha média

$\mathrm{Ra}$ rugosidade média

Rz média das distâncias verticais entre a maior protusão e a maior depressão em cada um dos cinco comprimentos de amostragem

Rp média das alturas das maiores protusões em relação à linha média em cada um dos cinco comprimentos de amostragem

T1 tratamento "glaze"

T2 "glaze" mais polidor EVE fino

T3 desgaste

T4 polidores EDENTA

T5 polidores EVE

T6 polidores EVE mais pasta contendo partículas de diamante

Grupo A porcelana Duceram Plus

Grupo B cerâmica Duceragold 
1 INTRODUÇÃO

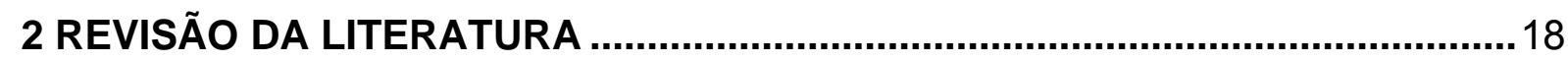

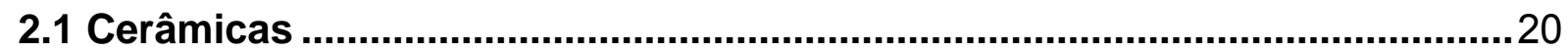

2.1.1 propriedades negativas das cerâmicas ………….......................................30

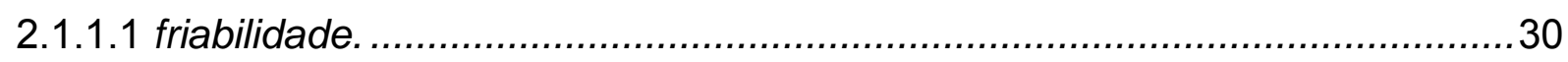

2.1.1.2 potencial de desgaste do antagonista .....................................................

2.2 Polimento.

2.2.1 polimento e a resistência mecânica das cerâmicas ........................................... 45

2.2.2 polimento e a adequação estética das cerâmicas.........................................50

2.2.3 polimento e a resistência química das cerâmicas .........................................51

2.2.4 técnicas e materiais para polimento............................................................. 53

3 PROPOSIÇÃO.

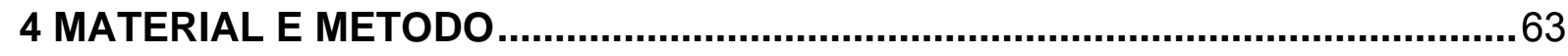

5 RESULTADOS

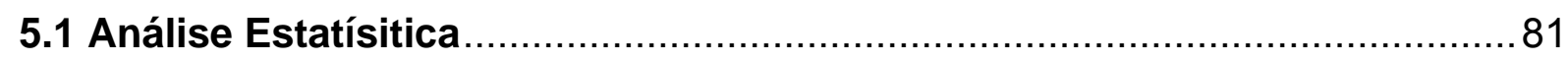

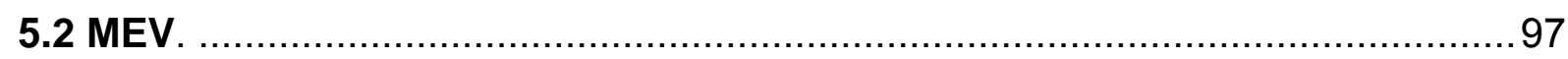

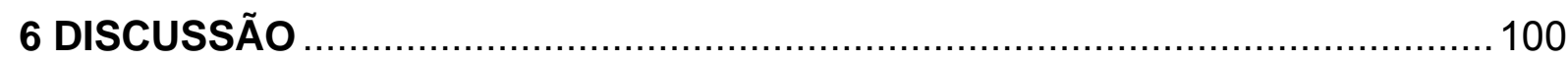

6.1 Comparativo entre os tratamentos realizados ........................................106

6.2 Comparativo entre as cerâmicas Duceram Plus e Duceragold frente

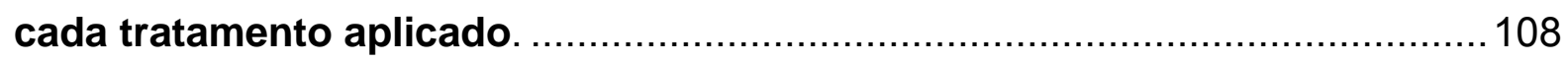

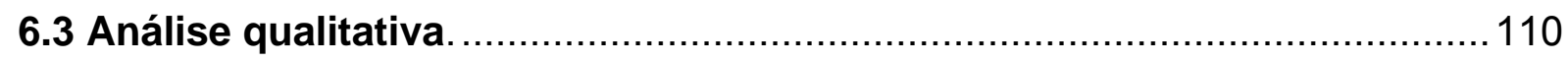


6.4 Considerações finais.

7 CONCLUSÕES.

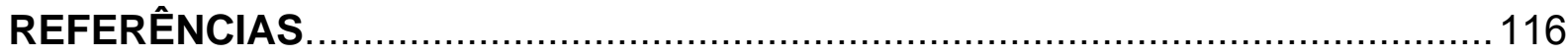

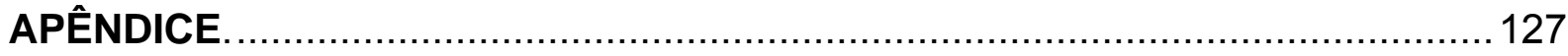




\section{INTRODUÇÃO}

A cerâmica destaca-se como uma alternativa que preenche os quesitos estéticos, biológicos, mecânicos e funcionais exigidos de um material restaurador, e tem sua indicação bem sedimentada tanto na Dentística como na Prótese. A obtenção de restaurações cerâmicas envolve um criterioso planejamento, preparo do elemento dental, técnica de confecção laboratorial, cimentação, ajuste funcional e polimento. Estas etapas apresentam igual importância para o sucesso imediato, mediato e em longo prazo das restaurações cerâmicas.

Sobre a denominação de cerâmica encontram-se materiais com características diversas, como a porcelana feldspática e a cerâmica infiltrada por alumina. Estes materiais são disponibilizados na forma de "kits", e apresentam indicações distintas relacionadas às suas propriedades mecânicas e estéticas. O que é comum à maioria destes sistemas é a aplicação, na superfície externa da restauração, de uma porcelana feldspática, responsável pelo aspecto estético. As porcelanas são um tipo de cerâmica, e pertencem ao grupo das louças brancas. Caracterizam-se por uma excelente lisura superficial, alta resistência à degradação por produtos químicos, alta resistência ao desgaste e excelentes propriedades estéticas quando comparadas ao esmalte e dentina (ANUSAVICE, 1992). Apresentam ainda alta dureza superficial, alto módulo de elasticidade, baixa tenacidade, baixa ductibilidade e baixa resistência flexural. A soma destes fatores resulta na excelência estética e também na friabilidade das restaurações confeccionadas apenas com uma porcelana feldspática. 
A fragilidade mecânica pode ser contornada com uma técnica de cimentação adesiva onde a resina composta viabiliza suporte à porcelana, à semelhança do papel que a dentina tem para o suporte e resistência do esmalte. No entanto, antes da colagem da restauração ao dente, o manejo e o ajuste da porcelana são passos críticos. Em especial, nas restaurações que apresentam pequena espessura, o ajuste dos contatos oclusais implica em risco de fratura, devendo ser realizado apenas após a cimentação. Este ajuste gera irregularidades na superfície da porcelana que devem ser eliminadas para que a compatibilidade biológica deste material em relação ao tecido gengival seja restabelecida (CAMPBELL, 1989), e para tornar mínimo o potencial de desgaste às superfícies antagonistas (GOLDSTEIN; BARNHARD; PENUGONDA, 1991).

A necessidade de polir restaurações cerâmicas não se restringe apenas às especialidades de dentística ou prótese, mas abrange também outras áreas, como a ortodontia, já que às coroas e facetas de porcelana pode-se colar brackets, viabilizando a movimentação ortodôntica de dentes já restaurados (KAO; BOLTZ; JOHNSTON, 1988). Ao término do tratamento deve-se remover brackets e resina, e devolver adequada lisura à restauração, o que só pode ser feito com uma técnica de polimento intra-oral.

São vários os materiais disponíveis para o polimento de uma porcelana, e o resultado obtido é classificado como adequado por diversos autores (CAMPBELL, 1989; GIORDANO; CAMPBELL; POBER, 1994; GIORDANO; CIMA; POBER, 1995; SCURRIA; POWERS, 1994; HULTERSTRÖM; BERGMAN, 1993; GOLDSTEIN; BARNHARD; PENUGONDA, 1991; RAIMONDO JR; RICHARDSON; WIEDNER, 1990; ROSENSTIEL; BAIKER; JOHNSTON, 1989; SHEARER et al., 1994; WINCHESTER, 1991; KELLY; NISHIMURA; CAMPBELL, 1996; AGRA; VIEIRA, 
2002; WARDAK; WIRZ; SCHMIDLI, 2001; FINGER; NOACK, 2000; GLAVINA et al., 2004).

A ação dos materiais e técnicas de polimento é aferida pela determinação da rugosidade da superfície através de métodos qualitativos e quantitativos. Dentre estes, os mais empregados são a observação da superfície por MEV (método qualitativo) e o uso de um rugosímetro (método quantitativo). Apesar de o polimento melhorar a lisura de superfície da porcelana após ajustes, não há unanimidade sobre o fato de que este propicie uma lisura igual ou superior à observada após o "glaze". Há também trabalhos que avaliam e comparam técnicas de polimento com o "glaze", valendo-se de MEV e leitura ao rugosímetro, e demonstram existir disparidades entre os resultados obtidos pelo método quantitativo e qualitativo (PATTERSON et al., 1992; FUZZI; ZACCHERONI; VALLANIA, 1996).

O objetivo deste trabalho é determinar se há correlação entre os resultados obtidos através de análise quantitativa com rugosímetro e qualitativa com MEV ao avaliarem-se duas cerâmicas (Duceram Plus e Duceragold) após diferentes tratamentos: "glaze", desgaste e diferentes técnicas de polimento. Além disso, determinar se há ou não correlação entre os parâmetros avaliados ao rugosímetro e os achados ao MEV. 


\section{REVISÃO DA LITERATURA}

Os métodos mais comumente utilizados para aferir a rugosidade de uma superfície são classificados como quantitativos - uso do rugosímetro - e qualitativos - microscopia eletrônica de varredura (WHITEHEAD et al., 1995; FINGER; NOACK, 2000). A avaliação do acabamento superficial é fundamental para materiais que serão submetidos ao atrito, desgaste ou corrosão, ou quando se deseja avaliar a aparência, propriedades ópticas, resistência à fadiga e transmissão de calor (AGOSTINHO; RODRIGUES; LIRANI, 1977).

Na literatura Odontológica, a avaliação da rugosidade de superfície tem sido usada para verificar a adaptação de restaurações de amálgama, o potencial de acúmulo de placa bacteriana sobre dentes e materiais restauradores, a eficácia de métodos de polimento, e a habilidade que uma superfície exibe para reter um material restaurador (LEITÃO; HEGDAHL, 1981).

Whitehead et al. (1995) compararam dois métodos empregados na observação da rugosidade de superfície de porcelanas polidas: determinação da quantidade de luz refletida após a aplicação de um feixe de laser e o emprego de um rugosímetro. Foram realizados diferentes tipos de polimento em blocos cerâmicos do material Dicor MGC. Os autores verificaram pouca similaridade entre os resultados obtidos com os dois métodos, e concluíram que o laser não deveria ser usado isoladamente para determinar a rugosidade de uma superfície. Segundo os autores, o rugosímetro propicia a obtenção de parâmetros que, ao mesmo tempo em que quantificam a rugosidade do material, provêm informações sobre a forma desta superfície. 
Agra e Vieira (2002) compararam a rugosidade de superfície de uma cerâmica após três tratamentos diferentes: "glaze", desgaste e polimento. A avaliação de diferentes parâmetros (Ra, Rz, Rp, Pc e Rp/Rz) possibilitou verificar disparidade entre os valores de $\mathrm{Ra}$ e os demais parâmetros em algumas das situações avaliadas. A conclusão dos autores é a de que uma melhor observação quantitativa das propriedades funcionais de uma superfície é atingida quando, além de Ra, avaliam-se também outros parâmetros.

Lee, Lai e Morgano (1995) empregaram o rugosímetro e o MEV para determinar o efeito que a raspagem e alisamento radicular têm sobre a margem cervical de restaurações de porcelana. Os resultados da leitura ao rugosímetro indicaram existir pouca diferença entre a porcelana em que o "glaze" foi mantido, e a que foi submetida ao procedimento de raspagem e alisamento radicular. No entanto, a análise qualitativa ao MEV revelou diferenças significativas entre a porcelana em que o "glaze" foi mantido, na qual se observou melhor lisura, e a que foi instrumentada.

Vermilyea, Prasanna e Agar (1994) avaliaram, através de MEV e rugosímetro, o efeito da aplicação de um instrumento periodontal montado em um aparelho de ultrasom e do uso de um jato de bicarbonato de sódio sobre uma porcelana de ombro. $\mathrm{O}$ emprego isolado do ultra-som resultou em uma superfície mais áspera do que quando, além do ultra-som, empregou-se também o jato de bicarbonato. No entanto, os dois tratamentos resultaram em dano à superfície da porcelana, indicando que os mesmos devem ser usados com extrema cautela.

Fuzzi, Zaccheroni e Vallania (1996) analisaram a rugosidade de corpos de prova da porcelana Vita VMK 68 após "glaze" e polimento. Foi empregado para a análise qualitativa o MEV, e para a análise quantitativa um rugosímetro. Ao MEV os 
espécimes em que o "glaze" foi preservado apresentavam aspecto menos rugoso que os espécimes polidos. No entanto, na avaliação com o rugosímetro, os espécimes polidos com uma seqüência de instrumentos diamantados finos apresentaram o melhor resultado. A MEV revelou que todas as superfícies polidas apresentavam poros ou pequenas fraturas, condição não observada nos corpos de prova em que o "glaze" foi mantido. Em função dos resultados, os autores concluíram não existir correlação entre os dados do rugosímetro e os resultados observados ao MEV.

Gürgan, Bolay e Alaçam (1997) avaliaram o efeito de agentes clareadores sobre a aderência de placa bacteriana na superfície do esmalte. Apesar dos espécimes tratados com os agentes clareadores apresentarem uma maior aderência de bactérias em comparação com os espécimes não tratados, a análise com o rugosímetro não detectou diferença na rugosidade entre os dois grupos.

\subsection{Cerâmicas}

As cerâmicas são mais bem definidas pelo que elas não são. Não são materiais metálicos ou orgânicos. Para diferenciá-las das rochas, são adicionalmente descritas como objetos sólidos, feitos pelo homem, e formados pela queima de minerais em altas temperaturas (ROSENBLUM; SCHULMAN, 1997). As cerâmicas são empregadas em grande escala na indústria, sobretudo como refratários e em aplicações que exigem materiais com alta resistência ao desgaste (CHIAVERINI, 1995; VAN NOORT, 2002). 
Há vários tipos de cerâmicas que encontram aplicação na Odontologia. Além da porcelana convencional, também chamada de feldspática, porcelana dental ou de porcelana para metalocerâmica, existem as porcelanas de baixa fusão, os vidros ceramizados, as porcelanas reforçadas por leucita, óxido de alumínio e óxido de zircônio. Somam-se a esta lista as cerâmicas que são usadas para formar copings ou infra-estruturas de reforço, e que são compostas por óxido de alumínio, óxido de zircônio ou óxido de magnésio (DENRY, 1996). Houve ainda a introdução recente de cerâmicas reforçadas por disilicato de lítio e porcelanas que incluem cristais de fluorapatita (CULP, 1999).

A porcelana dental é um tipo de cerâmica. Pertence ao grupo das louças brancas, mesmo grupo dos azulejos, louças sanitárias e isolantes elétricos. É composta por feldspato $\left(\mathrm{K}_{2} \mathrm{O}-\mathrm{Al}_{2} \mathrm{O}_{3}-6 \mathrm{SiO}_{2}\right)$, quartzo $\left(\mathrm{SiO}_{2}\right)$, e argila $\left(\mathrm{Al}_{2} \mathrm{O}_{3}-2 \mathrm{SiO}_{2}-\right.$ $\mathrm{xH}_{2} \mathrm{O}$ ) (ROSENBLUM; SCHULMAN, 1997). Anusavice (1992) identifica de outro modo os componentes de uma porcelana dental. Descreve que esta é composta majoritariamente por sílica $\left(\mathrm{SiO}_{2}\right)$ associada a diferentes óxidos, como o óxido de sódio, de potássio, de cálcio, de alumínio, de boro e de zinco. Há ainda a presença de óxidos que são responsáveis pela cor (óxido de ferro, de níquel, de cobre, de manganês e de cobalto), e de óxidos que atuam na opacidade (óxido de estrôncio, de zircônio e de titânio).

Várias são as propriedades positivas das porcelanas como material restaurador: excelente estética, compatibilidade biológica, baixa condutibilidade térmica e elétrica, resistência mecânica e resistência à ação de agentes químicos (exceto para soluções de flúor acidulado, amônio bifluorídro e ácido fluorídrico) (ANUSAVICE, 1992). A porcelana, como material restaurador, é bem tolerada, apresentando perfil de toxicidade e potencial alergênico aceitáveis (RYKKE, 1992). 
As porcelanas apresentam características negativas que não devem ser menosprezadas. A primeira é a friabilidade, que faz com que o manejo das restaurações de porcelana sem infra-estrutura metálica ou cerâmica seja crítico quanto à ocorrência de fraturas; a segunda refere-se ao potencial de desgaste que este material apresenta para os dentes antagonistas se não existir uma lisura de superfície adequada (ROSENBLUM; SCHULMAN, 1997; PIDDOCK; QUALTROUGH, 1990).

As restaurações cerâmicas são obtidas através de diferentes métodos de confecção: fresagem, prensagem e sinterização (tabela 2.1). Na fresagem, um equipamento promove o desgaste de um bloco uniforme e denso de cerâmica, e dá forma à restauração tendo como referência uma informação gerada pela captura de uma imagem digital do dente preparado (método CAD-CAM) (ESTAFAN, 1999), ou pelo escaneamento de um padrão de resina obtido sobre um troquel de gesso ou diretamente sobre o dente preparado (método pantográfico) (WARDAK; WIRZ; SCHMIDLI, 2001). O sistema CAD/CAM (P.Ex. Cerec - Sirona) permite, além do uso de blocos de porcelana feldspática, a confecção de infra-estruturas de cerâmica reforçada a partir de blocos de óxido de alumínio, óxido de magnésio ou óxido de zircônio. 
Tabela 2.1 - Métodos de confecção das restaurações cerâmicas

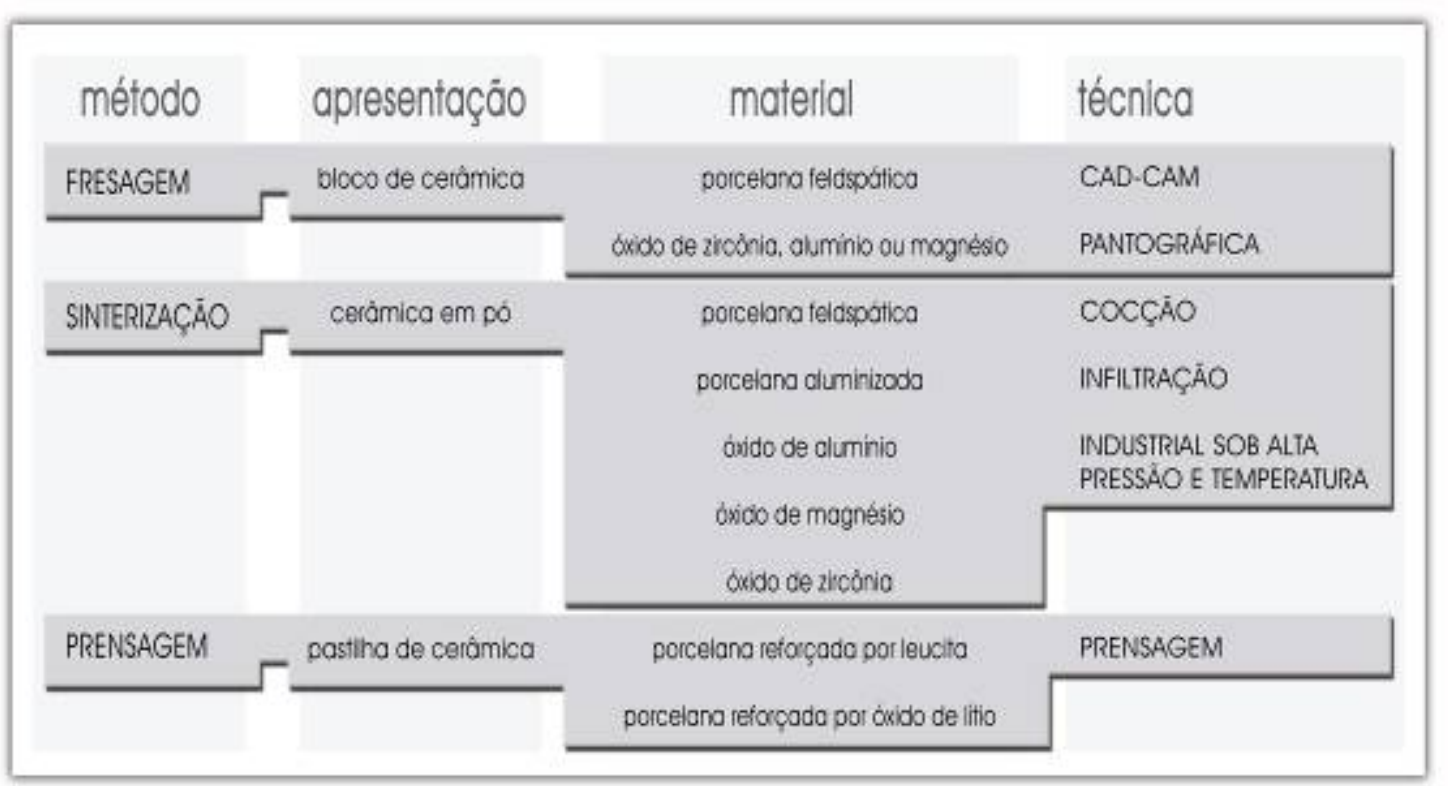

O método de prensagem permite ao técnico em prótese dental executar uma restauração cerâmica a partir de um padrão de cera. As restaurações são esculpidas devolvendo a anatomia ao dente por completo ou de modo parcial - formando uma base. As cerâmicas que podem ser empregadas nesta técnica apresentam diferentes composições, sendo que as reforçadas por leucita e por disilicato de lítio são as mais usadas. A cerâmica é apresentada na forma de pastilhas de diferentes cores e opacidades. O padrão de cera é incluído em material refratário que, após aquecimento e conseqüente eliminação da cera, resulta no contramolde da restauração desejada. O processo de prensagem ocorre em um forno especial onde, através de calor, se dá de modo controlado o amolecimento da pastilha e a gradual introdução por pressão da cerâmica no interior do contramolde. Findado o processo, a restauração é removida do refratário e adaptada ao troquel de trabalho. Nesta fase, a cerâmica apresenta aspecto irregular e pouco estético. Assim, quando a opção é a de prensar a restauração por completo, são aplicados pigmentos de cerâmica por toda a superfície externa da restauração. A restauração vai ao forno de 
porcelana para se processar a cocção desta camada, e adquire lisura e brilho superficial que garantem um aspecto natural à restauração. Esta técnica é conhecida como maquiagem. A desvantagem de toda caracterização extrínseca é a possibilidade de que com o passar do tempo a escovação determine alterações na cor pela remoção da camada mais externa da restauração (ANIL; BOLAY, 2002).

Quando a escultura é feita de modo parcial, sobre a base de cerâmica que foi prensada aplicam-se porcelanas feldspáticas, acrescidas na forma de camadas e levadas à cocção em forno de porcelana até que se obtenha a forma desejada para a restauração. Esta técnica é semelhante à empregada na técnica de coroas metalocerâmicas, e é denominada de estratificação. A cerâmica Duceragold, avaliada neste trabalho, presta-se para a técnica de estratificação dentro de um sistema para a obtenção de restaurações prensadas comercializado com o nome de Cergogold (Degussa), e sobre metal (Golden Gate System - Degussa). Duceragold difere das porcelanas convencionais. Apresenta menor temperatura de queima (abaixo de $800^{\circ} \mathrm{C}$ ) e dispersão mais homogênea dos cristais de leucita na matriz vítrea, o que resulta em uma superfície com morfologia mais suave que a observada nas porcelanas convencionais. Por tratar-se de um material que apresenta menor concentração de estrutura cristalina do que as porcelanas feldspáticas, Duceragold é classificada como um vidro hidrotérmico. Este termo refere-se ao modo como este material é fabricado. Cerâmica fundida é aspergida em um ambiente úmido, possibilitando a incorporação de radicais hidroxilas em sua composição (MEIER et al., 1993).

Os métodos de sinterização empregam o calor para conformar a restauração cerâmica. A sinterização é definida como o processo que torna um material poroso em um material forte e denso através de transformações que ocorrem a altas 
temperaturas (DENRY, 1996). Há três técnicas que empregam o método de sinterização: cocção, infiltração e a industrial sob alta pressão e temperatura. A técnica de infiltração e a técnica industrial sob alta pressão e temperatura resultam na formação de um coping cerâmico de alta resistência mecânica (óxido de alumínio, óxido de magnésio ou óxido de zircônio). Sobre estes copings aplicam-se porcelanas de baixa fusão, aluminizadas ou feldspáticas que serão responsáveis por dar forma anatômica e estética à restauração. Estes materiais são chamados de porcelanas de revestimento estético, e necessitam ser queimados em forno de porcelana pela técnica de cocção.

A técnica de cocção é a mais antiga e a mais empregada para a obtenção de restaurações de porcelana. A porcelana, na forma de um fino pó, é misturada a um líquido que permite a manipulação e a aplicação da massa criada com uma espátula ou pincel. A porcelana é depositada sobre refratário, coping cerâmico ou coping metálico e levada ao forno de cerâmica para a queima. Esta é a técnica que possibilita a maior versatilidade - possibilidade de empregar uma combinação ampla de porcelanas com diferentes cores e opacidades - e uma melhor morfologia. Por isso, ainda é a primeira opção quando o objetivo é criar um resultado estético excelente (KREJCl et al., 1993; VAN NOORT, 2002; MAGNE; BELSER, 2003).

$\mathrm{Na}$ técnica de cocção, a porcelana passa por diferentes estágios durante o processo de sinterização (KOMMA, 1993). Como descrito por Vieira et al. (1995), inicialmente agregasse ao pó de porcelana um líquido aglutinante específico, formando uma massa com consistência cremosa que favorece a escultura da restauração. A regularidade da superfície e a resistência intrínseca de uma porcelana podem ser afetadas por esta etapa da confecção, já que uma proporção exagerada de líquido aglutinante em relação à de pó leva à formação de 
porosidades (ZHANG; GRIGGS; BENHAM, 2004). Áreas com porosidades alteram a translucidez da cerâmica, já que a luz será refletida de modo difuso. Outro problema diz respeito ao fato de que um desgaste da camada superficial (submetida ao "glaze") leva à exposição das porosidades, o que compromete a estética e a lisura superficial (VAN NOORT, 2002).

Feitos os acréscimos e a escultura desejada, o excesso de aglutinante é removido com o auxílio de papel absorvente e a restauração é posicionada próxima à entrada da mufla do forno - designação do compartimento do forno onde a porcelana fica exposta às altas temperaturas. Começa o processo de evaporação do líquido aglutinante e compactação da massa de porcelana. Esta evaporação ocorre de modo gradual até o fechamento da mufla, e é chamada de secagem. Fechada a mufla, há um aumento gradativo da temperatura do forno até a temperatura final de queima do material, em um ambiente do qual foi removido todo o ar. O vácuo reduz a quantidade de porosidades na porcelana, o que melhora as propriedades mecânicas e aumenta a translucidez (CLAUS; RAUTER, 1989). Exposta a este aumento gradativo da temperatura, a porcelana passa por diferentes graus de compactação que resultam em aumento da densidade e em diminuição volumétrica de 20 a 40\% (DENRY, 1996; VAN NOORT, 2002).

Vieira et al. (1995) explanam a sinterização utilizando como exemplo um material cuja temperatura final de queima é de $950^{\circ} \mathrm{C}$. Quando a temperatura dentro da mufla atinge $930^{\circ} \mathrm{C}$, a porcelana apresenta-se compacta, mas irregular. Esta etapa da queima é chamada de baixo "biscuit". A palavra inglesa "biscuit" tem como origem a palavra latina "bis coctus", e significa, além de biscoito, um material argiloso que foi queimado apenas uma vez, e que não passou pelo "glaze"; a palavra inglesa "glaze" significa dar brilho ou lustro a uma superfície. Ainda segundo Vieira 
et al. (1995), quando o forno atinge a temperatura de $950^{\circ} \mathrm{C}$, a compactação é maior, e a porcelana apresenta uma superfície mais regular. Esta etapa é chamada de médio "bicuit". Mantendo-se a temperatura do forno em $950^{\circ} \mathrm{C}$ por alguns segundos, a porcelana torna-se brilhante e mais translúcida. Esta etapa da queima é conhecida como alto "biscuit", ou "glaze" natural da porcelana, sendo este o ponto em que a porcelana adquire melhor lisura (AL-WAHADNI; MARTIN, 1998). Além de brilho, o "glaze" fecha as fendas que porventura existam na superfície, o que dificulta o acúmulo de placa bacteriana (FAIRHURST et al., 1992). O esquema de queima descrito acima vale para todas as porcelanas apresentadas na forma de pó, variando a temperatura final de queima, o tempo de secagem, a velocidade de aumento da temperatura do forno e o tempo que o material deve permanecer na temperatura final para que se processe o "glaze". Há outra forma de obter-se o "glaze". Pode-se abrir mão de um vidro com temperatura de queima inferior à do material cerâmico empregado. Estes vidros são conhecidos como pós ou líquidos de "glaze" e, após a queima, fundem-se à camada vítrea da restauração, estabelecendo o selamento de fendas e porosidades existentes (VAN NOORT, 2002). A técnica de cocção pode ser usada em conjunto com outros métodos de confecção (figura 2.1). 


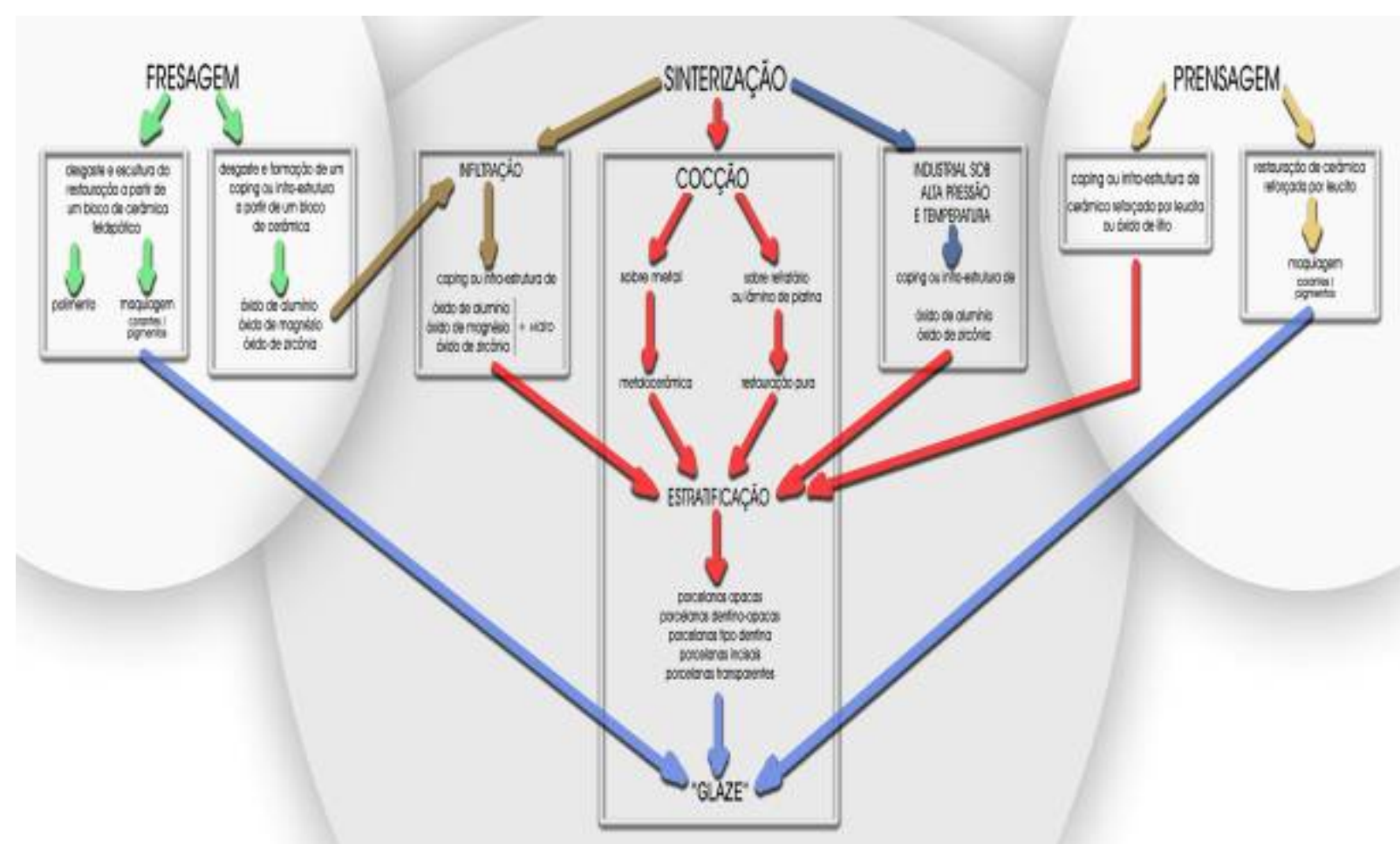

Figura 2.1 - A maior parte das diferentes técnicas de confecção vale-se do processo de cocção para a obtenção do aspecto final da restauração, seja pela queima de pigmentos na superfície do material, ou pelo acréscimo de porcelanas de revestimento

As porcelanas que necessitam de uma temperatura superior a $800^{\circ} \mathrm{C}$ para que ocorra a sinterização do material são classificadas como de alta fusão. As que necessitam de temperatura inferior a $800^{\circ} \mathrm{C}$ para que a queima do material ocorra são classificadas como de baixa fusão (VIEIRA et al., 1995).

Após a sinterização da porcelana feldspática de alta fusão é possível distinguir duas fases: a vítrea e a cristalina (KOMMA, 1993). A fase cristalina apresenta cristais, normalmente de leucita, e fica circundada pela fase vítrea, composta por sílica. Os cristais de leucita estão presentes em maior ou menor concentração para controlar o coeficiente de expansão térmico linear do material, compatibilizando-o com o da liga metálica ou material refratário empregado durante a confecção laboratorial; assim, minimiza-se o estresse térmico residual sobre a porcelana, originário da expansão e posterior contração que os materiais apresentam quando 
expostos às altas temperaturas e posterior resfriamento (MACKERT JR; WILLIAMS, 1996; YAMAMOTO, 1985).

A fase cristalina é considerada instável, já que repetidas queimas, resfriamento excessivamente rápido ou lento, ou a manutenção da porcelana em alta temperatura por um período longo podem alterar a sua concentração em relação à fase vítrea (KELLY; NISHIMURA; CAMPBELL, 1996). A resistência flexural diminui com o aumento no percentual de leucita, o que favorece a formação de linhas de fratura no interior da porcelana (MACKERT JR; EVANS, 1991; FAIRHURST et al., 1992). Mesmo quando não ocorre o aumento no percentual de leucita, o resfriamento rápido da cerâmica leva a uma contração acelerada da camada externa da cerâmica, que resulta em tensão sobre as camadas mais internas. Este estresse é liberado com a ocorrência de inúmeras pequenas fraturas ("cracks") no interior do material, e que podem ser as responsáveis pela ocorrência de falhas catastróficas das restaurações (VAN NOORT, 2002). 
2.1.1 propriedades negativas das cerâmicas

\subsubsection{1 friabilidade}

As porcelanas são susceptíveis à fratura quando colocadas sob tensão em função de seu alto módulo de elasticidade, propriedade que não as tornam passíveis de deformação ante a incidência de uma carga (VAN NOORT, 2002; ROSENBLUM; SCHULMAN, 1997). A solução tradicional para contornar a friabilidade são as restaurações metalocerâmicas, técnica em que a porcelana é aplicada sobre uma infra-estrutura metálica que fornece suporte e evita a ocorrência de fraturas (PIDDOCK; QUALTROUGH, 1990; KELLY; NISHIMURA; CAMPBELL, 1996; YAMAMOTO, 1985). Esta técnica apresenta o inconveniente do aspecto pouco estético do metal, e demanda o uso de porcelanas opacas que o recubram. 0 opaco pode dificultar a obtenção de uma restauração de aspecto natural quando o preparo protético não viabiliza espaço adequado, especialmente na região cervical (QUALTROUGH; PIDDOCK, 1997; KELLY; NISHIMURA; CAMPBELL, 1996; UBASSY, 1993).

Os sistemas compostos de uma infra-estrutura cerâmica de alta resistência mecânica, sobre a qual se aplica uma porcelana de revestimento estético, representam uma tendência atual, e são frutos da preocupação em criar alternativas às metalocerâmicas. A porcelana aplicada como revestimento externo da restauração deixa de ser frágil devido à união a uma infra-estrutura de cerâmica, 
com propriedades estéticas superiores às dos copings metálicos (CRONIN; CAGNA, 1997; UBASSY, 1993).

Pallis et al. (2004) verificaram a resistência à fratura de restaurações confeccionadas com três diferentes sistemas cerâmicos (IPS Empress 2, Procera All-Ceram e In-Ceram Zirconia). Não houve diferença significativa na resistência à fratura entre os três sistemas. No entanto, a origem da falha que levou à fratura não foi similar entre os sistemas. No sistema IPS Empress 2 (técnica de prensagem com estratificação) a origem da falha foi geralmente encontrada na interface entre a base cerâmica e a porcelana de revestimento. Nos outros dois sistemas a origem da falha encontrou-se na interface entre o coping cerâmico e a camada do agente usado como cimento.

Outra técnica que visa contornar a baixa resistência à fratura da porcelana é a colagem das restaurações diretamente à estrutura dental. A colagem é feita através do condicionamento com ácido fosfórico e aplicação de sistema adesivo sobre esmalte e dentina. O condicionamento da porcelana com ácido fluorídrico e a aplicação do silano são os outros quesitos essenciais para a união do cimento resinoso à porcelana (STEWART; JAIN; HODGES, 2002), apesar de existir trabalhos que mostram a possibilidade de alcançar um valor significativo de união apenas com o uso de um silano (ATTIA; KERN, 2004). A colagem possibilita que as cargas aplicadas sobre a restauração sejam transmitidas ao dente (PROOS et al., 2003); além disso, traz como vantagem melhor estética, necessidade de um preparo menos extenso e melhora no selamento marginal da restauração (BURKE; QUALTROUGH; HALE, 1995; QUALTROUGH; PIDDOCK, 1997). Os preparos para facetas laminadas requerem aproximadamente de um quarto à metade da quantidade de redução da estrutura dental necessária para a realização de uma coroa total 
convencional (EDELHOFF; SORENSEN, 2002). A colagem é fundamental em técnicas restauradoras como as facetas laminadas, "inlays/onlays" e coroas ocas de porcelana. Devido à íntima união criada entre a estrutura dental e a porcelana, a forma de retenção e de resistência exigida nos preparos é menos crítica do que quando se trabalha com restaurações em que são empregados cimentos convencionais, como o fosfato de zinco (CRINALDI; DENRY; ROSENTIEL, 1994). A colagem também propicia aumento na resistência à fratura dos dentes. Há um aumento significativo na resistência após a colagem de restaurações de cerâmica do tipo "inlay" (DIETSCHI et al., 1990; LOPES; LEITÃO; DOUGLAS, 1991; LANG et al., 2004). Onlays de cerâmica são uma efetiva alternativa para restabelecer resistência mecânica nos dentes posteriores enfraquecidos devido a uma grande perda de estrutura (MAGNE; BELSER, 2003; DALPINO et al., 2002; FRADEANI, 2003; GEURTSEN; GARCIA-GODOY, 1999). Outros trabalhos demonstram valores de resistência à fratura de dentes restaurados com porcelana colada à estrutura dental que são comparáveis aos apresentados pelos dentes íntegros (JENSEN; SHETH; TOLLIVER, 1989; BURKE; WATTS, 1994; MAGNE; DOUGLAS, 1999; SHOR et al., 2003; GORUCU; OZGUNALTAY, 2003). A resistência à compressão de dentes restaurados com coroas totais confeccionadas com porcelana feldspática e coladas à estrutura dental é semelhante à observada quando a restauração é confeccionada com uma cerâmica reforçada por leucita empregada na técnica de prensagem (BURKE; QUALTROUGH; WILSON, 1998).

Smales e Etemadi (2004) compararam a resistência à fratura de restaurações do tipo onlay confeccionadas com porcelana feldspática com e sem a presença de uma infra-estrutura metálica. Cinqüenta pacientes foram acompanhados durante seis anos, e os autores observaram uma incidência similar de falhas por fratura das 
restaurações localizadas na região de molares, independente da presença ou não de uma infra-estrutura metálica de reforço.

Magne e Belser (2003) afirmam que as abordagens restauradoras recentes, que permitem a colagem da restauração à estrutura dental, tornam desnecessário criar restaurações ainda mais fortes, pois, com as porcelanas convencionais obtêmse restaurações compatíveis com as propriedades mecânicas, biológicas e ópticas dos tecidos dentais.

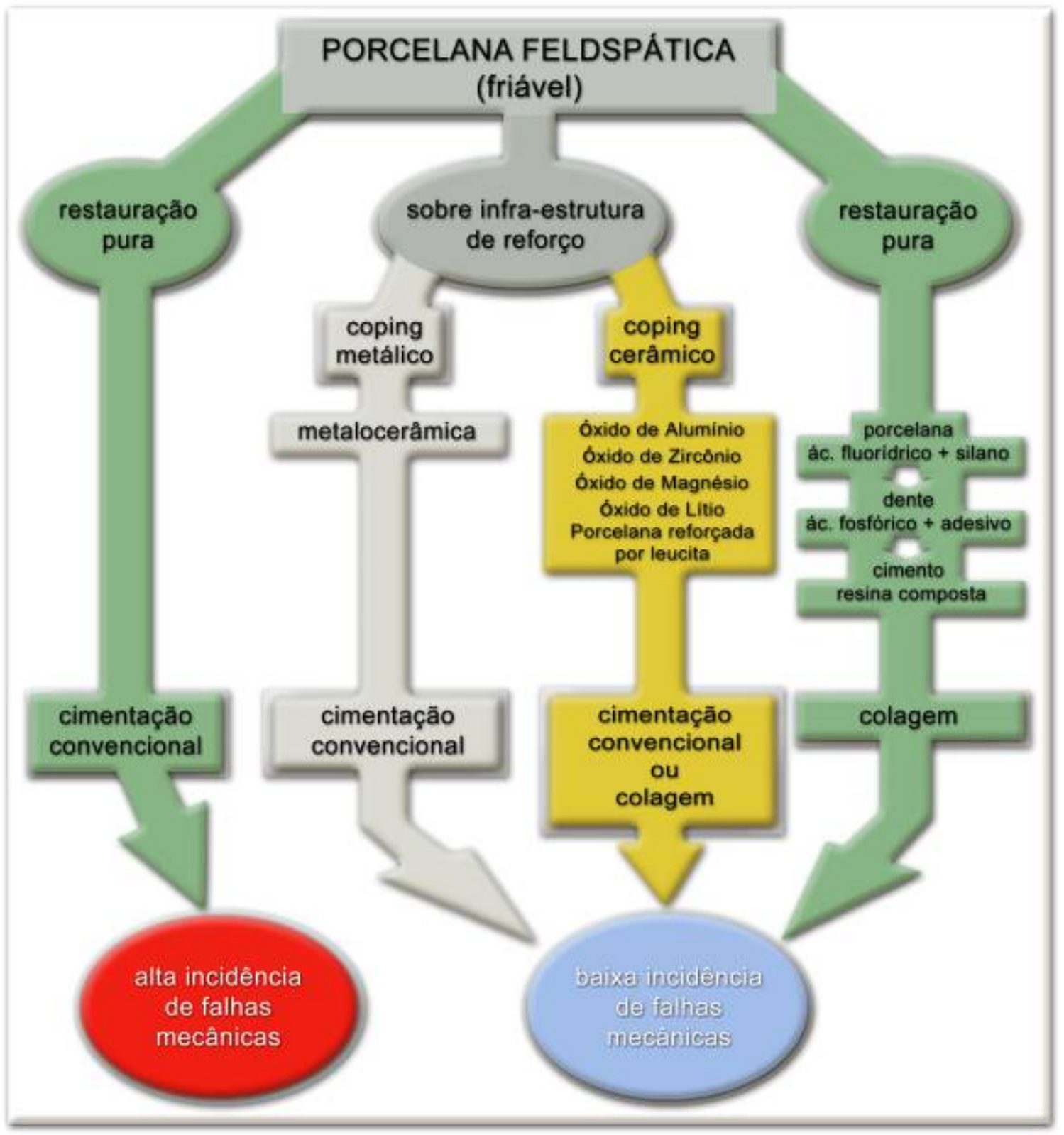

Figura 2.2 - Diferentes possibilidades de prover reforço à porcelana feldspática 


\subsubsection{2 potencial de desgaste do antagonista}

O desgaste dos tecidos duros dos dentes é um processo natural que acontece em maior ou menor grau nas duas dentições (DELONG et al., 1989). A necessidade de realizar restaurações na cavidade oral pode deturpar este processo (RAMFJORD; ASH, 1971). Os parâmetros para a escolha do material restaurador a ser empregado de modo a criar a menor interferência possível estão baseados na experiência clínica individual do profissional e nos resultados de trabalhos que buscam consolidar o conhecimento científico sobre o mecanismo de desgaste dos dentes e restaurações (EKFELDT; OILO, 1988). Este conhecimento ainda é parco, e a maioria dos estudos é realizada in vitro, não simulando adequadamente a complexidade presente na cavidade oral (EKFELDT; OILO, 1988; WILSON, 1990).

Os fabricantes das porcelanas odontológicas utilizam os valores de dureza como referência para o possível potencial de desgaste que estes materiais representariam para os dentes antagonistas, apontando vantagens nos materiais com dureza similar à do esmalte dental. No entanto, a dureza parece não ser o principal fator, mas sim um dos fatores que determinam o potencial de desgaste de uma porcelana (KELLY; NISHIMURA; CAMPBELL, 1996). Seghi, Rosenstiel e Bauer (1991) analisaram diferentes materiais cerâmicos e verificaram existir pouca correlação entre a dureza e o potencial de desgaste do material. Sugerem que o potencial de desgaste teria como fator principal as variações na composição das diferentes cerâmicas. Larsen-Basse (1994) julga que o potencial de desgaste está diretamente relacionado à ocorrência de rupturas na lisura de superfície da 
porcelana; a configuração, tamanho e formato destas rupturas são dependentes da composição, resistência à fratura e dureza da porcelana.

Pober e Giordano (2002) compararam o desgaste promovido no esmalte humano por uma porcelana feldspática que apresenta estrutura cristalina fina e outra que apresenta estrutura cristalina grosseira. A de estrutura fina promoveu desgaste no esmalte semelhante ao encontrado no contato entre o esmalte com o próprio esmalte. $\mathrm{O}$ desgaste promovido pela porcelana de estrutura cristalina grosseira foi significativamente maior.

Clelland et al. (2003) avaliou o desgaste do esmalte humano em contato com cinco porcelanas que os autores classificam como de baixa fusão (Finesse, Rhapsody, IPS d.Sign, Omega 900 e Duceram LFC). A porcelana convencional Vita VMK68 foi usada como controle. Os resultados dos testes de desgaste indicaram que as cerâmicas avaliadas não promoveram desgaste no esmalte menor que o promovido pela porcelana convencional. Ao contrário, as cerâmicas Rhapsody, Omega 900 e Duceram LFC causaram desgaste superior que o promovido pela porcelana VMK68. Os autores concluem que variações na composição e na micro estrutura de uma cerâmica afetam o potencial de desgaste do material. No entanto, cerâmicas de baixa fusão não garantem necessariamente menor desgaste do esmalte.

Além dos fatores já citados, intrínsecos às características dos materiais, devese observar a questão do acabamento superficial. O "glaze" propicia excelente lisura superficial na porcelana por promover o fechamento de fendas (FAIRHURST et al., 1992; AL-WAHADNI; MARTIN, 1998) e, idealmente, as restaurações de porcelana deveriam preservar esta camada intacta (PATTERSON et al., 1992). Quando existe a necessidade de realizar ajustes com instrumentos cortantes ou abrasivos das 
restaurações de porcelana há a remoção da camada externa que foi exposta ao "glaze", e formam-se inúmeras irregularidades. Quando a restauração não pode retornar ao forno para nova queima, deve-se sempre executar o polimento, passo essencial no controle do desgaste das superfícies oclusais ou incisais dos dentes antagonistas (GOLDSTEIN; BARNHARD; PENUGONDA, 1991), e para que se evite o acúmulo de placa bacteriana sobre a restauração (AL-WAHADNI; MARTIN, 1998). Ward, Tate e Powers (1995) ressaltam que o acabamento dado às superfícies dos materiais restauradores pode deturpar o processo natural de desgaste dos dentes antagonistas. Como regra sabe-se que quanto maior a área de contato entre os materiais menor será o desgaste produzido, e que o polimento aumenta a área de contato possível pela eliminação de irregularidades (MATEOS, 1974). O polimento assegura harmonia entre a restauração de porcelana e os tecidos gengivais circunvizinhos, sendo importante para que a ótima compatibilidade biológica deste material no que tange à resposta do tecido gengival seja preservada (CAMPBELL, 1989; WARD; TATE; POWERS 1995; GLAVINA et al., 2004). Estudos in vivo e in vitro sobre a compatibilidade biológica de diferentes materiais mostram que a resposta inflamatória dos tecidos é proporcional ao grau de rugosidade que os materiais apresentam (RICHTER et al., 1980; SALTHOUSE; MATLAGA, 1980).

Kawai, Urano e Ebisu (2000) determinou a relação entre o acabamento superficial de uma cerâmica (blocos Vita Celay, A3M-9, Vita Zahnfabrik, Bad Sackingen, Germany) e o grau de acúmulo de placa bacteriana. Comparou espécimes em que pó de "glaze" foi aplicado (IPS Glaze, Ivoclar, Schaan, Lichtenstein) a outros com distintos graus de rugosidade superficial obtidos com diferentes técnicas de polimento. Os espécimes polidos com pasta contendo partículas de diamante apresentaram rugosidade média (Ra) inferior à dos 
submetidos ao "glaze". Os autores concluem que, entre os espécimes polidos com diferentes combinações de lixas de diversas granulosidades e pasta com partículas de diamante, quanto maior a rugosidade superficial, maior a aderência de placa. Surpreendentemente, os espécimes em que o "glaze" foi preservado foram os que apresentaram o maior acúmulo de placa bacteriana. O simples polimento com uma pasta contendo partículas de diamante da superfície submetida ao "glaze" trouxe uma significativa diminuição no acúmulo de placa.

Wang et al. (2003) também avaliou a aderência de placa bacteriana à blocos de porcelana submetidos ao "glaze", polidos e desgastados. Os autores concluem que quanto maior a rugosidade superficial, maior o acúmulo de placa. No entanto, neste trabalho os autores encontram valores similares de aderência de placa tanto para a porcelana polida como para a submetida ao "glaze".

Al-Hiyasat et al. (1997) verificaram o efeito sobre o esmalte humano in vitro de diferentes acabamentos de superfície em corpos de prova de alguns tipos de porcelana (convencional, reforçada por leucita e reforçada com alumina). Sessenta pares de espécimes de porcelana foram testados imersos em água destilada ou em refrigerante. O desgaste do esmalte foi medido após 5000, 15000 e 25000 ciclos que simularam o contato entre os dentes durante a mastigação. Após os 25000 ciclos não existiu diferença significativa entre o desgaste causado por porcelanas em que o "glaze" foi mantido ou que foram polidas. No entanto, o desgaste causado pelos espécimes desgastados e não polidos foi significativamente maior. Os espécimes testados imersos em refrigerante provocaram maior desgaste do esmalte tanto para a porcelana em que o "glaze" foi mantido, polida ou desgastada, e revela a importância que o hábito alimentar tem para a durabilidade de um tratamento 
restaurador. O tipo de acabamento presente na superfície dos corpos de prova de porcelana não influenciou o desgaste deste material.

Metzler et al. (1999) avaliaram o desgaste promovido no esmalte humano por três porcelanas: Ceramco II, Finesse e Omega 900. Os corpos de prova foram confeccionados de acordo com as instruções de cada fabricante e a seguir polidos com uma pasta contendo partículas de diamante de 0,25 micra. $O$ desgaste resultante do contato entre a porcelana e os espécimes de esmalte foi medido em diferentes intervalos de tempo. Em cada um destes momentos, também foi aferida a rugosidade dos corpos de prova com o emprego de um rugosímetro. A análise estatística demonstrou que os corpos de prova das porcelanas Finesse (Dentsply) e Omega 900 (Vita) causaram um desgaste do esmalte significativamente menor que os corpos de prova confeccionados com a porcelana Ceranco II (Dentsply). A análise ao rugosímetro não revelou diferenças significativas na rugosidade superficial das porcelanas avaliadas. A diferença de composição entre os materiais fica evidenciada como fator determinante no desgaste promovido.

Jagger e Harrison (1994) avaliaram o desgaste produzido por corpos de prova de porcelana aluminizada (Vitadur $\mathrm{N}$ ) em espécimes de esmalte humano. $\mathrm{O}$ teste foi realizado em máquina específica para simular o ciclo mastigatório. As porcelanas submetidas ao "glaze" - manutenção dos corpos de prova por 2 minutos na temperatura final de queima de $970^{\circ} \mathrm{C}$ - e as porcelanas que não permaneceram na temperatura final de queima tempo suficiente para que a superfície apresentasse o aspecto característico do "glaze", promoveram desgaste similar no esmalte. No entanto, os corpos de prova de porcelana polidos com discos impregnados por óxido de alumínio (Sof-Lex, 3M) e pontas de silicone (Ceramisté, Shofu) promoveram desgaste substancialmente menor. A análise dos corpos de prova demonstrou que a 
camada de "glaze" foi removida em menos de duas horas após o início do ciclo na máquina de desgaste. Segundo os autores, as restaurações de porcelana deveriam ser sempre polidas, e não submetidas a uma nova queima.

Jacobi, Shillingburg Jr e Duncanson Jr (1991) compararam a abrasão promovida por ouro do tipo III e seis diferentes cerâmicas contra dentes extraídos. O ranking dos materiais restauradores do menos para o mais abrasivo foi: ouro polido, vidro ceramizado polido (Dicor), porcelana polida, vidro ceramizado polido e com caracterização extrínseca, porcelana polida e porcelana que foi submetida ao "glaze" (VMK 68), vidro ceramizado com caracterização extrínseca e vidro ceramizado sem tratamento. Ou seja, do mesmo modo que no estudo de Jagger e Harrison (1994), os autores concluíram que o desgaste promovido pela porcelana polida foi inferior ao apresentado pela porcelana que teve o "glaze" mantido ou removido com desgaste.

Krejci, Lutz e Reimer (1994) avaliaram in vitro o desgaste promovido por diferentes porcelanas no esmalte. Foram estudadas porcelanas empregadas na técnica de fresagem: Dicor MGC, Cerec Vita Mk I, Cerec Vita Mk II V7R e Cerec. Os autores observaram que as porcelanas Dicor MGC, Cerec Vita Mk I e Cerec sofreram desgaste menor que o observado no amálgama quando em contato com o esmalte, ou que o esmalte quando em contato com esmalte. No entanto, o desgaste promovido por estas três porcelanas no esmalte foi maior que o promovido pelo amálgama ou esmalte. Somente a porcelana Cerec Vita Mk II apresentou abrasividade menor, promovendo um desgaste total equivalente ao existente no contato entre esmalte e esmalte. Os autores reputam esta menor abrasividade à composição micro estrutural da porcelana, que apresenta estrutura cristalina mais fina, mais organizada e menos irregular que as porcelanas feldspáticas convencionais. 
Ratledge, Smith e Wilson (1994) avaliaram o desgaste promovido sobre o esmalte por diferentes materiais: amálgama, resina composta Concise, SR-Isosit Inlay/Onlay, porcelana Vitadur-N submetida ao "glaze", cerâmica IPS Empress não submetida ao "glaze" e esmalte (grupo controle). O teste foi realizado com os espécimes submetidos a 25000 ciclos de desgaste contra esmalte humano, com carga máxima de $40 \mathrm{~N}$. Metade dos espécimes foi testada em meio à água, e a outra metade em meio a ácido cítrico $(\mathrm{pH}=4)$. O perfil da superfície foi registrado a cada 5000 ciclos com rugosímetro e com um programa de análise de imagens em computador que determinou a perda de estrutura. Todos os espécimes testados em meio ácido apresentaram perda maior do que os testados em água. Quanto aos materiais, a porcelana Vitadur- $\mathrm{N}$ apresentou-se como a mais destrutiva para $\mathrm{o}$ esmalte, seguida de perto pela cerâmica IPS Empress e pelo esmalte.

Ramp et al. (1997) avaliaram o desgaste promovido no esmalte pelos materiais Dicor MGC, Vita Mark II e IPS Empress, usando como controle o desgaste promovido por dentes restaurados com ouro tipo III. Ao contrário dos resultados de Krejci, Lutz e Reimer (1994), os autores concluíram que dentre os materiais cerâmicos, o que promoveu menor desgaste foi o Dicor MGC.

Hacker, Wagner e Razzoog (1996) compararam o desgaste do esmalte quando em contato com uma porcelana de baixa fusão (Procera All-Ceram), uma porcelana feldspática (Ceramco) e uma liga áurea (Olympia). O desgaste promovido pela porcelana de baixa fusão (60 mícron) foi maior que o promovido pelo ouro (nove mícron) e menor que o promovido pela porcelana feldspática (230 mícron). O desgaste promovido pela porcelana de baixa fusão foi $74 \%$ menor que o promovido pela porcelana feldspática, e o desgaste promovido pelo ouro foi $96 \%$ menor que o observado entre a porcelana feldspática e o esmalte. Quanto ao desgaste do 
material restaurador, a porcelana feldspática apresentou desgaste de 3,7 mícron, o ouro de 0,32 mícron e a porcelana de baixa fusão de 4,3 mícron. A conclusão dos autores é a de que a porcelana de baixa fusão Procera All-Ceram mostrou-se menos agressiva ao esmalte do que a porcelana feldspática.

Ekfeldt e Oilo (1988) avaliaram in vivo o desgaste de diversos materiais (ouro, compósito e porcelana) quando em contato com dentes de resina e de porcelana. Os resultados mostraram que todos os materiais apresentaram maior desgaste quando em contato com os dentes de porcelana. A resina ativada por calor e pressão Biodent, que não apresenta carga inorgânica, foi o material que apresentou maior perda de substância, seguida da resina foto-ativada (Dentacolor), porcelana (Vita VMK 68) e ouro. O desgaste da porcelana ocorreu principalmente por fadiga, caracterizada pelo desprendimento de pequenas porções da superfície da porcelana. Este padrão de desgaste foi verificado em outros estudos in vivo (EKFELDT, 1989; EKFELDT; OILO, 1990; EKFELDT et al., 1993).

Magne et al. (1999) compararam o desgaste promovido no esmalte por três tipos de cerâmica: uma porcelana feldspática (Creation), uma porcelana aluminizada (Vitadur Alpha), e uma porcelana de baixa fusão (Duceram-LFC). A porcelana de baixa fusão foi a que causou o maior desgaste do esmalte e a que apresentou maior perda de sua própria estrutura. Os autores reputam o resultado ao fato de que entre os materiais avaliados, a porcelana de baixa fusão é a que apresenta menor resistência mecânica, maior friabilidade e um número maior de defeitos em sua superfície quando observada por MEV. 


\subsection{Polimento}

A rugosidade de superfície é uma importante característica dos materiais. Tem o efeito de aumentar a área de superfície, afetar a fricção e prover sítios para a retenção mecânica de placa bacteriana (LEITÃO; HEGDAHL, 1981). O polimento previne que as superfícies irregulares estejam sujeitas a pigmentação, promovam o desgaste do esmalte antagonista, causem desconforto ao paciente e evita a propagação de linhas de fratura na superfície da cerâmica (MCLEAN, 1988). Feito após a colagem da restauração, o polimento gera uma excelente e homogênea região de transição entre o dente, o cimento e a porcelana (WARDAK; WIRZ; SCHMIDLI, 2001).

A evolução das técnicas que propiciam a união entre a porcelana e o dente permitiu a disseminação da indicação de restaurações confeccionadas com este material sem uma infra-estrutura metálica ou cerâmica (BURKE; QUALTROUGH; WILSON, 1998). Aumentou também o interesse pelos métodos para a obtenção de uma lisura de superfície adequada após ajustes das restaurações de porcelana, já que, em função da técnica de confecção e do tipo de porcelana empregada, nem sempre a obtenção do "glaze" em forno de porcelana após ajustes é possível (PATTERSON et al., 1992). Situação diferente da que ocorre com as coroas metalocerâmicas, que podem ser ajustadas e levadas ao forno para um novo "glaze". O coping metálico serve de base para a porcelana, evitando que a mesma deforme-se durante a queima (YAMAMOTO, 1985). Para as restaurações puras sem infra-estrutura metálica - este papel de suporte durante a queima é dado pelo troquel refratário, sobre o qual a porcelana é aplicada. Após o término da confecção 
destas restaurações faz-se a remoção do material refratário. Caso haja a necessidade de executar ajustes na restauração após a prova sobre o dente, não há como retornar estas peças ao forno para um novo "glaze". A queima sem a presença do material refratário, que suporta a porcelana, leva a deformação da porcelana e conseqüente perda de contorno e adaptação da restauração (UBASSY, 1993).

Existem técnicas que contornam esta limitação que a aplicação sobre troquel refratário impõe. Pode-se combinar o uso de uma porcelana de alta fusão sob uma porcelana de baixa fusão. A porcelana de alta fusão é queimada sobre o troquel refratário, e forma uma camada fina e uniforme que recobre todas as paredes do preparo até o limite cavo - superficial. Sobre esta camada a restauração é esculpida com uma porcelana de baixa fusão. A camada de alta fusão suporta a porcelana de baixa fusão durante a sua queima, e a manutenção do troquel refratário torna-se opcional. A porcelana de alta fusão apresenta papel semelhante ao do coping metálico nas restaurações metalocerâmicas, e permite que após a conclusão da restauração esta seja provada, ajustada e novamente levada ao forno quando necessário. Desde que a temperatura de queima da porcelana de baixa fusão seja respeitada, não existe risco de que a restauração sofra deformação (KOMMA, 1993). A confecção da restauração apenas com uma porcelana de baixa fusão resulta em pequena força de união entre este material e o cimento resinoso, devido à ausência de uma estrutura cristalina que permita a formação de microscópicos nichos retentivos (ATTIA; KERN, 2004).

O uso de uma delgada lâmina de platina, intimamente adaptada ao troquel de trabalho de gesso de tal modo que esta reproduza a forma do preparo executado sobre o dente, se presta como alternativa à técnica de troquel refratário A porcelana é aplicada sobre a lâmina de platina. Findados os acréscimos desejados, a lâmina é 
cuidadosamente destacada do troquel de gesso, e o conjunto lâmina de platina e porcelana é levado ao forno para a queima. Terminada a restauração, a mesma pode ser levada à boca do paciente, ajustada e, enquanto não se fizer a remoção da lâmina de platina, pode ser retornada ao forno para novo "glaze" (VIEIRA et al., 1995).

Apesar destas alternativas à técnica do troquel refratário, deve-se considerar o risco de executar ajustes devido à friabilidade da porcelana. Facetas e restaurações “inlay/onlay" são geralmente delgadas, sujeitas à fratura se expostas ao contato com os dentes antagonistas ou se ajustadas antes da colagem ao dente. Portanto, mesmo quando se emprega a técnica de alta e baixa fusão ou da lâmina de platina, deve-se avaliar o risco de realizar qualquer ajuste antes da cimentação devido à possibilidade da ocorrência de fratura da restauração (VIEIRA; AGRA, 1998).

As restaurações obtidas através do método de fresagem necessitam de um regime efetivo de polimento intra-oral. Na técnica de confecção assistida por computador (CAD-CAM) ocorre a escultura do aspecto interno e proximal da restauração. Na superfície oclusal das restaurações para dentes posteriores o aparelho executa um desgaste que define uma anatomia por vezes pouco precisa. Há a necessidade de refiná-la, o que é conseguido empregando instrumentos abrasivos rotatórios após a colagem da restauração (ROULET; HERDER, 1991; DE JAGER; FEILZER; DAVIDSON, 2000). A última versão do software do aparelho CEREC (Siemens) permite criar uma anatomia oclusal mais refinada. Há a possibilidade de tomar a imagem de um registro oclusal em cera e relacioná-la à restauração que o aparelho esculpirá, definindo as regiões de contato oclusal. No entanto, após a colagem da restauração é comum a necessidade de realizar pequenos ajustes na porcelana. As irregularidades criadas podem ser eliminadas de 
modo efetivo através do emprego de instrumentos rotatórios diamantados finos (FINGER; NOACK, 2000).

\subsection{1 polimento e a resistência mecânica das cerâmicas}

Há uma correlação positiva entre a rugosidade da superfície e a resistência flexural de uma porcelana: quanto melhor for a lisura superficial, maior a resistência do material (ALBAKRY; GUAZZATO; SWAIN , 2004; KITAZAKI et al., 2001; DE JAGER; FEILZER; DAVIDSON, 2000; NAKAZATO et al., 1999; FISCHER; SCHAFER; MARX, 2003). O polimento propicia maior resistência à porcelana devido à eliminação de fendas que tenham persistido após o "glaze", e devido ao desenvolvimento de um estresse compressivo na superfície do material (FAIRHURST et al., 1992; GIORDANO; CIMA; POBER, 1995). A rugosidade superficial não é o único fator que afeta a resistência flexural. Outros fatores como porosidades, estresse residual, defeitos internos e fendas na superfície devem ser considerados (ALBAKRY; GUAZZATO; SWAIN , 2004). O tamanho dos cristais de leucita que compõem a porcelana também interfere na resistência flexural. Caso estes sejam grandes, e induzam a formação de linhas de fratura, a resistência do material independerá da qualidade da lisura superficial (DE JAGER; FEILZER; DAVIDSON, 2000). A maior resistência flexural indica que o polimento seria vantajoso, e deveria ser executado rotineiramente pelos laboratórios de prótese (KELLY; NISHIMURA; CAMPBELL, 1996). 
Rosenstiel, Baiker e Johnston (1989) compararam a resistência à fratura e à pigmentação de corpos de prova em que o "glaze" foi mantido intacto contra outros que passaram por polimento. Os corpos de prova foram confeccionados com uma porcelana feldspática (Vita VMK68). Os autores observaram que o polimento resultou em maior resistência à fratura e igual resistência à pigmentação em comparação com a porcelana em que o "glaze" foi mantido intacto.

Giordano, Cima e Pober (1995) verificaram os efeitos do polimento na resistência flexural de duas porcelanas feldspáticas (Vita Mark I e Vita VMK 68) e de uma porcelana aluminizada (Vitadur N). O desgaste foi realizado com uma roda com partículas de diamante com granulação de 30 mícron e o polimento feito de modo seqüencial com pastas com partículas de diamante de diferentes granulações $(15,9$, 6, e 3 mícron). Os autores concluíram que o polimento acarretou em um aumento significativo da resistência flexural (15 a 30\%); o "glaze" aumenta a resistência flexural, mas o aumento alcançado com o polimento é significativamente maior.

Williamson, Kovarik e Mitchell (1996) avaliaram os efeitos que o acabamento da superfície e a umidade apresentam sobre a resistência flexural de uma porcelana reforçada por leucita. Os tratamentos na superfície da porcelana foram: desgaste com instrumento diamantado; desgaste e retorno da porcelana ao forno para novo "glaze"; desgaste e polimento. Metade dos espécimes foi mantida imersa em água destilada, e a outra metade foi mantida seca. Os resultados demonstraram que, como as porcelanas feldspáticas convencionais, as reforçadas por leucita apresentam uma menor resistência após o desgaste. O polimento ou o retorno da porcelana ao forno para novo "glaze" possibilita ganho na resistência flexural. Os métodos usados pelos autores não possibilitaram detectar a influência da umidade na resistência flexural desta porcelana. 
Chen et al. (1999) determinaram a resistência à fratura de coroas totais confeccionadas com diferentes cerâmicas: Vita Mark II, ProCAD (Ivoclar) e IPS Empress. As cerâmicas Vita Mark II e ProCAD são empregadas na técnica de fresagem com CAD-CAM (Cerec, Siemens). Testaram-se dois tratamentos de superfície: "glaze" e polimento. Antes de realizar o teste de resistência à fratura, metade das amostras foi submetida à aplicação de uma carga compressiva de modo cíclico que objetivou simular o que ocorre na cavidade oral. Ao compararem-se espécimes polidos e não submetidos a uma carga cíclica anterior ao teste de fratura, as coroas de ProCAD foram significativamente mais resistentes que as coroas confeccionadas com a porcelana Vita Mark II. No entanto, não foram diferentes das coroas de IPS-Empress. O "glaze" das coroas de ProCAD resultou em significativo aumento da resistência à fratura em comparação com o polimento. Submeter as coroas ao estresse de uma carga cíclica levou a diminuição da resistência de todos os materiais. No entanto, esta redução de resistência foi menor para as coroas confeccionadas por fresagem (Vita Mark II e ProCAD) do que para as obtidas por prensagem (IPS Empress).

Chu, Frankel e Smales (2000) avaliaram a rugosidade superficial e a resistência flexural de amostras de In-Ceram (alumina infiltrada por vidro) recobertas com a porcelana aluminizada Vitadur Alpha, e submetidas a três diferentes acabamentos de superfície: "glaze" (grupo 1), polimento (grupo 2) e polimento seguido de novo "glaze" (grupo 3). O parâmetro rugosidade média (Ra) foi avaliado com um rugosímetro. Os grupos 1 e 3 apresentaram rugosidade significativamente inferior à do grupo 2. Os espécimes que passaram por novo "glaze" após polimento (grupo 3) apresentaram rugosidade média significativamente inferior à observada no grupo 1 . A resistência flexural dos grupos 1 e 3 foi similar, e significativamente superior à 
observada nas amostras polidas. Os autores concluem que em comparação com o polimento, um novo "glaze" traz resultados superiores quanto à lisura e resistência flexural.

A literatura apresenta resultados díspares quando avalia porcelanas que, após desgaste, são submetidas a um novo "glaze". Para Griggs, Thompson e Anusavice (1996) uma nova queima após desgaste é capaz de regularizar a superfície, mas não aumenta a resistência flexural da porcelana. Ao avaliar a porcelana Vita VMK68, Edge e Wagner (1994), verificaram que após polimento e novo "glaze", a superfície do material apresentava pequenas fendas, não observadas após o "glaze" inicial, ou após a execução do "glaze" e polimento. Os autores sugerem que estas fendas podem ser determinantes de um maior potencial de desgaste da porcelana contra as estruturas antagonistas. Correr Sobrinho et al. (2002) avaliaram a dureza Vickers e a rugosidade superficial da porcelana Duceram Plus (Degussa) antes e após a simulação de um ajuste oclusal. O polimento acarretou em aumento significativo da dureza Vickers em comparação com a existente após o "glaze" (553,2 VHN contra 513.1 VHN).

Bhamra, Palin e Fleming (2002) compararam a resistência flexural de espécimes confeccionados com a porcelana Vitadur-Alpha. O grupo controle não recebeu qualquer tratamento após a sinterização, enquanto os outros grupos foram submetidos ao desgaste com lixas de diferentes granulosidades. Na comparação entre os grupos, o controle foi o que apresentou maior resistência flexural. Entre os grupos que sofreram desgaste, a resistência flexural foi inversamente proporcional à granulosidade das lixas empregadas. Quanto mais grosseira a granulosidade, menor a resistência flexural. 
Albakry, Guazzato e Swain (2004) verificaram o efeito que o "glaze", desgaste, polimento e aplicação de jato de óxido de alumínio apresentam sobre a resistência flexural de duas cerâmicas empregadas na técnica de prensagem (IPS Empress e IPS Empress 2). Verificaram que estes tratamentos afetam a resistência pela influência que apresentam na introdução ou não de falhas microscópicas na superfície dos materiais. Os espécimes polidos apresentaram a menor rugosidade superficial e a maior resistência flexural. 
2.2.2 polimento e a adequação estética das cerâmicas

O polimento também propicia um melhor controle sobre a textura e brilho da superfície, favorecendo uma adequação estética entre o dente restaurado e os dentes naturais vizinhos (ANCOWITZ; TORRES; ROSTAMI, 1998; YAMAMOTO; MIYOSHI; KATAOKA, 1990/1991; ROSENSTIEL; BAIKER; JOHNSTON, 1989; BREWER et al.,1990; VIEIRA; AGRA, 1999; WARDAK; WIRZ; SCHMIDLI, 2001; MAGNE; BELSER, 2003).

Kim et al. (2003) avaliaram as diferenças de cor em função da topografia da superfície de uma porcelana. Foram confeccionados discos de porcelana feldspática da cor A3. Os espécimes foram divididos de acordo com os tratamentos aplicados: não polidos, polidos com lixas de diferentes granulosidades e os submetidos ao "glaze". Após a medida da rugosidade média da superfície (Ra), a cor foi determinada sob o iluminante A (correspondente a uma lâmpada de tungstênio) e o D65 (correspondente à luz do dia). Os valores CIE L* (medida que apresenta todos os valores de cromaticidade para as cores visíveis) foram distintos em relação aos tratamentos realizados. A porcelana submetida ao "glaze" apresentou valores de luminosidade significativamente menores em comparação com as porcelanas polidas. 


\subsection{3 polimento e a resistência química das cerâmicas}

As porcelanas de baixa fusão (vidros hidrotérmicos) apresentam, segundo os fabricantes, a capacidade de formar uma camada superficial de hidróxido de silício que sela e homogeneíza a superfície quando a restauração é exposta ao meio úmido (KOMMA, 1993). Esta afirmação não encontra respaldo no trabalho de Palin, Fleming e Marquis (2003), que observou que as fendas existentes no material após o "glaze" só são controladas empregando-se uma técnica de polimento adequada.

Hammad e Khalil (1994) verificaram, através de MEV, a micro morfologia de corpos de prova da porcelana feldspática Vita VMK 68 após "glaze" e após polimento, submetidos à exposição de produtos com flúor, de diferentes concentrações e $\mathrm{pH}$. O polimento da porcelana foi feito com pontas de silicone e uma pasta com partículas de diamante. A porcelana após o "glaze" mostrou-se mais resistente aos produtos fluorados do que a porcelana polida. Produtos com $\mathrm{pH}$ mais baixo e maior concentração de flúor causaram maior dano à cerâmica, o que está em concordância com as observações de Anusavice (1992). Os autores recomendam o uso de soluções neutras e com baixa concentração de flúor. Os autores indicam ainda que uma porcelana, após o ajuste oclusal, deveria ser sempre submetida a novo "glaze" em forno de porcelana.

Butler et al. (2004) verificaram o efeito de duas soluções contendo flúor (flúor acidulado a $1,23 \%$ e fluoreto de estanho a $0,4 \%$ ) e de uma contendo peróxido de carbamida a $10 \%$ sobre a rugosidade média $(\mathrm{Ra})$ da superfície de três porcelanas: Finesse (baixa fusão), Ceramco II (feldspática convencional) e All-Ceram (porcelana aluminizada). Os espécimes receberam dois tratamentos: "glaze" e polimento. O 
efeito das soluções foi variado para as diferentes porcelanas e tratamentos. A solução de flúor acidulado a 1,23\% promoveu o condicionamento das superfícies submetidas ao "glaze" das três porcelanas. A porcelana Finesse mostrou valores de Ra menores após a imersão por 48 horas em solução fluorada em comparação com os valores após o "glaze". A porcelana All-Ceram apresentou valores de Ra significativamente maiores após a imersão nas três soluções em comparação com o tratamento "glaze". A porcelana Ceramco II também foi afetada pelas três soluções, apresentando valores de Ra menores que os existentes após o "glaze". A imersão nas três soluções não causou efeito sobre os espécimes polidos das três porcelanas. 


\subsection{4 técnicas e materiais para polimento}

Há vários métodos e materiais disponíveis para o polimento de restaurações cerâmicas. Esta parte da revisão da literatura faz um apanhado cronológico dos trabalhos que comparam métodos e materiais para o polimento intra-oral.

Eustaquio, Garner e Moore (1988) avaliaram a possibilidade de realizar o polimento de restaurações de porcelana após a remoção de brackets ortodônticos, e observaram que o uso de pastas de polimento com partículas finas de diamante foi efetivo para restaurar a lisura de superfície da porcelana.

Campbell (1989) avaliou através de MEV o efeito do polimento em dois materiais: Dicor e Cerestore. Os espécimes que não foram polidos apresentaram aspecto áspero. As tentativas de polir o material de base da cerâmica Cerestore mostraram-se infrutíferas. O polimento da cerâmica Dicor com o kit de ajuste Shofu e pasta de polimento com partículas de diamante de 0,2 mícron resultou em uma superfície lisa, mas com fissuras. O polimento resultou em lisura inferior à alcançada com a aplicação das porcelanas de revestimento próprias para a caracterização extrínseca de cada sistema.

Haywood, Heymann e Scurria (1989) avaliaram através de MEV o resultado do polimento de uma porcelana feldspática (Ceramco) com 47 diferentes combinações de instrumentos e materiais de polimento. Os autores verificaram qual a influência do emprego dos instrumentos com moderada ou alta velocidade e sob refrigeração ou

não. A melhor lisura de superfície foi obtida com o emprego da seguinte seqüência: inicialmente pontas de diamante com granulação progressivamente menor, sob refrigeração e com velocidade moderada; a seguir, ponta multilaminada - 30 lâminas 
- em alta velocidade e sem refrigeração; por fim, uma pasta com partículas de diamante aplicada com taça de borracha. Em todas as seqüências testadas, os melhores resultados foram obtidos com os instrumentos diamantados usados sob refrigeração e velocidade moderada, ou com os instrumentos multilaminados usados sem refrigeração e em alta velocidade.

Raimondo Jr, Richardson e Wiedner (1990) compararam a lisura alcançada com o uso de quatro diferentes pastas contendo partículas de diamante contra o obtido por um novo "glaze" e pelo uso de um kit de pontas de silicone (Shofu) para ajuste e polimento de porcelana. Os corpos de prova foram avaliados por observadores independentes e por MEV. Pela inspeção visual, o polimento com pastas contendo partículas de diamante apresentou resultados iguais ou melhores que o da porcelana após o "glaze". Pela MEV, o kit que emprega pontas de silicone apresentou melhor aspecto que os outros sistemas. Os autores sugerem que para um refinamento do resultado, o kit de pontas de silicone deveria ser empregado em associação com uma pasta de polimento contendo partículas de diamante.

Goldstein, Barnhard e Penugonda (1991) avaliaram cinco diferentes métodos de polimento de porcelana através do uso de um rugosímetro, MEV e inspeção visual. Discos de porcelana feldspática das marcas Biobond e Ceramco foram desgastados com uma pedra montada verde e polidos com diferentes sistemas de polimento. Os sistemas da Brasseler, Dedeco, Dentsply, e Shofu foram apropriados para remover a rugosidade dos discos desgastados. No entanto, a avaliação clínica correlacionada com os dados obtidos ao rugosímetro e MEV revelou uma superioridade do conjunto de pontas diamantadas finas (Brasseler) para o polimento da porcelana Ceramco. 
Patterson et al. (1991) avaliaram o efeito sobre uma porcelana feldspática de um "kit" de polimento que emprega instrumentos diamantados de granulosidade fina. A avaliação foi feita qualitativamente através de MEV, e quantitativamente com o emprego de um rugosímetro. O kit foi incapaz de restaurar a lisura do "glaze", mas reduziu significativamente a rugosidade de superfície da porcelana desgastada. Os autores discutem a importância de distinguir a integridade da superfície que uma porcelana submetida ao "glaze" apresenta da menor rugosidade, determinada pelo rugosímetro, que a porcelana polida apresenta. Sugerem que o polimento deveria ficar confinado apenas às regiões ajustadas, preservando ao máximo o aspecto que a superfície assume após o "glaze".

Winchester (1991) comparou dois métodos de polimento após a remoção de brackets ortodônticos aderidos às restaurações cerâmicas. Metade das amostras foi polida com pontas de silicone (Shofu Enamel Adjustment Kit), e a outra metade com uma pasta de polimento contendo partículas de diamante aplicada com taça de borracha (Vita VMK Diamond Polishing Paste). Após análise ao MEV, o autor verificou que o polimento com pasta de diamante foi superior ao proporcionado pelo kit de pontas de silicone.

Patterson et al. (1992) verificaram ao MEV e rugosímetro a eficácia de instrumentos diamantados de 30 e 15 mícron para alta velocidade no polimento de uma porcelana com alto percentual de alumina em sua composição (Vitadur N). Apesar de estes instrumentos terem tornado a superfície desgastada significativamente mais lisa, os resultados ao MEV e rugosímetro demonstraram que as superfícies polidas apresentavam rugosidade maior que a observada no "glaze". Os autores sugerem que o emprego adicional de um instrumento diamantado com 
granulosidade inferior a 15 mícron permitiria que a superfície apresentasse lisura comparável à do "glaze".

Hulterström e Bergman (1993) compararam a ação de vários sistemas de polimento sobre a porcelana feldspática Vita Mark I, própria para o sistema CADCAM. Os sistemas que produziram os melhores resultados - discos de papel impregnados com abrasivo (Sof-Lex, 3M) e pontas de silicone impregnadas com abrasivo (Shofu Porcelain Laminate Polishing Kit) - foram selecionados e testados em combinação com uma pasta de polimento de diamante em outras porcelanas (Vitadur, Dicor, Dicor MGC, IPS Empress, Mirage e Vita Mark II). A avaliação com rugosímetro demonstrou que os dois sistemas possibilitaram um polimento satisfatório nas diferentes cerâmicas. O uso de uma pasta de polimento de diamante não trouxe melhora na rugosidade quando o sistema SofLex foi empregado. Para o polimento com o sistema da Shofu o efeito da pasta foi positivo.

Scurria e Powers (1994) verificaram a rugosidade de superfície de dois materiais cerâmicos (Ceramco II e Dicor MGC) após a aplicação de combinações de cinco diferentes sistemas de polimento (1- instrumentos diamantados com granulação de 45, 25, e 10 mícron; 2- instrumento multilaminado de 30 lâminas; 3 pontas de silicone ; 4 - pastas de diamante de quatro e um mícron; 5 - uma ponta de óxido de alumínio e duas pastas de óxido de alumínio). Foram mantidos para controle discos da porcelana feldspática Ceramco II submetidos apenas ao "glaze" e discos de vidro ceramizado Dicor MGC desgastados com a roda de diamante do sistema Cerec. Os discos controle da porcelana feldspática foram ajustados com pedra verde e jatos de partículas de óxido de alumínio 25 mícron antes do "glaze". A análise ao rugosímetro revelou que a porcelana feldspática polida apresentou menor rugosidade do que a que passou apenas pelo "glaze", e que o vidro ceramizado 
apresentou menor rugosidade do que a porcelana feldspática. O uso dos instrumentos diamantados de 45, 25, e 10 mícron seguidos da aplicação das pastas contendo partículas de diamante garantiu a menor rugosidade. Para o vidro ceramizado a aplicação de pontas de óxido de alumínio e pastas de óxido de alumínio produziu efeito similar ao conseguido com os instrumentos diamantados seguidos das pastas contendo partículas de diamante. Tanto para a porcelana feldspática como para o vidro ceramizado, o polimento resultou em uma rugosidade menor que a observada nos discos controle. $O$ emprego de instrumento multilaminados de 30 lâminas não resultou em melhora na rugosidade dos corpos de prova.

Shearer et al. (1994) avaliaram seis diferentes métodos de polimento em restaurações confeccionadas pelo método CAD-CAM com a cerâmica Dicor MGC. Os materiais para polimento avaliados foram: instrumentos multilaminados; pontas de silicone impregnadas com abrasivo; pontas diamantadas de granulação fina; discos de papel impregnados com abrasivo (SofLex); pasta contendo partículas de diamante. A avaliação da reflexão especular após a aplicação de um feixe de laser foi o método avaliado para determinar a rugosidade da superfície, e indicou que para esta cerâmica todos os materiais de polimento trouxeram resultados adequados.

Ward, Tate e Powers (1995) verificaram o efeito de oito técnicas de polimento em três diferentes porcelanas opalescentes. A porcelana opalescente é aplicada nas regiões correspondentes à camada de esmalte e possibilita que as restaurações apresentem aspecto mais natural, por apresentar propriedades ópticas semelhantes às do esmalte. Apresenta aspecto azulado quando a luz é incidida sobre a superfície, e alaranjado quando se observa a luz atravessar a estrutura (YAMAMOTO, 1985). A rugosidade média foi aferida antes e depois dos 
procedimentos de polimento com um rugosímetro e os resultados foram comparados aos obtidos com corpos de prova submetidos apenas ao "glaze". Cinco das oito técnicas propiciaram um valor de rugosidade menor para o polimento que para o "glaze". O uso de pontas diamantadas de granulação fina, seguido do uso de um instrumento multilaminados de 30 lâminas e da aplicação de uma pasta contendo partículas de diamante foi o tratamento que resultou em menor rugosidade.

Fuzzi, Zaccheroni e Vallania (1996) avaliaram com MEV e rugosímetro a textura de superfície de 54 corpos de prova da porcelana feldspática Vita VMK 68. Os corpos de prova foram divididos em nove grupos, sendo que no primeiro foi mantido o "glaze" e no segundo foi realizado desgaste com um instrumento diamantado de 30 mícron. Os sete grupos restantes, após o desgaste com instrumento diamantado de 30 mícron, receberam sete diferentes tipos de polimento. O desgaste e os diferentes polimentos foram realizados simulando a prática clínica. Ao MEV a porcelana submetida apenas ao "glaze" apresentou a menor rugosidade. Os grupos desgastados e polidos apresentaram superfícies parcialmente porosas e com trincas. No entanto, ao rugosímetro (análise quantitativa), a menor rugosidade de superfície foi observada no grupo em que foram aplicados instrumentos diamantados com partículas progressivamente menores (30, 15, e 8 mícron). A maior rugosidade ocorreu no grupo em que os corpos de prova foram desgastados com o instrumento diamantado de 30 mícron. A análise dos dados mostrou que não existiu diferença significativa entre os resultados obtidos nos grupos em que se realizou o polimento e nos grupos onde o "glaze" foi mantido.

Folwaczny et al. (1998) avaliaram através de análise quantitativa com rugosímetro e qualitativa com MEV a possibilidade de efetuar o polimento de diferentes cerâmicas com o emprego de um laser do tipo $\mathrm{XeCl}$ excimer, irradiando 
no comprimento de onda de $308 \mathrm{~nm}$ de modo pulsado e com diferentes intensidades de energia. Concluíram que este método melhora a lisura da porcelana, mas não é suficiente para devolver uniformidade à mesma, e seu uso deve ser complementado por outro método de polimento.

Finger e Noack (2000) verificaram através de MEV e leitura ao rugosímetro a eficácia de instrumentos rotatórios diamantados de granulosidades distintas $45 \mu \mathrm{m}$, $25 \mu \mathrm{m}$ e $10 \mu \mathrm{m}$ (Two Striper MFS diamond burs) associados ou não a uma pasta de polimento com partículas finas de diamante (Luminescence diamond polishing gel) no polimento de discos da porcelana própria para a técnica de fresagem por CADCAM, Vita Mark II. Valendo-se dos parâmetros Ra (rugosidade média) e Rz (média das distâncias verticais entre a maior protusão e a maior depressão em cada um dos cinco comprimentos de amostragem) e das imagens da MEV, os autores concluíram não existir a necessidade do uso da pasta contendo partículas de diamante após o emprego da seqüência de instrumentos diamantados finos. Neste trabalho os autores verificaram existir correlação entre os resultados quantitativos e qualitativos obtidos.

Jung (2002) avaliou o polimento alcançado com pastas contendo partículas de diamantes, discos abrasivos (SofLex) e pontas de silicone impregnadas com abrasivo (Ceramisté, Shofu) em uma resina composta híbrida e uma cerâmica reforçada por leucita (IPS Empress). Para a análise qualitativa foi empregado um MEV, e para a análise quantitativa um rugosímetro. O polimento da cerâmica garantiu um aspecto de superfície semelhante ao observado no "glaze". Neste trabalho houve correlação entre os achados quantitativos e qualitativos.

Driscroll et al. (2002) avaliaram a rugosidade de superfície da porcelana de baixa fusão Finesse após o "glaze", desgaste com instrumento diamantado de 
granulosidade média, e polimento com três kits (Axis Dental, Jelenko e Brasseler). Empregou-se na aferição da superfície um rugosímetro e um microscópio óptico. Os valores da rugosidade média ( $\mathrm{Ra}$ ) demonstraram que os kits da Brasseler e Jelenko apresentaram melhor resultado que o da Axis Dental - pontas de silicone impregnadas com partículas de diamante. A conclusão dos autores indica que o polimento garante uma superfície cuja lisura pode ser superior à alcançada com o "glaze".

Correr Sobrinho et al. (2002) avaliaram a dureza Vickers e a rugosidade superficial da porcelana Duceram Plus (Degussa) antes e após a simulação de um ajuste oclusal. O polimento com o kit selecionado (Edenta) resultou em uma superfície com rugosidade média $(\mathrm{Ra})$ superior à existente após o "glaze" $(0,3234$ contra 0,1681 mícron).

Martinez-Gomis et al. (2003) avaliou o efeito de quatro técnicas de polimento sobre a porcelana IPS Classic. Inicialmente, todos os corpos de prova passaram por desgaste com instrumento rotatório diamantado. $\mathrm{O}$ primeiro dos quatro grupos foi polido com borrachas Komet; o segundo grupo foi polido com pontas de silicone da Shofu; O terceiro grupo foi polido com instrumentos diamantados fino de 30 e 15 mícron; o quarto grupo foi polido com discos Sof-Lex. Todos os espécimes foram adicionalmente polidos com pasta contendo partículas de diamante. Através da leitura com rugosímetro, os parâmetros $\mathrm{Ra}, \mathrm{Rpm}$ e $\mathrm{Rz}$ foram anotados. Os autores verificaram que todos os métodos implicaram em diminuição da rugosidade. Porém, o mais efetivo, foi o grupo em que os discos Sof-Lex foram empregados. A eficácia da pasta de diamante não foi evidente.

Wright et al. (2004) avaliou três sistemas de polimento (Axis Dental, Jelenko, e Brasseler) sobre uma porcelana de baixa fusão (Finesse). A superfície dos 
espécimes foi avaliada com rugosímetro e MEV. Houve concordância entre os valores de rugosidade média $(\mathrm{Ra})$ e os achados ao MEV. Todos os sistemas de polimento resultaram em lisura superficial superior à observada nos espécimes submetidos ao "glaze". Dentre os sistemas de polimento, o da Axis Dental promoveu a melhor lisura.

Schmidlin e Gohring (2004) relacionaram a eficácia de diferentes instrumentos de polimento com o potencial destrutivo destes em relação às margens da restauração e o cavo-superficial de esmalte. A rugosidade média $(\mathrm{Ra})$ e a qualidade da margem (expressa como o percentual de margens livres de fraturas) foram avaliadas. A ponta de diamante fina $(0,8 \mathrm{~mm})$ e as brocas carbide de 40 lâminas produziram a menor deterioração da linha de término e promoveram a melhor lisura superficial.

Glavina et al. (2004) avaliaram quatro diferentes métodos de polimento em facetas confeccionadas com o sistema CAD CAM (Cerec 2 - Sirona AG, Bensheim, Alemanha) usando blocos cerâmicos VITA MARK II (Vita Zahnfabrik, Bad Sackingen, Alemanha). Compararam-se os seguintes materiais de polimento: 1. discos Sof-lex (3M, St. Paul, MN, EUA); 2. escovas Hawe (Hawe Neos Dental, Bioggio, Suíça); 3. escovas Hawe e pasta contendo partículas de diamante Diabrill (Oralia Dental $\mathrm{GmbH}$, Kostanz, Alemanha); 4. taças de borracha Politip-P (Vivadent, Schaan, Liechtenstein). Os parâmetros $R z, R a, R k$ e Rpk foram avaliados com um rugosímetro. Os autores verificaram que a melhor superfície foi alcançada com os discos Sof-lex. Todos os outros métodos foram considerados clinicamente aceitáveis. Ressaltam que a seleção de um material ou técnica está condicionada à geometria do instrumento de polimento, e à possibilidade de alcançar as regiões da restauração que devem ser polidas. 


\section{PROPOSIÇÃO}

Este trabalho teve como objetivos:

. Comparar a rugosidade dos corpos de prova em três momentos que ocorrem durante as fases laboratoriais e clínicas quando se trabalha com restaurações de porcelana: "glaze", desgaste com instrumento rotatório diamantado e polimento. Estas fases serão denominadas doravante de tratamentos.

- Verificar se há diferenças na rugosidade de superfície dos dois materiais cerâmicos avaliados, Duceram Plus e Duceragold, para cada um dos tratamentos;

- Avaliar se há correlação entre os resultados obtidos através do método quantitativo (rugosímetro) e qualitativo (MEV).

- Avaliar a correlação entre os diferentes parâmetros observados ao rugosímetro.

. Determinar se a seqüência, materiais e instrumentos empregados nas diferentes técnicas de polimento avaliadas são adequados no papel de atenuar a rugosidade superficial após desgaste. 


\section{MATERIAIS E MÉTODOS}

Foram selecionadas duas cerâmicas: Duceram Plus (Ducera Dental, Alemanha) e Duceragold (Ducera Dental, Alemanha). Para a análise quantitativa (rugosímetro), 36 corpos de prova foram confeccionados com a massa denominada de incisal. A seleção desta ocorreu por tratar-se do tipo de material que pode ser usado para formar a camada externa das restaurações e que, como conseqüência, estará em contato direto com as estruturas antagônicas ao dente restaurado.

Os corpos de prova foram confeccionados por apenas um CD com a intenção de padronizá-los o máximo possível. Sobre uma placa de vidro, o pó de porcelana foi misturado ao líquido aglutinante específico: Duceram SD Carving Liquid (Ducera Dental, Alemanha, lote 3235/2). À massa de cerâmica foi dada a forma de um paralelepípedo. O excesso de líquido foi removido com papel absorvente. Com uma lâmina de bisturi de número 11 a massa foi seccionada em cinco porções (figura 4.1). As seis pastilhas resultantes foram destacadas da placa de vidro com uma espátula e depositadas sobre uma lâmina de lã de vidro (figura 4.2). 


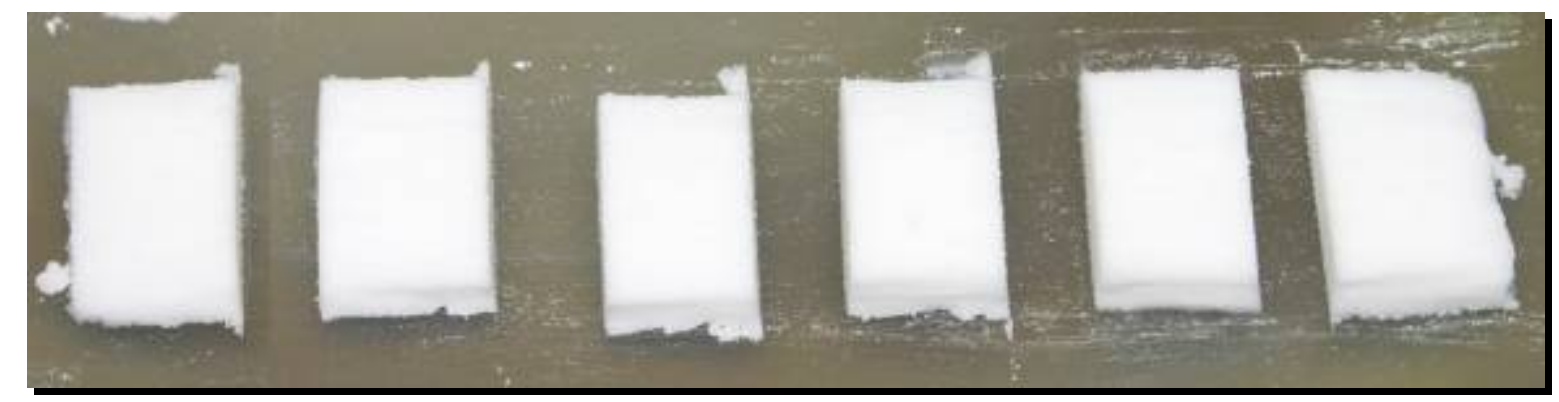

Figura 4.1 - Pastilhas de porcelana antes da sinterização

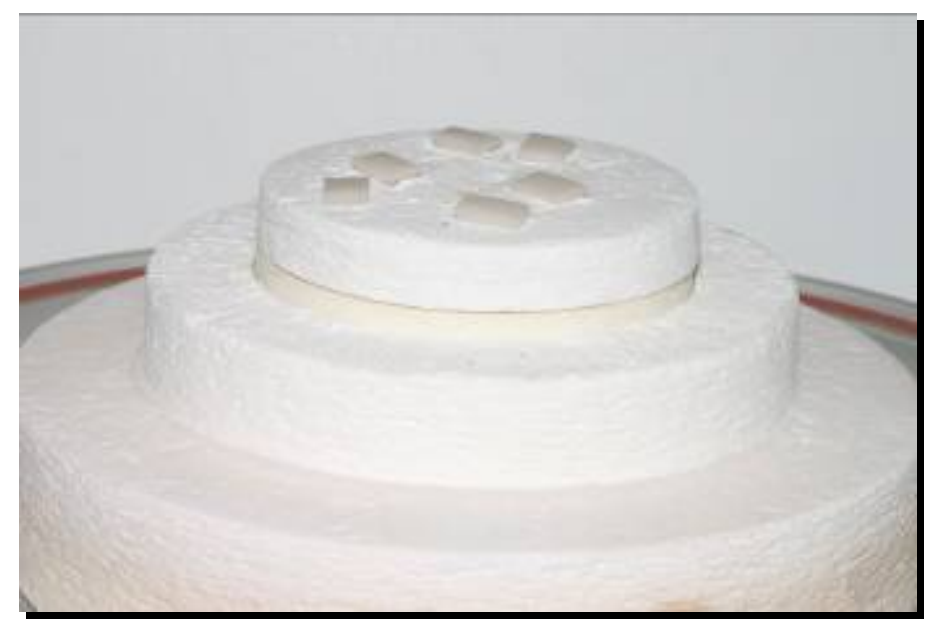

Figura 4.2 - Pastilhas de porcelana depositadas sobre lâmina de vidro e posicionadas sob a mufla do forno de porcelana

O forno de porcelana (Cerampress QEX, Dentsply) foi calibrado de acordo com as instruções do fabricante. Os corpos de prova de porcelana foram queimados usando como referência tempos e temperaturas estabelecidos pelo fabricante (tabela 4.1 e figura 4.2). A cada queima, foram colocados no forno apenas seis corpos de prova. Isto evitou a desigualdade na qualidade da cocção existente quando um volume grande de cerâmica é queimado ao mesmo tempo. Findada a queima, os corpos de prova apresentavam comprimento médio de $12 \mathrm{~mm}$, largura de $5 \mathrm{~mm}$ e altura de $3 \mathrm{~mm}$.

Após a primeira queima as superfícies apresentavam-se irregulares. A semelhança do processo executado rotineiramente na confecção de trabalhos protéticos de cerâmica, empregou-se uma pedra abrasiva impregnada com óxido de 
alumínio para regularizar toda a superfície dos corpos de prova (Dura-Green Stone, formato CN1 p/ contra-ângulo, Shofu Dental Co, EUA). Seguiu-se então uma nova queima no forno de porcelana, referida pelos TPDs como "glaze" natural, já que não emprega outros artifícios (p.ex. aplicação de pó ou líquido de "glaze") para dar brilho à superfície.

A queima de "glaze" apresenta peculiaridades relacionadas à técnica laboratorial, como a habilidade do técnico em prótese dental, as características do forno de porcelana, o instrumental de escultura empregado e a necessidade de conciliar o brilho da restauração com o existente nos demais dentes do paciente. Neste trabalho, a qualidade da queima de "glaze" foi aferida visualmente. A presença de bolhas ou irregularidades geométricas acentuadas resultou no descarte das pastilhas e confecção de novos corpos de prova.

Tabela 4.1 - Etapas e temperaturas de queima realizadas na confecção dos corpos de prova das porcelanas Duceram Plus e DuceraGold

\begin{tabular}{|c|c|c|c|c|c|c|c|}
\hline & Secagem & $\begin{array}{c}\text { Pré- } \\
\text { Aquecimento }\end{array}$ & $\begin{array}{c}\text { Temperatura } \\
\text { Inicial }\end{array}$ & $\begin{array}{c}\text { Taxa de } \\
\text { Elevação }\end{array}$ & $\begin{array}{c}\text { Temperatura } \\
\text { Final }\end{array}$ & $\begin{array}{c}\text { Tempo de } \\
\text { manutenção } \\
\text { sem vácuo }\end{array}$ \\
\hline $\begin{array}{c}\text { Duceram } \\
\text { Plus } 1^{\mathrm{a}} \\
\text { queima }\end{array}$ & $5 \mathrm{~min}$ & $3 \mathrm{~min}$. & $575^{\circ} \mathrm{C}$ & $55^{\circ} \mathrm{C} / \mathrm{min}$ & $910^{\circ} \mathrm{C}$ & $\operatorname{sim}$ & $1 \mathrm{~min}$ a $910^{\circ} \mathrm{C}$ \\
\hline $\begin{array}{c}\text { Duceram } \\
\text { Plus "glaze" }\end{array}$ & $3 \mathrm{~min}$ & $2 \mathrm{~min}$ & $575^{\circ} \mathrm{C}$ & $55^{\circ} \mathrm{C} / \mathrm{min}$ & $890^{\circ} \mathrm{C}$ & não & $1,5 \mathrm{~min}$ a $890^{\circ} \mathrm{C}$ \\
\hline $\begin{array}{c}\text { DuceraGold } \\
1^{\mathrm{a}} \text { queima }\end{array}$ & $5 \mathrm{~min}$ & - & $380^{\circ} \mathrm{C}$ & $45^{\circ} \mathrm{C} / \mathrm{min}$ & $780^{\circ} \mathrm{C}$ & $\operatorname{sim}$ & $1 \mathrm{~min}$ a $780^{\circ} \mathrm{C}$ \\
\hline $\begin{array}{c}\text { DuceraGold } \\
\text { "glaze" }\end{array}$ & $3 \mathrm{~min}$ & - & $450^{\circ} \mathrm{C}$ & $45^{\circ} \mathrm{C} / \mathrm{min}$ & $770^{\circ} \mathrm{C}$ & não & 2 min a $770^{\circ} \mathrm{C}$ \\
\hline
\end{tabular}



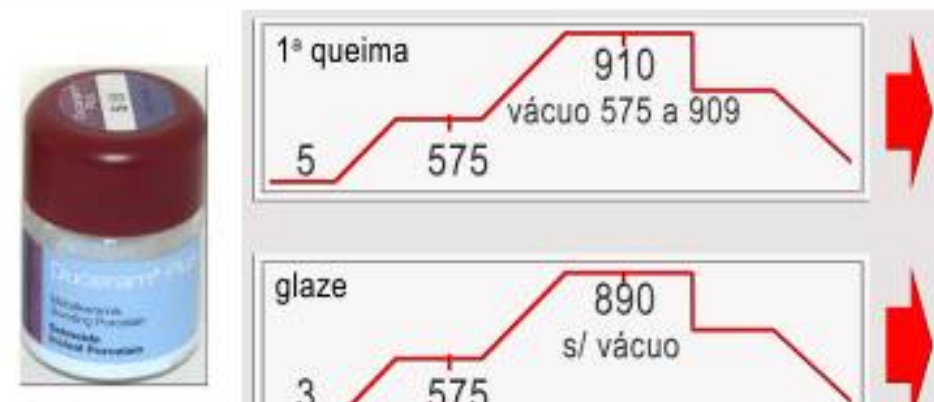

secagem $5 \mathrm{~min}$ pré-aquecimento $3 \mathrm{~min}$ temp inicial $575^{\circ} \mathrm{C}$ temp final $910^{\circ} \mathrm{C}$ taxa de elevação $55^{\circ} \mathrm{C} / \mathrm{min}$ vácuo SIM manutenção na temp final $1 \mathrm{~min}$

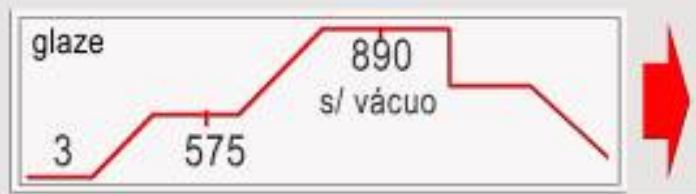

secagem $3 \mathrm{~min} \quad$ pré-aquecimento $2 \mathrm{~min}$ temp inicial $575^{\circ} \mathrm{C}$ temp final $890^{\circ} \mathrm{C}$ taxa de elevação $55^{\circ} \mathrm{C} / \mathrm{min}$ vácuo $\mathrm{NÃO}$ manutenção na temp final $1,5 \mathrm{~min}$
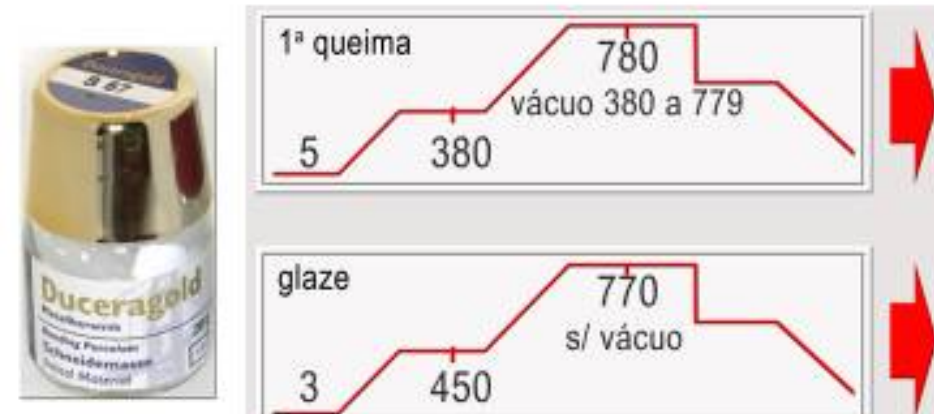

secagem $5 \mathrm{~min}$ pré-aquecimento $0 \mathrm{~min}$ temp inicial $380^{\circ} \mathrm{C}$ temp final $780^{\circ} \mathrm{C}$ taxa de elevação $45^{\circ} \mathrm{C} / \mathrm{min}$ vácuo SIM manutenção na temp final $1 \mathrm{~min}$

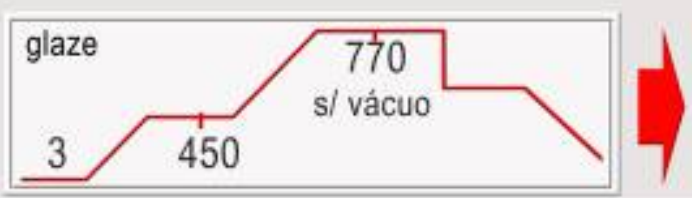

secagem $3 \mathrm{~min} \quad$ pré-aquecimento $0 \mathrm{~min}$ temp inicial $450^{\circ} \mathrm{C}$ temp final $770^{\circ} \mathrm{C}$ taxa de elevação $45^{\circ} \mathrm{C} / \mathrm{min}$ vácuo $\mathrm{N} A ̃ O$ manutenção na temp final $2 \mathrm{~min}$

Figura 4.3 - Representação gráfica do esquema de queima das cerâmicas

Foram confeccionadas bases de resina acrílica de lenta polimerização com lojas de dimensões pouco maiores que as dos corpos de prova. Resina acrílica de rápida polimerização foi colocada nas lojas e os corpos de prova foram assentados de modo que a superfície submetida ao "glaze" permanecesse exposta. A fixação favorece a realização dos tratamentos e o posicionamento dos corpos de prova para a leitura da rugosidade.

O rugosímetro Surftest SJ-201P (Mitutoyo do Brasil Ind. e Com. Ltda.) foi empregado para a realização das medidas. O rugosímetro, também conhecido como apalpador elétrico, determina o perfil de uma superfície, expressando numericamente a rugosidade em função das irregularidades presentes no material (LEITÃO; HEGDAHL, 1981). O rugosímetro é composto de um sensor (unidade de acionamento) que está acoplado a uma unidade de leitura. Na unidade de leitura 
determinam-se os parâmetros que serão pesquisados e observa-se de modo digital os resultados das medidas.

A determinação de irregularidades em toda a superfície de um material é quase impraticável e, por isso, faz-se a leitura da rugosidade ao longo de linhas que constituem o perfil da superfície (ZANETTI, 1994). As irregularidades são compostas por protusões e depressões (FUZZI; ZACCHERONI; VALLANIA, 1996). A superfície é considerada rugosa se apresentar depressões e protusões de alta amplitude e baixo comprimento de onda; se o comprimento de onda for longo, a superfície pode ser considerada ondulada ao invés de rugosa (LEITÃO; HEGDAHL, 1981). As depressões da superfície também são conhecidas como vales, e as protusões também são chamadas de picos (FUZZI; ZACCHERONI; VALLANIA, 1996).

É importante que o rugosímetro possibilite distinguir rugosidade de ondulação, já que, se nenhuma espécie de filtro para esta distinção for empregado aumenta-se a chance de ter para duas superfícies diferentes os mesmo valores de rugosidade (LEITÃO; HEGDAHL, 1981; BESSING; WIKTORSON, 1983). O filtro separa os componentes de alta freqüência e curto comprimento (rugosidade) dos que apresentam freqüência menos intensa, correspondendo a mudanças mais graduais no perfil da superfície (ondulações). Ao optar pelo emprego de um filtro elétrico, determinam-se limites para a atuação deste através da seleção de um valor de "cut off" $(\lambda c)$, também chamado de ponto de corte ou comprimento de onda limite (NBR 6405). O "cut off" especifica numericamente qual amplitude das freqüências deve ser desconsiderada, e permite que apenas valores consideravelmente menores que os determinados como "cut off" sejam percebidos (figura 4.4). O valor de "cut off" $(\lambda c)$ varia na grande maioria dos rugosímetros de 0,25 a 2,5 $\mu \mathrm{m}$. 


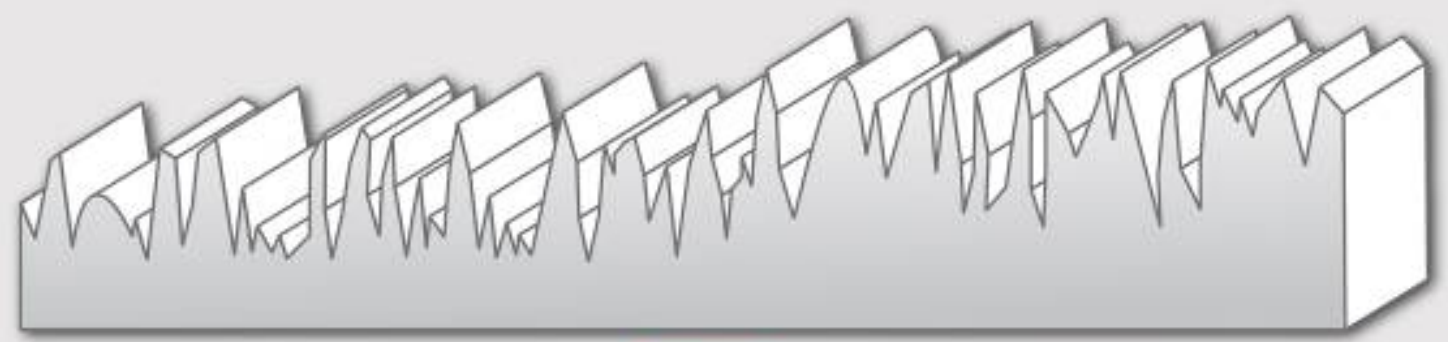

perfil não filtrado

rugosidade

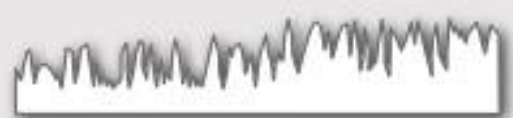

$\lambda \mathrm{c}=2,5 \mathrm{~mm}$

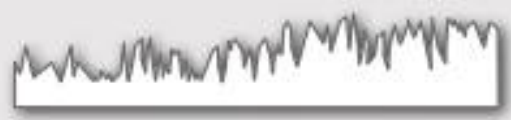

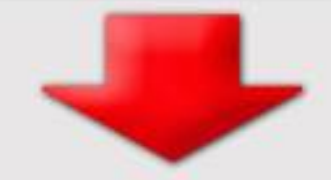

$\lambda \mathrm{c}=0,8 \mathrm{~mm}$

mummonnmonnm

$\lambda \mathrm{c}=0,25 \mathrm{~mm}$

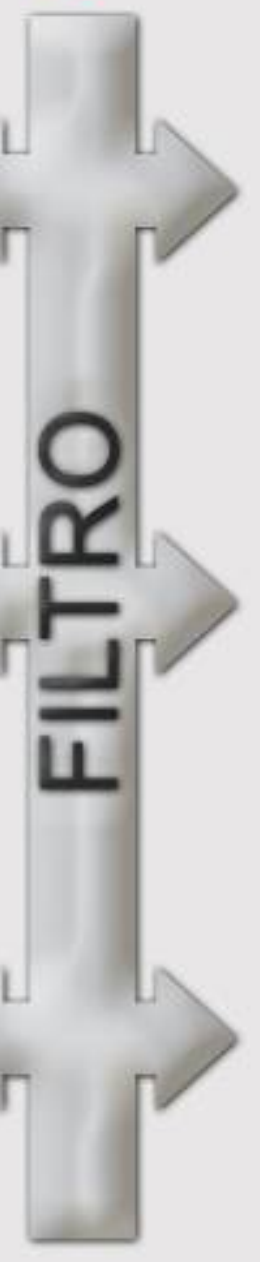

\section{ondulação}
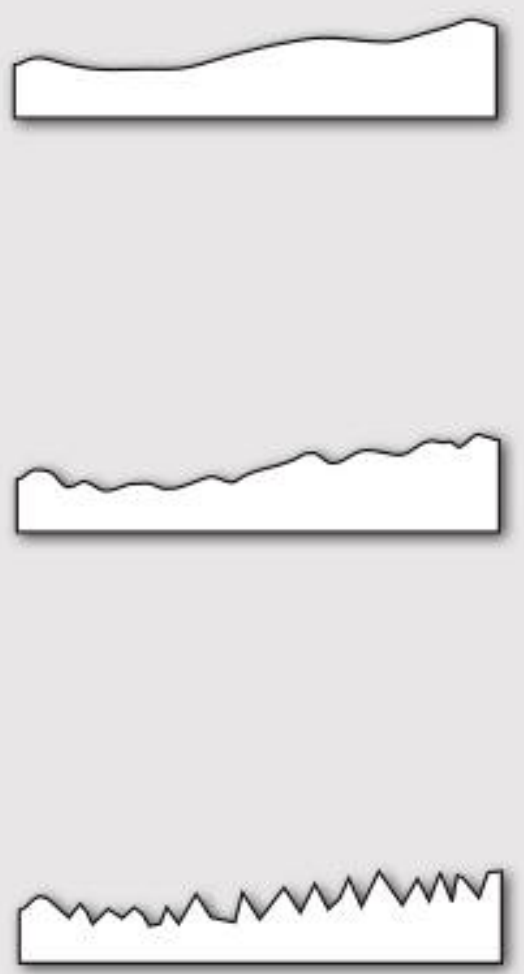

Figura 4.4 - Representação da ação do filtro elétrico e seus diferentes valores de $\lambda c$ sobre a "percepção" da rugosidade da superfície

Há valores tabelados (tabela 4.2) que orientam a correta seleção do valor de "cut off" em função da rugosidade média $(\mathrm{Ra})$ da superfície que será analisada (FERRARESI, 1977; NBR 6405; CARPINNETTI, 1996). O aparelho empregado 
neste estudo é munido de um filtro elétrico conhecido por $2 \mathrm{RC}$, que foi acionado durante as leituras.

O rugosímetro foi calibrado de acordo com as instruções contidas no manual do equipamento. Para determinar o valor do comprimento de amostragem adequado foram confeccionados dois corpos de prova, um de cada porcelana, com comprimento de $2 \mathrm{~cm}$. Estes corpos de prova, submetidos ao "glaze" da mesma maneira descrita anteriormente, serviram apenas para a realização de três leituras do parâmetro Ra (rugosidade média). Em cada uma destas leituras ajustou-se o aparelho para uma das três diferentes opções de comprimento de amostragem oferecidas $(0,25,0,8$ e $2,5 \mathrm{~mm})$. Os valores obtidos foram anotados e avaliados em relação à tabela 4.2. O comprimento de amostragem mínimo selecionado foi de 0,8 mm, determinando o tamanho mínimo que os 60 corpos de prova deveriam apresentar. A seleção de um valor de "cut off" menor ou maior exigiria um tamanho de corpo de prova também menor $(1,5 \mathrm{~mm})$ ou maior $(15 \mathrm{~mm})$, de modo que apresentasse dimensões proporcionais ao tamanho do percurso da sonda sobre o corpo de prova.

Tabela 4.2 - Valores mínimos de comprimento de amostragem em função da rugosidade média (Ra) (FERRARESI, 1977; NBR 6405; CARPINNETTI, 1996)

\begin{tabular}{|c|c|}
\hline Rugosidade Ra (mícron) & Comprimento de amostragem mínimo $(\mathrm{mm})$ \\
\cline { 2 - 2 } De 0 até 0,3 & 0,25 \\
\cline { 2 - 2 } Maior que 0,3 até 3,0 & 0,8 \\
\cline { 2 - 2 } Maior que 3,0 & 2,5 \\
\hline
\end{tabular}

O trajeto da sonda sobre uma superfície é chamado de percurso de avaliação (Im). Quando o filtro elétrico está ativado, a extensão do percurso de avaliação depende do valor do comprimento de amostragem ("cut off" - $\lambda c$ ) e do número de comprimentos de amostragem selecionado no aparelho (1, 3 ou 5). Um número maior de comprimentos de amostragem demanda corpos de prova de dimensões 
maiores, mas permite uma amostragem mais fiel da rugosidade superficial. Neste trabalho foi selecionado o comprimento de amostragem de $0,8 \mathrm{~mm}$, e a leitura foi executada por uma extensão equivalente a cinco comprimentos de amostragem $(0,8$ $\mathrm{mm} \times \mathrm{5}$ ). A leitura da superfície e a conseqüente definição do perfil permitem ao rugosímetro determinar uma linha média (LM), paralela à direção geral do perfil, e posicionada de tal modo que a soma das áreas superiores compreendidas entre ela e o perfil seja igual à soma das áreas inferiores (AGOSTINHO; RODRIGUES; LIRANI, 1977; NBR 6405; CARPINNETTI, 1996) (figura 4.5).

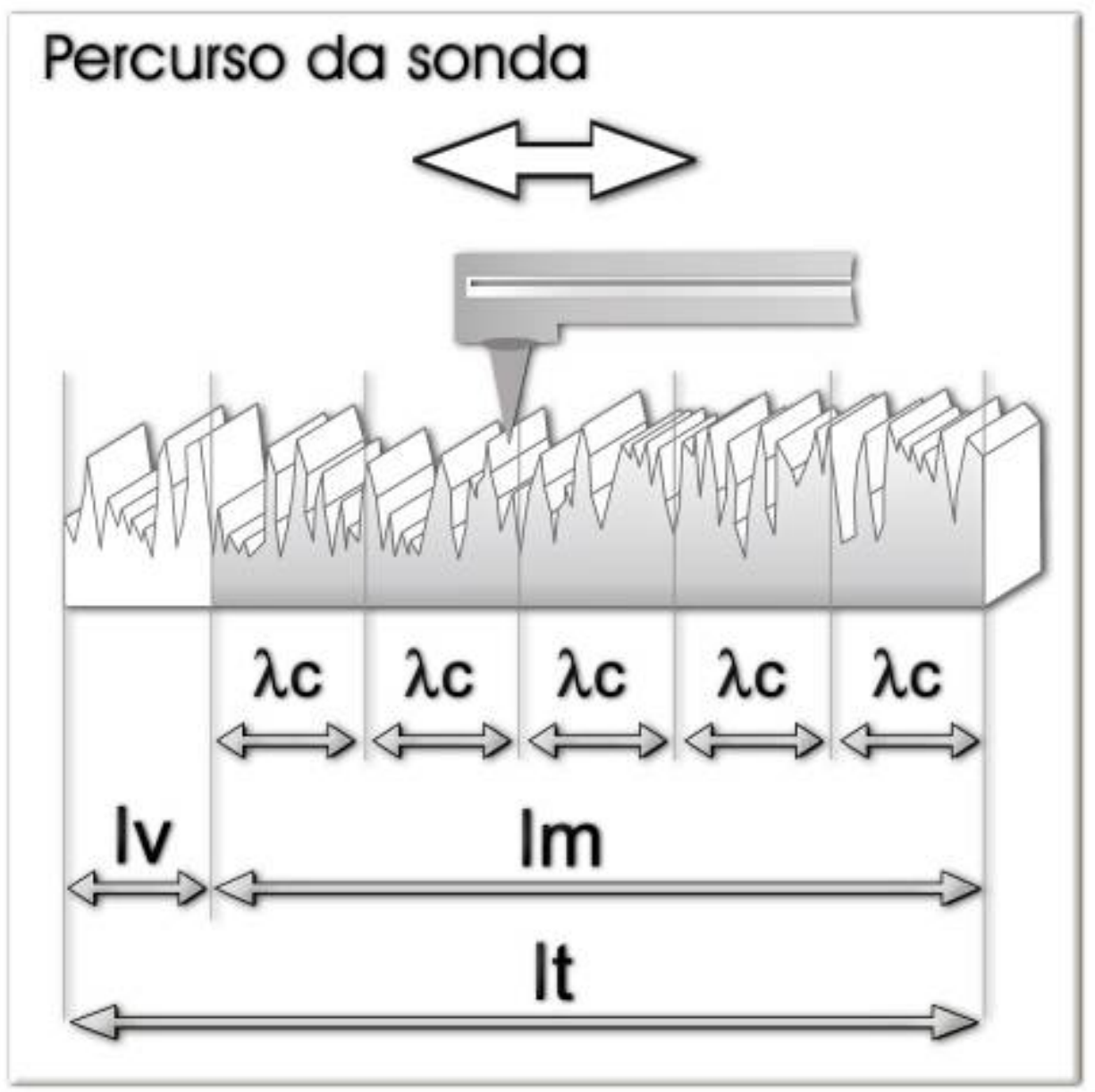

Figura 4.5 - Percurso da sonda apalpadora sobre a superfície. $\lambda c$ - comprimento de amostragem; Iv percurso para calibragem; Im - percurso de medição; It - percurso total, Iv+Im

Parâmetros de rugosidade são procedimentos técnicos normalizados, utilizados para avaliar a configuração geométrica das superfícies. Podem ser classificados em 
três grupos: os que descrevem a profundidade das rugosidades, parâmetros que descrevem medidas horizontais e parâmetros que se baseiam em medidas proporcionais (ZANETTI, 1994). Alguns exemplos destes parâmetros estão listados na tabela 4.3. Da seleção dos parâmetros depende a possibilidade de descrever com fidelidade qual a característica de uma superfície através do uso de um rugosímetro (ZANETTI, 1994; LEITÃO; HEGDAHL, 1981; WHITEHEAD et al., 1995).

Tabela 4.3 - Exemplos de parâmetros para avaliação da rugosidade superficial

\begin{tabular}{l|l}
$\begin{array}{l}\text { Parâmetros que } \\
\text { descrevem } \\
\text { profundidade }\end{array}$ & $\begin{array}{l}\mathrm{Ra} \text { - rugosidade média } \\
\mathrm{Rz} \text { - média das distâncias verticais entre a maior protusão e a maior } \\
\text { depressão em cada um dos cinco comprimentos de amostragem } \\
\mathrm{Rp} \text { - média das alturas das maiores protusões em relação à linha média } \\
\text { em cada um dos cinco comprimentos de amostragem }\end{array}$ \\
\hline $\begin{array}{l}\text { Parâmetros que } \\
\text { descrevem medidas } \\
\text { horizontais }\end{array}$ & $\mathrm{Pc}$ - contagem de picos \\
\hline $\begin{array}{l}\text { Parâmetros baseados } \\
\text { em medidas } \\
\text { proporcionais }\end{array}$ & $\begin{array}{l}\text { Rp/Rz - coeficiente resultante da divisão de Rp por Rz, que permite } \\
\text { identificar a proporção existente entre a média das alturas dos maiores } \\
\text { picos em relação à linha média, e a distância média entre as maiores } \\
\text { protusões e as maiores depressões ao longo dos } 5 \text { comprimentos de } \\
\text { amostragem }\end{array}$
\end{tabular}




\subsection{Parâmetros de rugosidade}

4.1.1 Ra

Abreviatura do termo inglês "roughness average" (rugosidade média) - é o mais empregado nos trabalhos que buscam caracterizar a superfície dos materiais cerâmicos (HULTERSTRÖM; BERGMAN, 1993; CARPINNETTI, 1996; NBR 6405). Determina a média aritmética dos valores absolutos das ordenadas do perfil em relação à linha média (LM) em um determinado comprimento de amostragem (Im - n vezes o valor de "cut off") (NBR 6405). O parâmetro Ra está representado na figura 4.6.

\subsubsection{Rz}

Média das distâncias verticais entre a maior protusão e a maior depressão em cada um dos cinco comprimentos de amostragem. O parâmetro Rz corresponde à média das distâncias entre duas linhas que tangenciam a protusão (pico) mais pronunciada e a depressão (vale) mais profunda medida dentro de cada comprimento de amostragem (figura 4.3) (AGOSTINHO; RODRIGUES; LIRANI, 1977; CARPINNETTI, 1996; NBR 6405). Individualmente, este parâmetro não 
caracteriza as propriedades funcionais de uma superfície quanto ao potencial de desgaste (ZANETTI, 1994).

\subsubsection{Rp}

Média das alturas das maiores protusões em relação à linha média em cada um dos cinco comprimentos de amostragem. O parâmetro Rp corresponde à média aritmética entre a distância do maior pico em relação à linha média em cinco comprimentos de amostragem adjacentes (CARPINNETTI, 1996; NBR 6405). Rp permite identificar um maior ou menor potencial de desgaste da superfície. 


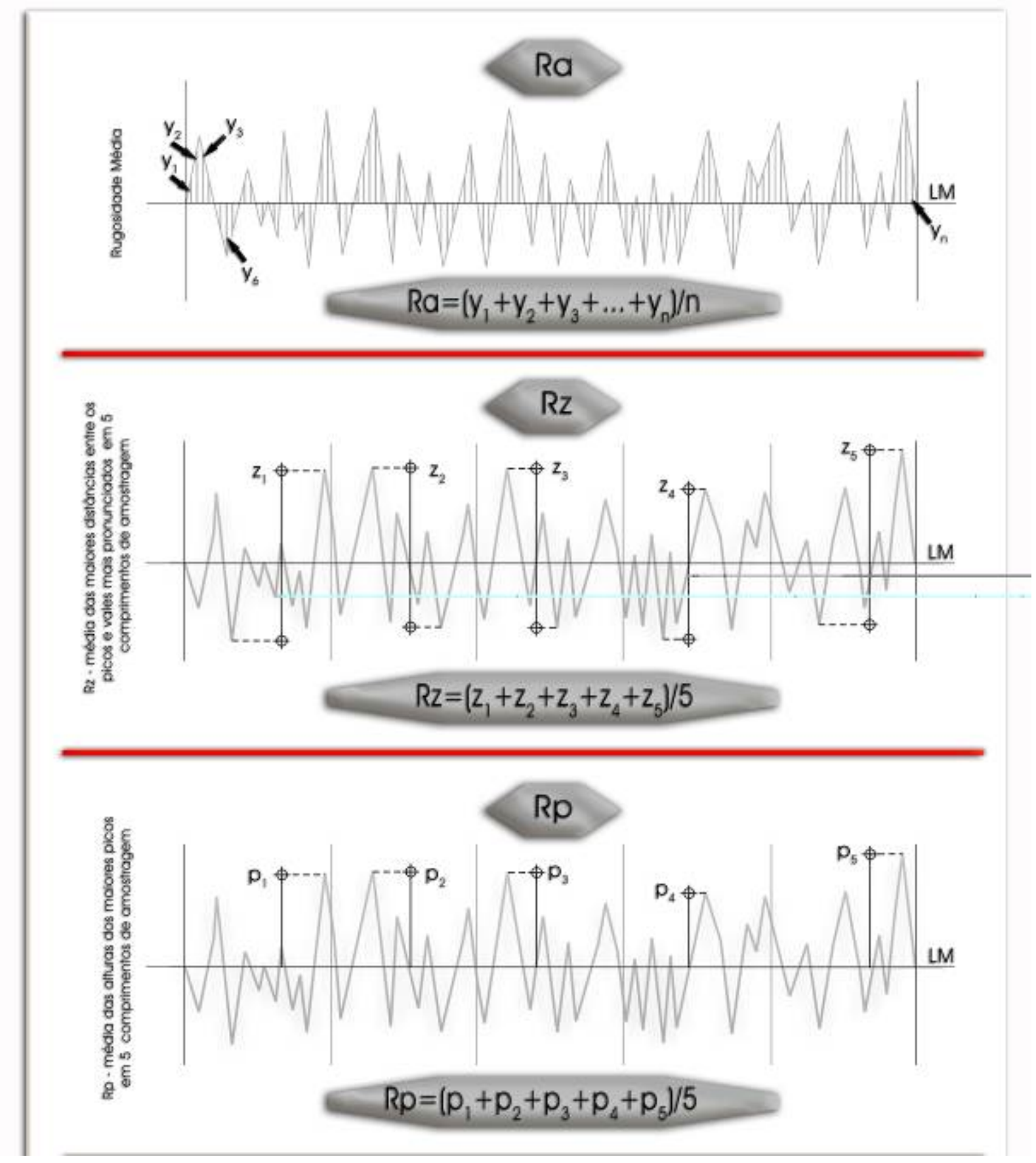

Figura 4.6 - Parâmetro Ra - Soma dos valores absolutos das ordenadas $(Y)$ em relação à linha média (LM), dividida pelo número de ordenadas (n). $\mathbf{R z}$ - média das distâncias verticais entre a maior protusão e a maior depressão em cada um dos cinco comprimentos de amostragem. Rz - média das distâncias verticais entre a maior protusão e a maior depressão em cada um dos cinco comprimentos de amostragem

Apesar de seu uso rotineiro, o parâmetro Ra representa apenas a média da rugosidade de uma superfície, não definindo a forma da irregularidade ou o perfil da superfície. Assim, para duas superfícies distintas podem-se ter valores de $\mathrm{Ra}$ 
semelhantes mesmo estando o filtro elétrico ativado (LEITÃO; HEGDAHL, 1981), (figura 4.7).

\section{$\mathrm{Ra}$ igual, superfícies diferentes}

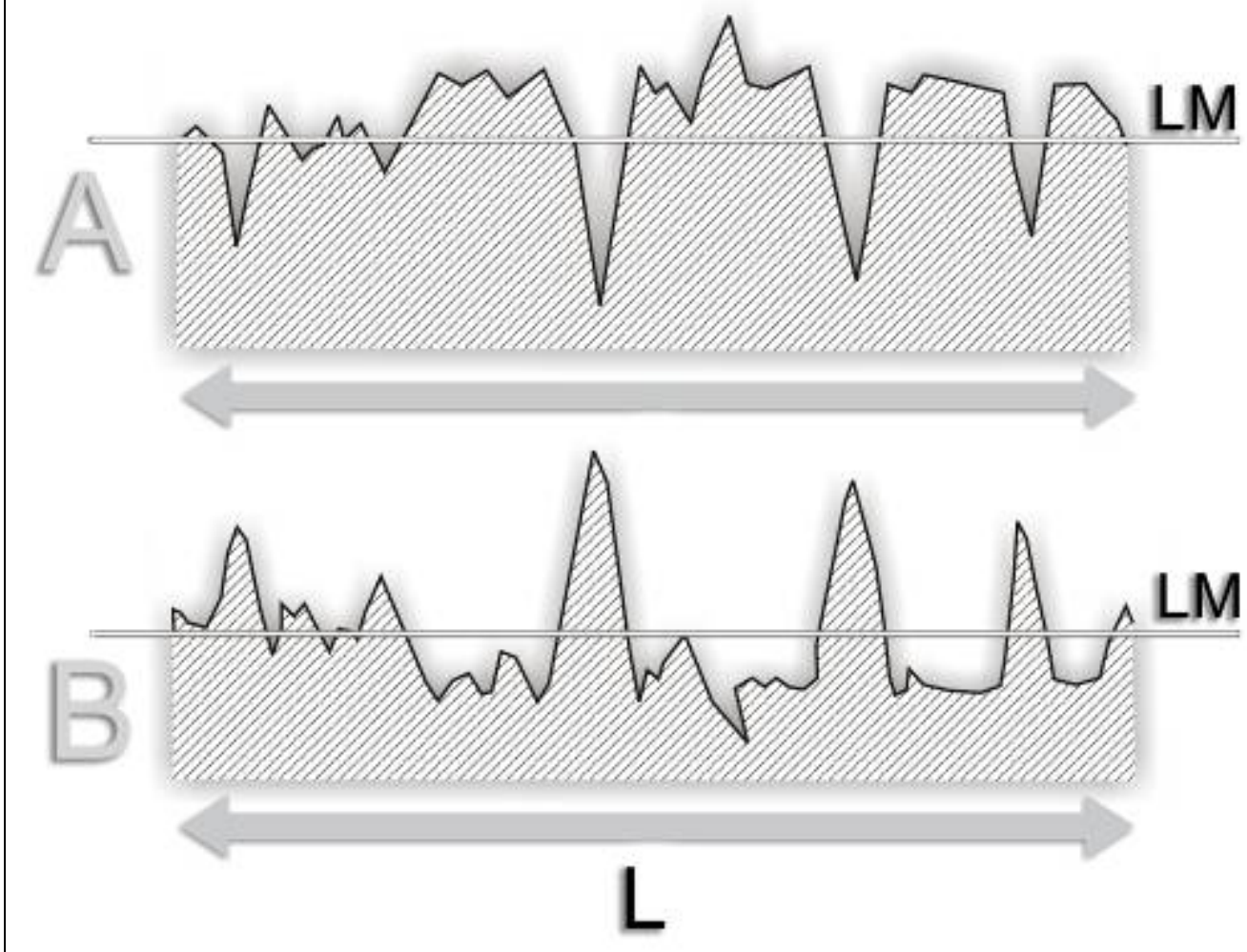

Figura 4.7 - Esquematização de duas superfícies diferentes que apresentam rugosidade média (Ra) igual

Os corpos de prova foram separados em dois grupos: grupo A (Duceram Plus) e grupo B (DuceraGold); receberam, além do "glaze" (T1), outros cinco diferentes tratamentos (T2 a T6), que estão resumidos na tabela 4.4. A rugosidade dos corpos de prova foi aferida com o rugosímetro após a execução de cada um dos seguintes tratamentos:

.T1 - "glaze" natural em forno de porcelana;

.T2 - após o "glaze" natural, polimento com uma roda de carbureto de silício fina (EVE KERAMIK R22NK, EVE, Alemanha); 
T3 - após o "glaze" natural, desgaste de toda a superfície com ponta diamantada de granulosidade grossa (45 mícron) de formato troncocônico em alta rotação e sob refrigeração (ponta diamantada número 4138, KG Sorensen, Brasil). Este desgaste foi realizado aplicando-se o instrumento com o seu longo eixo paralelo à superfície e ao maior comprimento do corpo de prova por aproximadamente 5 segundos, e buscou simular o ajuste de uma restauração de porcelana. As pontas foram descartadas e substituídas por novas após o desgaste de seis corpos de prova;

T4 - 6 pastilhas de cada grupo passaram pelo "glaze" natural e foram desgastadas com instrumento abrasivo diamantado rotatório de grana grossa - processo idêntico ao tratamento T3. Para o polimento empregouse uma seqüência de instrumentos para cerâmica da marca EDENTA (EDENTA AG, Suíça): EXA-CERAPOL 0301UM para o pré-polimento; EXA-CERAPOL 0306UM para o polimento; CERAPOL SUPER 0374PM para o polimento final (figura 4.8). De modo a controlar e uniformizar a rotação dos polidores empregou-se um micro-motor elétrico (KAVO K9, Kavo Dental, Alemanha) com a rotação fixada em $20.000 \mathrm{rpm}$ para as borrachas 0301UM e 0306UM, e em 5000 rpm para a borracha 0374PM. Os instrumentos foram aplicados por aproximadamente 10 segundos, até que o efeito dos mesmos fosse observado.

T5 - após o tratamento T3, fez-se o polimento com duas rodas de silicone impregnadas com carbureto de silício; a primeira de granulosidade média (EVE KERAMIK R22VK, EVE, Alemanha), e a segunda de granulosidade fina (EVE KERAMIK R22NK, EVE, Alemanha). De modo a controlar e 
uniformizar a rotação dos polidores empregou-se um micro-motor elétrico (KAVO K9, Kavo Dental, Alemanha) com a rotação fixada em 15.000 rpm. Os polidores foram empregados de acordo com as instruções do fabricante, evitando uma compressão excessiva sobre os corpos de prova e realizando pequenos movimentos circulares. O tempo médio de aplicação de 10 segundos foi suficiente para que se verificasse o efeito de cada um dos polidores de silicone sobre a superfície;

T6 - após o tratamento T5, fez-se a aplicação de uma roda de feltro montada em mandril para contra-ângulo impregnada com uma pasta contendo partículas finas de diamante - Crystar Past, Kota Ind. e COM.LTDA., Brasil (figura 4.9).

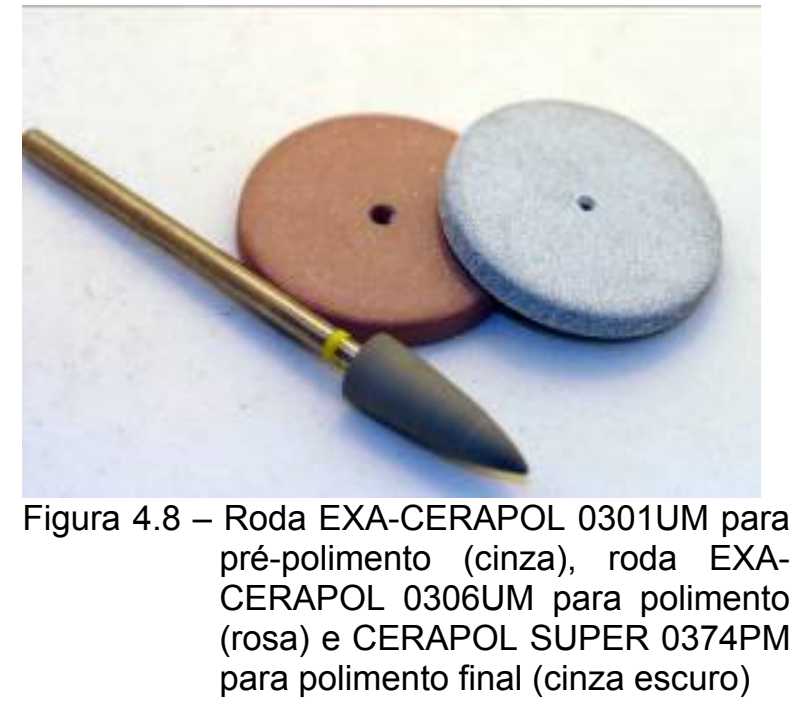

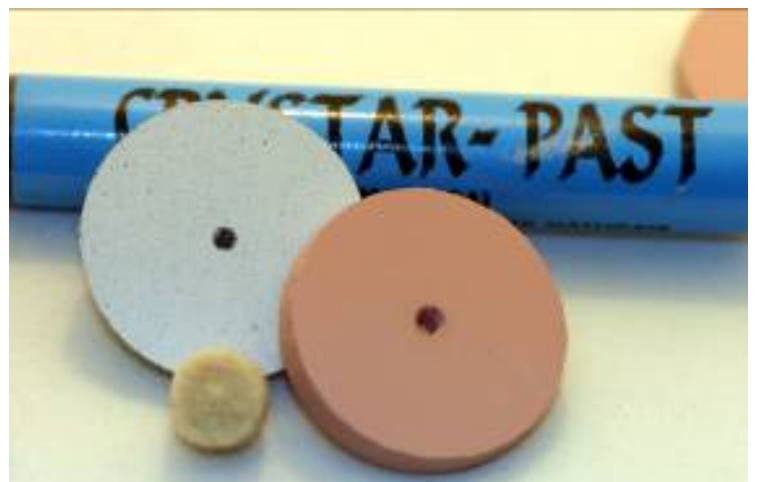

Figura 4.9 - Roda de granulosidade média (EVE KERAMIK R22VK - cinza), de granulosidade fina (EVE KERAMIK R22NK - rosa), roda de feltro e pasta contendo partículas de diamante (Crystar Past) 
Tabela 4.4 - Número de corpos de prova, tratamentos e especificações da análise quantitativa

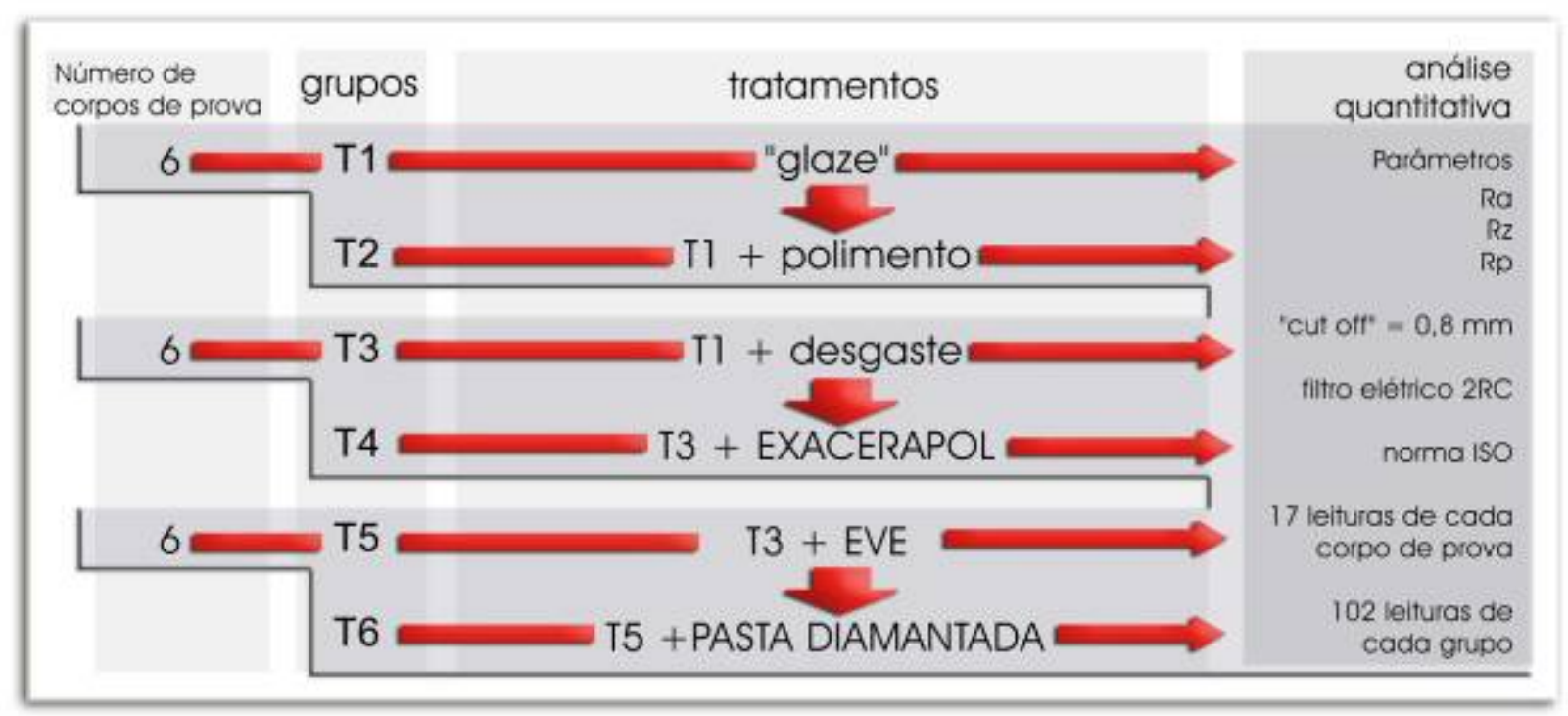

Findada cada uma das etapas acima descritas, os corpos de prova foram colocados em aparelho de ultra-som (Thornton T14, Thornthon Inpec Eletrônica Ltda., São Paulo, Brasil), preenchido com água destilada, para a remoção de qualquer resquício de material de polimento ou outro agente que pudesse prejudicar a qualidade da leitura ao rugosímetro.

Os corpos de prova foram avaliados visualmente de modo a identificar a existência de ranhuras, e qual a direção destas. A fixação dos corpos de prova à base de resina acrílica permitiu padronizar a direção de aplicação do instrumento diamantado que promoveu o desgaste da superfície dos corpos de prova. Quando eram visíveis, as ranhuras existentes apresentavam orientação definida, sempre perpendicular ao sentido do maior comprimento dos corpos de prova em função do modo como o desgaste foi realizado. Assim, o sentido do percurso do sensor do rugosímetro sobre os corpos de prova foi sempre paralelo ao maior comprimento destes.

Cada corpo de prova foi avaliado em 17 diferentes porções aleatoriamente selecionadas pela movimentação para a direita e para a esquerda deste em relação 
ao sensor. Três parâmetros foram lidos com o filtro elétrico $2 \mathrm{RC}$ do rugosímetro ativado:

Ra - rugosidade média;

$\mathrm{Rz}$ - média das distâncias verticais entre a maior protusão e a maior depressão em cada um dos cinco comprimentos de amostragem;

Rp - média das alturas das maiores protusões em relação à linha média em cada um dos cinco comprimentos de amostragem.

Após as leituras, o resultado da divisão do parâmetro Rp por Rz foi calculado.

Os resultados receberam tratamento estatístico. Os dados não apresentaram distribuição normal, indicando a conveniência da realização de um teste estatístico não paramétrico. Por tratar-se de dados não emparelhados e existirem mais do que dois grupos (T1A à T6B), o teste Kruskal-Wallis foi o selecionado. Este teste permite identificar se há ou não diferença significativa entre as situações avaliadas, porém não identifica quais grupos apresentam diferenças significativas, ou se todos os grupos apresentam diferenças significativas. Com o intento de realizar tal identificação foi aplicado o teste Mann-Whitney, que compara as diferenças entre dois grupos distintos.

Para a avaliação qualitativa ao MEV, foram adicionalmente confeccionados 24 corpos de prova, 12 de cada cerâmica. Em cada corpo de prova foi executado um dos seis tratamentos descritos anteriormente (T1 a T6). As imagens foram tomadas com o aparelho JEOL JSM-5300 Scanning. As figuras 4.10 e 4.11 mostram o aspecto dos corpos de prova após a metalização. 


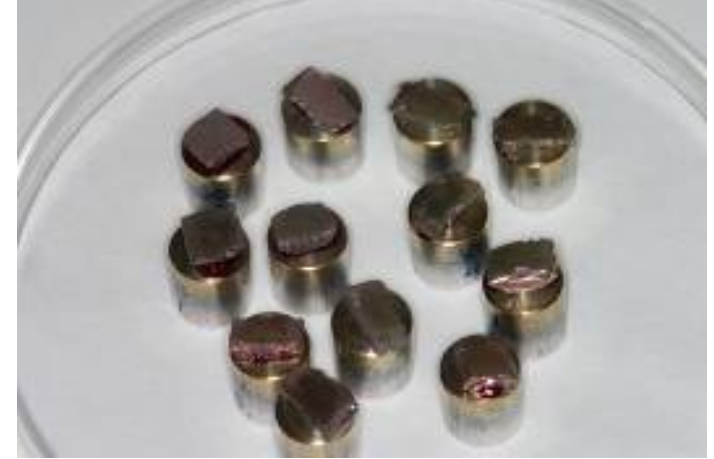

Figura 4.10 - corpos de prova colados aos "stubs" e com a camada condutora já aplicada ("sputtering")

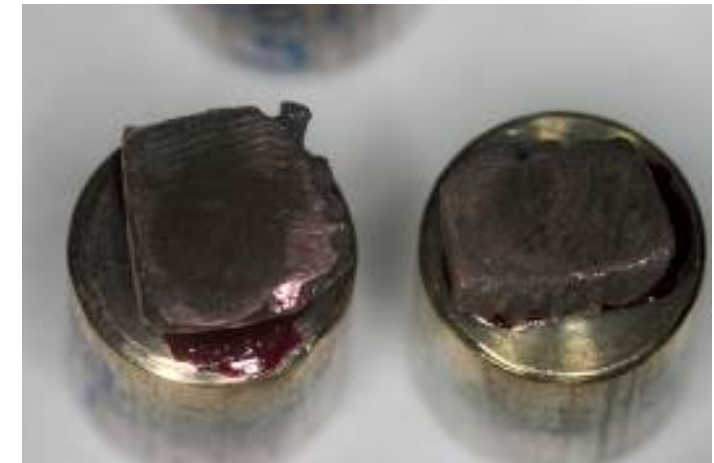

Figura 4.11 - detalhe dos corpos de prova após a metalização 


\section{RESULTADOS}

\subsection{Análise Estatística}

As tabelas 5.1 e 5.2 apresentam os valores médios dos diferentes parâmetros apurados com o rugosímetro. Resultados do teste Kruskal-Wallis para os parâmetros $\mathrm{Ra}, \mathrm{Rz}$ e $\mathrm{Rp}$, e para o coeficiente $\mathrm{Rp} / \mathrm{Rz}$ (tabelas 5.3 e 5.4) identificaram a existência de diferenças significativas entre os tratamentos. Para verificar quais grupos apresentavam diferença significativa, realizou-se o teste Mann-Whitney. Os valores médios dos postos obtidos com o teste Mann-Whitney são apresentados na tabela 5.3. Os resultados da interação entre os 12 grupos estão demonstrados nas tabelas 5.5 a 5.8. Os gráficos 5.1 a 5.4 apresentam as médias dos valores dos postos para os diferentes parâmetros e coeficiente Rp/Rz. Adicionalmente foi aplicado o teste de correlação não-paramétrica de Spearman para cada tipo de tratamento (T1 a T6), que buscou determinar quão consistentemente os valores obtidos na análise dos parâmetros (Ra, Rz e Rp) mudam em conjunto (tabelas 5.9 e 5.10). O coeficiente de correlação é um número puro, usado para classificar a correlação em perfeita $(r=1)$, forte $(r>0,75)$, média $(r>0,5)$, fraca $(r<0,5)$ e inexistente $(r=0)$. 
Tabela 5.1 - Valores médios de rugosidade dos parâmetros Ra e Rz. Desvio padrão e valores máximos e mínimos apurados

\begin{tabular}{|c|c|c|c|c|c|c|}
\hline \multicolumn{2}{|c|}{ TRATAMENTO } & \multirow{2}{*}{$\frac{N}{102}$} & \multirow{2}{*}{$\begin{array}{l}\text { Média } \\
1,2846\end{array}$} & \multirow{2}{*}{$\begin{array}{l}\text { Desvio } \\
\text { Padrão } \\
\text { 24983 }\end{array}$} & \multirow{2}{*}{$\begin{array}{c}\begin{array}{c}\text { Valor } \\
\text { Mínimo }\end{array} \\
, 76\end{array}$} & \multirow{2}{*}{$\begin{array}{c}\begin{array}{c}\text { Valor } \\
\text { Máximo }\end{array} \\
1,80\end{array}$} \\
\hline $\mathrm{Ra}$ & T1A & & & & & \\
\hline & T1B & 102 & 1,3165 & ,30974 & ,63 & 2,15 \\
\hline & T2A & 102 & 1,0911 & 19902 &, 71 & 1,74 \\
\hline & T2B & 102 & 1,2856 & ,40532 & ,62 & 2,08 \\
\hline & T3A & 102 & 6,4222 & ,61987 & 4,89 & 7,90 \\
\hline & T3B & 102 & 5,9072 & 1,06592 & 3,46 & 7,58 \\
\hline & T4A & 102 & ,8173 & ,20315 & ,39 & 1,15 \\
\hline & T4B & 102 & 8474 & ,13551 &, 53 & 1,18 \\
\hline & T5A & 102 & 1,1086 & ,21576 &, 55 & 1,59 \\
\hline & T5B & 102 & ,9960 & ,17484 & ,65 & 1,33 \\
\hline & T6A & 102 & 1,1503 & ,32121 &, 51 & 1,68 \\
\hline & T6B & 102 & 1,0311 & , 14869 & ,70 & 1,39 \\
\hline & Total & 1224 & 1,9381 & 1,94599 & ,39 & 7,90 \\
\hline \multirow[t]{13}{*}{$\mathrm{Rz}$} & T1A & 102 & 5,0553 & 1,05486 & 3,31 & 9,84 \\
\hline & T1B & 102 & 5,0439 & 1,52439 & 2,68 & 11,18 \\
\hline & T2A & 102 & 4,6567 & 1,05572 & 2,54 & 8,62 \\
\hline & T2B & 102 & 4,8936 & 1,81543 & 2,59 & 9,67 \\
\hline & T3A & 102 & 33,9080 & 3,99954 & 25,19 & 43,86 \\
\hline & T3B & 102 & 32,6091 & 5,85424 & 19,37 & 44,30 \\
\hline & T4A & 102 & 3,3305 & ,59867 & 2,23 & 4,94 \\
\hline & T4B & 102 & 3,3757 & ,67737 & 2,17 & 5,55 \\
\hline & T5A & 102 & 4,2179 &, 75420 & 2,82 & 6,72 \\
\hline & T5B & 102 & 4,5398 & ,87340 & 3,12 & 6,82 \\
\hline & T6A & 102 & 4,1443 & 1,01940 & 2,29 & 6,61 \\
\hline & T6B & 102 & 4,0684 & ,73156 & 2,26 & 6,11 \\
\hline & Total & 1224 & 9,1536 & 11,03524 & 2,17 & 44,30 \\
\hline
\end{tabular}


Tabela 5.2 - Valores médios de rugosidade do parâmetro Rp e do coeficiente Rp/Rz. Desvio padrão e valores máximos e mínimos apurados

\begin{tabular}{|c|c|c|c|c|c|c|}
\hline \multicolumn{2}{|c|}{ TRATAMENTO } & \multirow{2}{*}{$\begin{array}{c}N \\
102\end{array}$} & \multirow{2}{*}{$\begin{array}{l}\text { Média } \\
2,4554\end{array}$} & \multirow{2}{*}{$\begin{array}{l}\text { Desvio } \\
\text { Padrão } \\
\text { 49773 }\end{array}$} & \multirow{2}{*}{$\begin{array}{c}\begin{array}{c}\text { Valor } \\
\text { Mínimo }\end{array} \\
1,47\end{array}$} & \multirow{2}{*}{$\begin{array}{c}\begin{array}{c}\text { Valor } \\
\text { Máximo }\end{array} \\
4,38\end{array}$} \\
\hline $\mathrm{Rp}$ & T1A & & & & & \\
\hline & T1B & 102 & 2,4980 & ,71465 & 1,22 & 4,56 \\
\hline & T2A & 102 & 2,2317 & ,57042 & 1,16 & 5,01 \\
\hline & T2B & 102 & 2,1215 & 82051 & 1,08 & 4,65 \\
\hline & T3A & 102 & 15,2302 & 1,94359 & 10,23 & 24,77 \\
\hline & T3B & 102 & 14,6186 & 2,81265 & 8,28 & 20,38 \\
\hline & T4A & 102 & 1,5514 & , 28755 & 1,03 & 2,31 \\
\hline & T4B & 102 & 1,4217 & , 31451 & ,84 & 2,56 \\
\hline & T5A & 102 & 1,8349 & ,34768 & 1,14 & 3,10 \\
\hline & T5B & 102 & 1,8536 & , 34770 & 1,10 & 2,92 \\
\hline & T6A & 102 & 1,7907 & ,43278 & 1,02 & 3,07 \\
\hline & T6B & 102 & 1,6084 & ,31776 & ,94 & 2,58 \\
\hline & Total & 1224 & 4,1013 & 4,97365 & ,84 & 24,77 \\
\hline $\mathrm{Rp} / \mathrm{Rz}$ & T1A & 102 & 4896, & 06182, & ,33 & ,64 \\
\hline & T1B & 102 & 4995, & ,05232 & ,36 & 61 \\
\hline & $\mathrm{T} 2 \mathrm{~A}$ & 102 & ,4807 & ,06273 & ,26 & ,64 \\
\hline & T2B & 102 & ,4372 & ,06991 & ,27 & ,65 \\
\hline & T3A & 102 & ,4511 & ,04362 & ,33 &, 56 \\
\hline & T3B & 102 & ,4510 & ,05550 & ,29 &, 56 \\
\hline & T4A & 102 & ,4677 & ,04682 & ,35 &, 56 \\
\hline & T4B & 102 & ,4254 & ,06906 & ,23 &, 59 \\
\hline & T5A & 102 & ,4383 & ,05845 & ,30 &, 56 \\
\hline & T5B & 102 & ,4136 & ,06348 & ,27 & ,56 \\
\hline & T6A & 102 & ,4379 & ,06154 & ,25 &, 55 \\
\hline & T6B & 102 & ,4000 & ,06551 & ,23 &, 55 \\
\hline & Total & 1224 & ,4493 & ,06622 & ,23 & 65 \\
\hline
\end{tabular}


Tabela 5.3 - Valores médios dos postos obtidos com o teste Kruskal-Wallis

\begin{tabular}{|c|c|c|c|c|c|}
\hline TRATAMENTO & Ra & Rz & Rp & $R p / R z$ \\
\hline T1A & 719,46 & 718,84 & 789,37 & 812,9 \\
\hline T1B & 718,5 & 662,33 & 748,98 & 884,6 \\
\hline T2A & 528,95 & 613,53 & 679,64 & 768,6 \\
\hline T2B & 641,33 & 581,46 & 557,75 & 535,8 \\
\hline T3A & 1135,4 & 1126,1 & 1127,9 & 615 \\
\hline T3B & 1109,6 & 1118,9 & 1117,1 & 636 \\
\hline T4A & 236,56 & 234,45 & 308,13 & 717,5 \\
\hline T4B & 230,34 & 250,86 & 219,78 & 492,6 \\
\hline T5A & 554,14 & 510,84 & 496,7 & 545,4 \\
\hline T5B & 425,43 & 594,67 & 507,25 & 419,8 \\
\hline T6A & 583,83 & 467,66 & 453,56 & 559,3 \\
\hline T6B & 466,45 & 470,38 & 343,84 & 362,5 \\
\hline
\end{tabular}

Tabela 5.4 - Resultado do teste Kruskal-Wallis para a variável de agrupamento TRATAMENTO (T1A à T6B)

\begin{tabular}{|c|c|c|c|c|}
\hline & $\mathrm{Ra}$ & Rz & $\mathrm{Rp}$ & $\mathrm{Rp} / \mathrm{Rz}$ \\
\hline $\begin{array}{l}\text { Chi- } \\
\text { Quadrado }\end{array}$ & 733,901 & 702,474 & 772,652 & 226,986 \\
\hline $\begin{array}{l}\text { Graus de } \\
\text { liberdade }\end{array}$ & 11 & 11 & 11 & 11 \\
\hline Sig. & ,000 & ,000 & 000 & 000 \\
\hline
\end{tabular}


Tabela 5.5 - Resultado do teste Mann-Whitney para o parâmetro Ra, comparando os diferentes grupos e verificando diferenças significativas entre os mesmos

\begin{tabular}{|c|c|c|c|c|c|c|c|c|c|c|c|c|}
\hline $\mathrm{Ra}$ & Médias & T1B & T2A & T2B & T3A & T3B & T4A & T4B & T5A & T5B & T6A & T6B \\
\hline T1A & 719,46 & n.s. & T1A & n.s. & T3 & T3B & T1A & T1A & T1A & T1A & T1A & T1A \\
\hline T1B & 718,5 & & T1B & n.s. & T3 & T3B & T1B & T1B & T1B & T1B & T1B & T1B \\
\hline T2A & 528,95 & & & T2B & T3 & T3B & T2A & T2A & n.s. & T2A & T6A & n.s. \\
\hline T2B & 641,33 & & & & T3 & T3B & T2B & T2B & T2B & T2B & n.s. & T2B \\
\hline T3A & 1135,4 & & & & & T3A & T3A & T3A & T3A & T3A & T3A & T3A \\
\hline T3B & 1109,6 & & & & & & T3B & T3B & T3В & T3B & T3B & T3B \\
\hline T4A & 236,56 & & & & & & & n.s. & T5A & T5B & T6A & T6B \\
\hline T4B & 230,34 & & & & & & & & T5A & T5B & T6A & T6B \\
\hline T5A & 554,14 & & & & & & & & & T5A & n.s. & T5A \\
\hline T5B & 425,43 & & & & & & & & & & T6A & n.s. \\
\hline T6A & 583,83 & & & & & & & & & & & T6A \\
\hline T6B & 466,45 & & & & & & & & & & & \\
\hline \multicolumn{13}{|c|}{ Rank e agrupamento dos tratamentos sem diferenças significantes } \\
\hline \multicolumn{2}{|c|}{ TRATAMENTO } & $\mathrm{N}$ & 1 & & 2 & 3 & 4 & 5 & 6 & T & 7 & 8 \\
\hline \multicolumn{2}{|c|}{ T4B } & 102 & \multicolumn{2}{|c|}{230,3} & & & & & & & & \\
\hline \multicolumn{2}{|l|}{ T4A } & 102 & & & & & & & & & \\
\hline \multicolumn{2}{|l|}{ T5B } & 102 & \multicolumn{2}{|c|}{236,6} & 425,4 & & & & & & & \\
\hline \multicolumn{2}{|l|}{ T6B } & 102 & & 466,5 & 466,5 & & & & & & \\
\hline \multicolumn{2}{|l|}{ T2A } & 102 & & & & 528,95 & 528,95 & & & & & \\
\hline \multicolumn{2}{|l|}{ T5A } & 102 & & & & & 554,1 & & & & & \\
\hline \multicolumn{2}{|l|}{ T6A } & 102 & & & & & & 554,1 & & & & \\
\hline T2B & & 102 & & & & & & 583,8 & 583,8 & & & \\
\hline T1B & & 102 & & & & & & & 718,5 & & & \\
\hline T1A & & 102 & & & & & & & 719,5 & & & \\
\hline T3B & & 102 & & & & & & & & & 1110 & \\
\hline T3A & & 102 & & & & & & & & & & 1135 \\
\hline
\end{tabular}




\section{Valores médios dos postos para o parâmetro Ra}

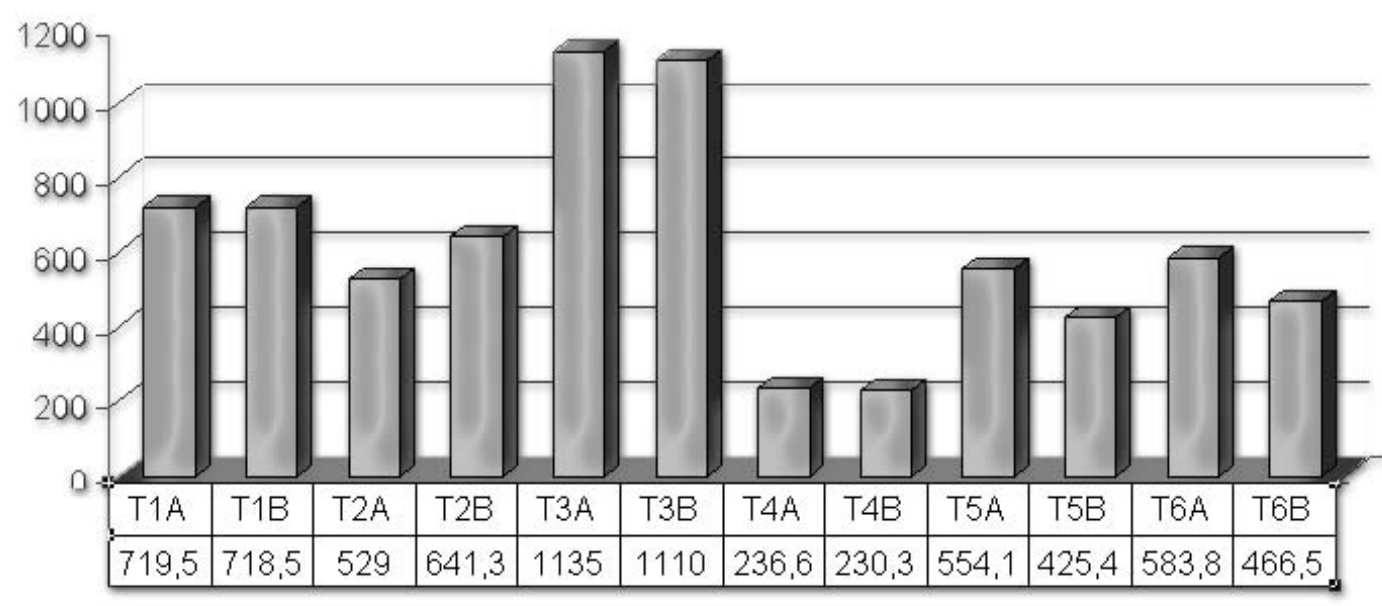

Gráfico 5.1 - Valores médios dos postos obtidos com o teste Kruskal-Wallis para o parâmetro Ra

A análise estatística de $\mathrm{Ra}$ identificou os grupos T4B e T4A como os que apresentaram menor rugosidade. O grupo T5B foi o que apresentou a terceira menor rugosidade média, que não foi significativamente diferente do quarto grupo, o T6B. Portanto, o parâmetro $\mathrm{Ra}$ não detectou vantagem no uso da pasta contendo partículas de diamante após o uso das rodas EVE no polimento da cerâmica DuceraGold. O grupo T6B não foi diferente do T2A, que por sua vez não foi significativamente diferente do grupo T5A. O grupo T5A apresentou lisura significativamente menor que o T6A, indicando que o uso da pasta contendo partículas de diamante piorou a lisura da cerâmica DuceramPlus após o uso das rodas EVE. O grupo T6A não foi significativamente diferente do grupo T2B, que por sua vez não foi significativamente diferente dos grupos T1B e T2A. Por último, os grupos que sofreram desgaste (T3) foram os que apresentaram pior lisura. 
Tabela 5.6 - Resultado do teste Mann-Whitney para o parâmetro Rz, comparando os diferentes grupos e verificando diferenças significativas entre os mesmos

\begin{tabular}{|c|c|c|c|c|c|c|c|c|c|c|c|c|}
\hline $\mathrm{Rz}$ & Médias & T1B & $\mathrm{T} 2 \mathrm{~A}$ & T2B & T3A & T3B & T4A & T4B & T5A & T5B & T6A & T6B \\
\hline $\mathrm{T} 1 \mathrm{~A}$ & 718,84 & n.s. & T1A & T1A & T3A & T3B & T1A & T1A & T1A & T1A & T1A & T1A \\
\hline T1B & 662,33 & & n.s. & T1B & T3A & T3B & T1B & T1B & T1B & T1B & T1B & T1B \\
\hline T2A & 613,53 & & & n.s. & T3A & T3B & T2A & T2A & T2A & n.s. & T2A & T2A \\
\hline T2B & 581,46 & & & & T3A & T3B & T2B & T2B & n.s. & n.s. & T2B & T2B \\
\hline T3A & 1126,1 & & & & & n.s. & T3A & T3A & T3A & T3A & T3A & T3A \\
\hline T3B & 1118,9 & & & & & & T3B & T3B & T3B & T3B & T3B & T3B \\
\hline T4A & 234,45 & & & & & & & n.s. & T5A & T5B & T6A & T6B \\
\hline T4B & 250,86 & & & & & & & & T5A & T5B & T6A & T6B \\
\hline T5A & 510,84 & & & & & & & & & T5B & n.s. & n.s. \\
\hline T5B & 594,67 & & & & & & & & & & T5B & T5B \\
\hline T6A & 467,66 & & & & & & & & & & & n.s. \\
\hline T6B & 470,38 & & & & & & & & & & & \\
\hline \multicolumn{13}{|c|}{ Rank e agrupamento dos tratamentos sem diferenças significantes } \\
\hline \multicolumn{2}{|c|}{ TRATAMENTO } & & $\mathrm{N}$ & 1 & 2 & 3 & 3 & 4 & 5 & & 6 & 7 \\
\hline \multicolumn{2}{|c|}{ T4A } & & 102 & 234,5 & & & & & & & & \\
\hline \multicolumn{2}{|l|}{ T4B } & & 102 & 250,9 & & & & & & & & \\
\hline \multicolumn{2}{|l|}{ T6A } & & 102 & & 467,7 & & & & & & & \\
\hline \multicolumn{2}{|l|}{ T6B } & & 102 & & 470,4 & & & & & & & \\
\hline \multicolumn{2}{|l|}{ T5A } & & 102 & & 510,8 & & 10,8 & & & & & \\
\hline \multicolumn{2}{|l|}{ T2B } & & 102 & & & & 81,5 & 581,5 & & & & \\
\hline \multicolumn{2}{|l|}{ T5B } & & 102 & & & & & 594,7 & & & & \\
\hline \multicolumn{2}{|l|}{$\mathrm{T} 2 \mathrm{~A}$} & & 102 & & & & & 613,5 & & 13,5 & & \\
\hline \multicolumn{2}{|l|}{ T1B } & & 102 & & & & & & & 62,3 & 662,3 & \\
\hline \multicolumn{2}{|l|}{$\mathrm{T} 1 \mathrm{~A}$} & & 102 & & & & & & & & 718,8 & \\
\hline \multicolumn{2}{|l|}{ T3B } & & 102 & & & & & & & & & 1119 \\
\hline \multicolumn{2}{|l|}{ T3A } & & 102 & & & & & & & & & 1126 \\
\hline
\end{tabular}


Valores médios dos postos para o parãmetro Rz

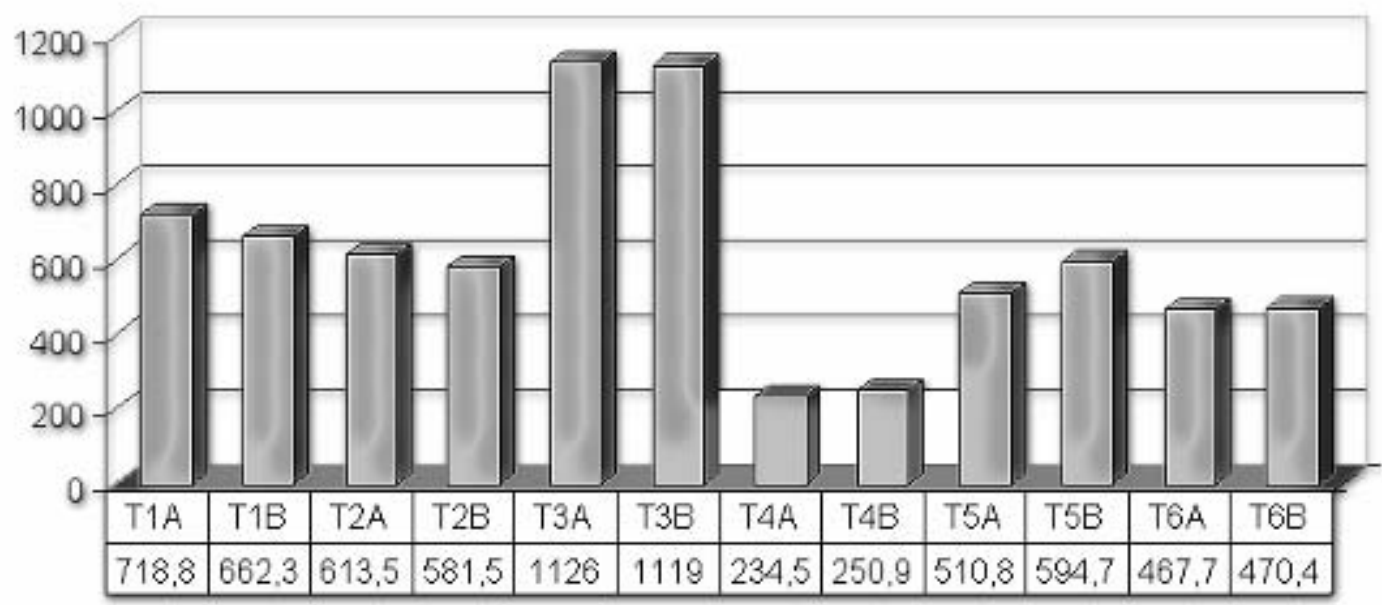

Gráfico 5.2 - Valores médios dos postos obtidos com o teste Kruskal-Wallis para o parâmetro Rz

A análise estatística do parâmetro Rz promoveu uma ordenação diferente entre os grupos daquela observada com a análise de Ra. A seqüência da ordenação foi: T4A/T4B, T6A/T6B/T5A, T5A/T2B, T2B/T5B/T2A, T2A/T1B, T1B/T1A, T3B/T3A. Os grupos que não apresentam diferenças significativas estão agrupados e separados por barras. Ao compararem-se os grupos T5A e T6A verifica-se que, diferente do que foi observado com Ra, não houve diferença significativa entre estes dois grupos. 
Tabela 5.7 - Resultado do teste Mann-Whitney para o parâmetro Rp, comparando os diferentes grupos e verificando diferenças significativas entre os mesmos

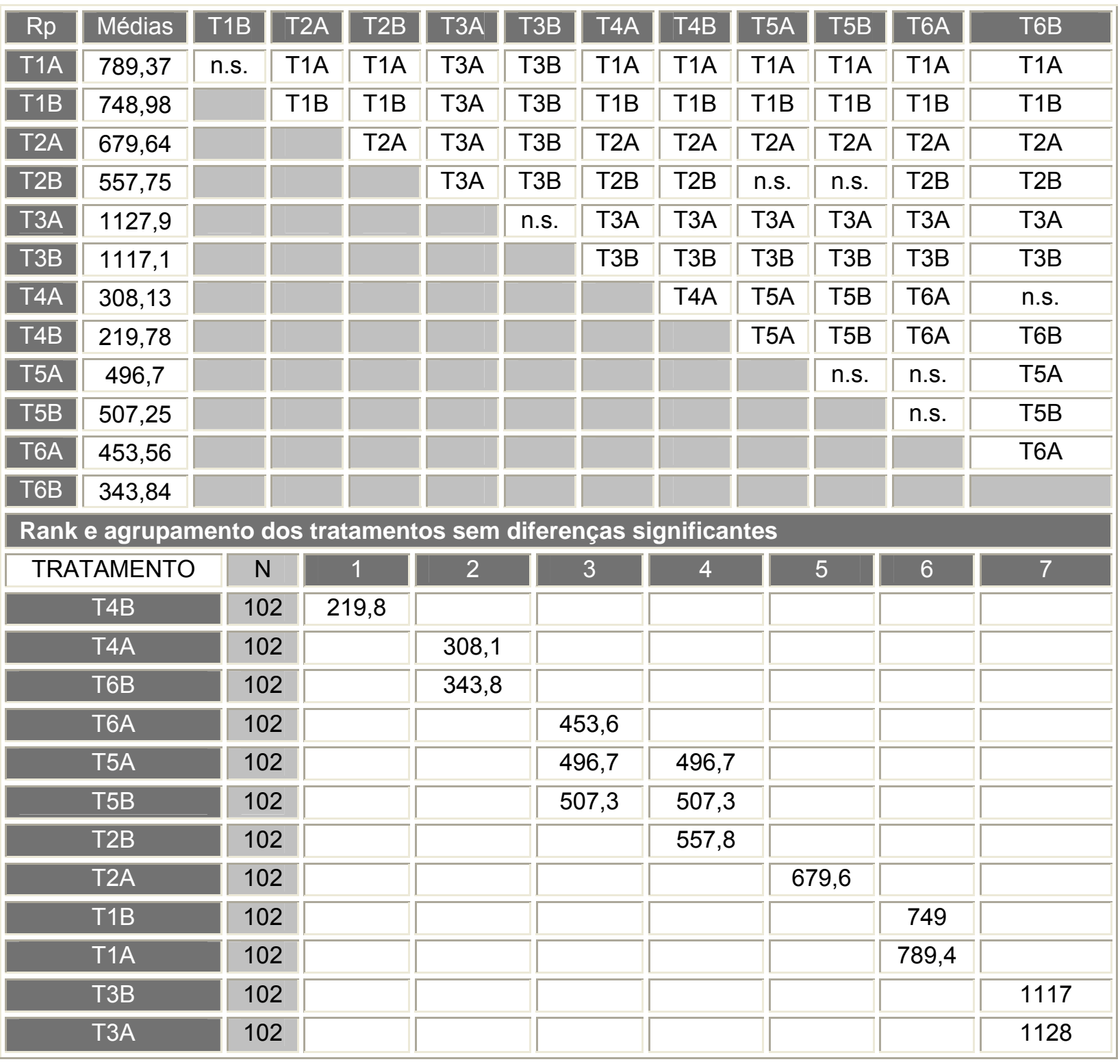




\section{Valores médios dos postos para o parâmetro Rp}

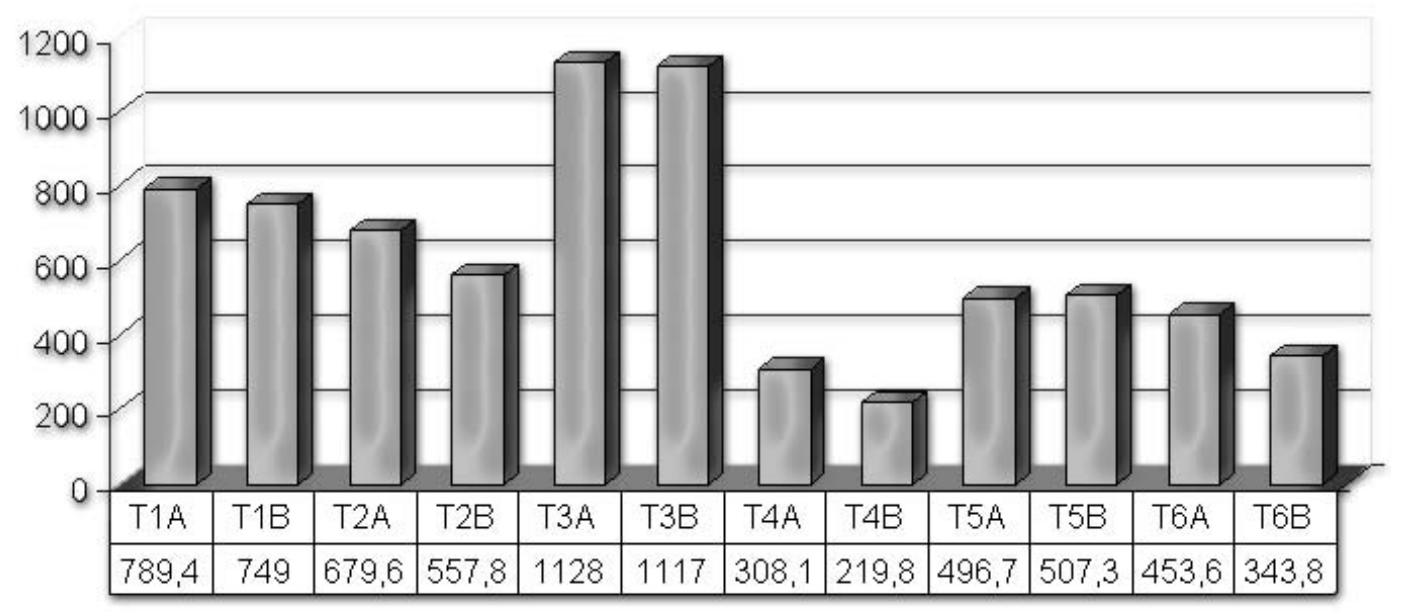

Gráfico 5.3 - Valores médios dos postos obtidos com o teste Kruskal-Wallis para o parâmetro Rp

A análise estatística do parâmetro Rp também promoveu uma ordenação diferente entre os grupos em comparação com a obtida com Ra e Rz. A seqüência da ordenação foi: T4B, T4A/T6B, T6A/T5A/T5B, T5A/T5B/T2B, T2A, T1B/T1A, T3B/T3A. Os grupos que não apresentam diferenças significativas estão agrupados e separados por barras. 
Tabela 5.8 - Resultado do teste Mann-Whitney para o coeficiente Rp/Rz, comparando os diferentes grupos e verificando diferenças significativas entre os mesmos

\begin{tabular}{|c|c|c|c|c|c|c|c|c|c|c|c|c|}
\hline Rp/Rz & Médias & T1B & T2A & T2B & T3A & T3B & T4A & T4B & T5A & T5B & T6A & T6B \\
\hline T1A & 812,9 & n.s. & n.s. & T1A & T1A & T1A & T1A & T1A & T1A & T1A & T1A & T1A \\
\hline T1B & 884,6 & & T1B & T1B & T1B & T1B & T1B & T1B & T1B & T1B & T1B & T1B \\
\hline T2A & 768,6 & & & T2A & T2A & T2A & n.s. & T2A & T2A & T2A & T2A & $\mathrm{T} 2 \mathrm{~A}$ \\
\hline T2B & 535,8 & & & & T3A & T3B & T4A & n.s. & n.s. & T2B & n.s. & $\mathrm{T} 2 \mathrm{~B}$ \\
\hline T3A & 614,96 & & & & & n.s. & T4A & T3A & n.s. & T5B & n.s. & T3A \\
\hline T3B & 635,95 & & & & & \multicolumn{2}{|c|}{ n.s. } & T3B & T3B & T3B & n.s. & T3B \\
\hline T4A & 717,5 & & & & & \multicolumn{2}{|c|}{\begin{tabular}{|l|l|} 
& \\
\end{tabular}} & T4A & T4A & T4A & T4A & T4A \\
\hline T4B & 492,6 & & & & & \multicolumn{2}{|c|}{\begin{tabular}{|l|l} 
& \\
\end{tabular}} & & n.s. & n.s. & n.s. & T4B \\
\hline T5A & 545,4 & & & & & & & & T5A & n.s. & T5A \\
\hline T5B & 419,8 & & & & & & & & & T6A & n.s. \\
\hline T6A & 559,3 & & & & & & & & & & T6A \\
\hline T6B & 362,5 & & & & & \multicolumn{2}{|c|}{ 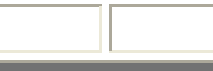 } & & & & & \\
\hline \multicolumn{13}{|c|}{ Rank e agrupamento dos tratamentos sem diferenças significantes } \\
\hline \multicolumn{2}{|c|}{ TRATAMENTO } & $\mathrm{N}$ & \multicolumn{2}{|c|}{1} & 2 & & 3 & \multicolumn{2}{|c|}{4} & 5 & & 6 \\
\hline \multicolumn{2}{|c|}{ T1B } & 102 & \multicolumn{2}{|c|}{884,6} & & & & & & & & \\
\hline \multicolumn{2}{|l|}{ T1A } & 102 & \multicolumn{2}{|c|}{812,9} & 812,9 & & & & & & & \\
\hline \multicolumn{2}{|l|}{ T2A } & 102 & & & 768,6 & & 768,6 & & & & & \\
\hline \multicolumn{2}{|l|}{ T4A } & 102 & & & & & 717,5 & & & & & \\
\hline \multicolumn{2}{|l|}{ T6A } & 102 & & & & & & \multicolumn{2}{|c|}{559,3} & & & \\
\hline \multicolumn{2}{|l|}{ T5A } & 102 & & & & & & \multicolumn{2}{|c|}{545,4} & & & \\
\hline \multicolumn{2}{|l|}{ T2B } & 102 & & & & & & \multicolumn{2}{|c|}{535,8} & & & \\
\hline \multicolumn{2}{|l|}{ T4B } & 102 & & & & & & 49 & & 492,6 & & \\
\hline T5B & & 102 & & & & & & & & 419,8 & & 419,8 \\
\hline T6B & & 102 & & & & & & & & & & 362,5 \\
\hline
\end{tabular}


Valores médios dos postos para o coeficiente Rp/Rz

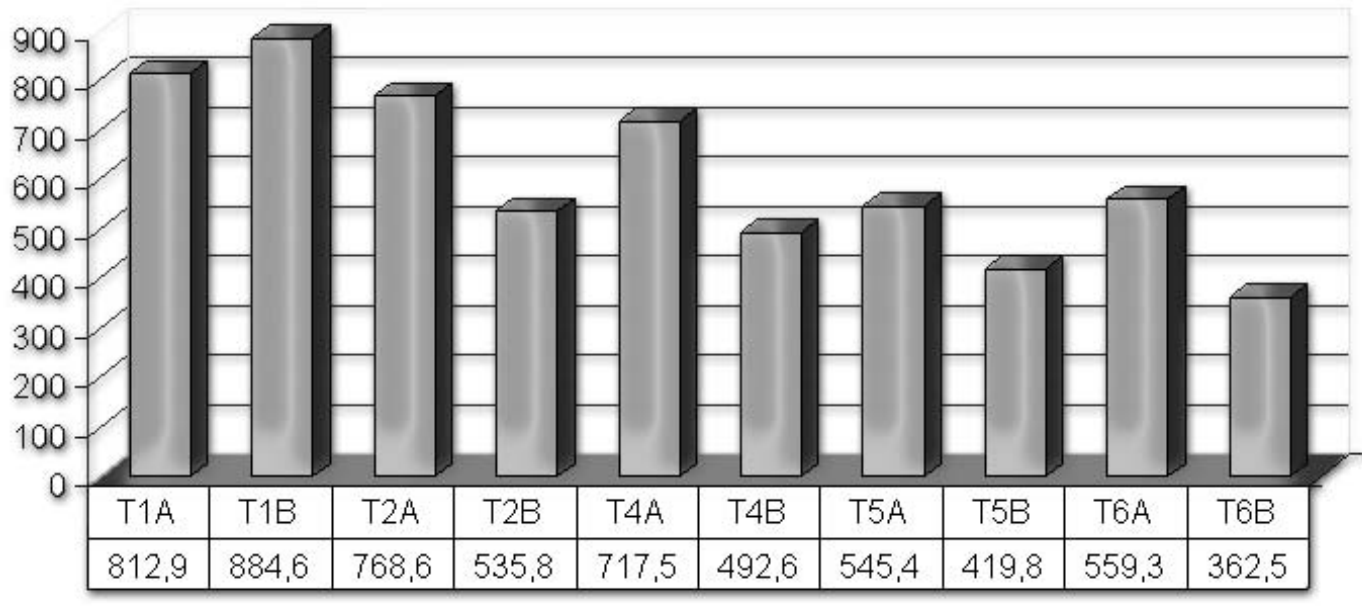

Gráfico 5.4 - Valores médios dos postos obtidos com o teste Kruskal-Wallis para o coeficiente Rp/Rz

A análise da interação de cada cerâmica com os tratamentos executados revelou comportamento distinto entre o parâmetro $\mathrm{Ra}, \mathrm{Rz}$ e Rp. Da comparação entre as duas cerâmicas para cada tratamento verificou-se que:

T1 - A análise dos três parâmetros não identificou diferenças significativas na rugosidade das cerâmicas do grupo A e B para o tratamento "glaze".

T2 - O "glaze" mais polimento com roda de carbureto de silício fina (EVE KERAMIK R22NK) resultou em menor rugosidade para as duas cerâmicas. Ra não foi sensível a esta diferença para o grupo $B$, além de não demonstrar diferença significativa entre os grupos T1A, T1B e T2B. O grupo T2A apresentou menor rugosidade média que $\mathrm{T} 2 \mathrm{~B}$. Já os valores de $\mathrm{Rz}$ apontaram não existir diferença significativa entre os grupos T2A e T2B. O parâmetro Rp apontou significativa superioridade quanto à lisura do grupo T2B sobre o T2A. 
T3 - O desgaste trouxe a pior rugosidade ante os três parâmetros. Enquanto os valores dos parâmetros Rz e Rp não apontaram diferenças significativas entre T3A e T3B, os valores de Ra indicaram menor rugosidade média para o grupo T3B.

T4 - O polimento com os instrumentos da EDENTA foram os que propiciaram a melhor lisura superficial. A análise dos parâmetros $R a$ e $R z$ não identificou diferenças significantes entre os grupos A e B. Já o parâmetro Rp identificou o grupo T4B como apresentando rugosidade significativamente menor que o T4A.

T5 - O comparativo entre as duas cerâmicas após o polimento com as rodas da EVE revelou resultados díspares. O parâmetro Ra demonstrou superioridade quanto à lisura do grupo T5B sobre o T5A. O parâmetro Rz demonstrou o contrário, apontando melhor lisura para o grupo T5A. O parâmetro Rp não identificou diferenças significativas entre os dois grupos.

T6 - Este tratamento apontou para superioridade de T6B sobre T6A em função dos resultados de Ra e Rp. O parâmetro Rz não identificou diferenças significativas entre os grupos.

A análise de qual tratamento resulta em melhor lisura de superfície para cada cerâmica também trouxe resultados díspares em função dos parâmetros de rugosidade avaliados. Da comparação entre os tratamentos dados 'a cada cerâmica verificou-se que:

GRUPO A - A cerâmica Duceram Plus apresentou a melhor lisura com o tratamento T4, fato identificado por todos os parâmetros. A ordenação dos tratamentos foi coincidente para os parâmetros Rz e Rp. Em ordem decrescente de lisura os melhores tratamentos foram T4, T6/T5, T2, T1 e T3. Os coeficientes Rp/Rz dos tratamentos T5 e T6 também não foram significativamente diferentes. A análise do parâmetro Ra resultou em uma seqüência distinta: T4, T2/T5, T6, T1 e T3. Os 
grupos separados por uma barra são os que não apresentaram diferenças significativas.

GRUPO B - O tratamento T4 também garantiu a melhor lisura para a cerâmica DuceraGold. A ordenação dos tratamentos foi coincidente para os parâmetros Rz e Rp. Em ordem decrescente de lisura, os melhores tratamentos foram T4, T6, T5/T2, T1 e T3. O coeficiente Rp/Rz de T2 foi significativamente maior que o de T5. Usando esta informação como meio de diferenciar estes dois grupos, a ordenação decrescente de lisura passaria a ser: T4, T6, T5, T2, T1 e T3. A análise do parâmetro Ra resultou em uma seqüência distinta: T4, T5/T6, T2/T1 e T3. Os grupos separados por uma barra são os que não apresentaram diferenças significativas. 
Tabela 5.9 - Teste de correlação não-paramétrica de Spearman

\begin{tabular}{|c|c|c|c|c|}
\hline \multicolumn{2}{|c|}{ Correlação dos dados de T1A e T1B } & $\mathrm{Ra}$ & Rz & $\mathrm{Rp}$ \\
\hline $\mathrm{Ra}$ & Coeficiente de Correlação & 1,000 &, $664(* *)$ &, $645\left(^{* *}\right)$ \\
\hline & Sig. & & 000 &, 000 \\
\hline & $\mathrm{N}$ & 204 & 204 & 204 \\
\hline $\mathrm{Rz}$ & Coeficiente de Correlação &, $664(* *)$ & 1,000 &, $872(* *)$ \\
\hline & Sig, & ,000 & & 000 \\
\hline & $\mathrm{N}$ & 204 & 204 & 204 \\
\hline$R p$ & Coeficiente de Correlação & ,645(**) &, $872\left({ }^{* *}\right)$ & 1,000 \\
\hline & Sig. &, 000 &, 000 & \\
\hline & $\mathrm{N}$ & 204 & 204 & 204 \\
\hline \multicolumn{2}{|c|}{ Correlação dos dados de T2A e T2B } & $\mathrm{Ra}$ & Rz & $\mathrm{Rp}$ \\
\hline $\mathrm{Ra}$ & Coeficiente de Correlação & 1,000 & ,643(**) & ,633(**) \\
\hline & Sig. & . &, 000 &, 000 \\
\hline & $\mathrm{N}$ & 204 & 204 & 204 \\
\hline Rz & Coeficiente de Correlação & ,643(**) & 1,000 &, $889(* *)$ \\
\hline & Sig, & 000 & &, 000 \\
\hline & $\mathrm{N}$ & 204 & 204 & 204 \\
\hline Rp & Coeficiente de Correlação & ,633(**) &, $889(* *)$ & 1,000 \\
\hline & Sig. &, 000 &, 000 & \\
\hline & $\mathrm{N}$ & 204 & 204 & 204 \\
\hline \multicolumn{2}{|c|}{ Correlação dos dados de T3A e T3B } & $\mathrm{Ra}$ & Rz & $\mathrm{Rp}$ \\
\hline $\mathrm{Ra}$ & Coeficiente de Correlação & 1,000 &, $681(* *)$ &, $725(* *)$ \\
\hline & Sig. & . &, 000 &, 000 \\
\hline & $\mathrm{N}$ & 204 & 204 & 204 \\
\hline $\mathrm{Rz}$ & Coeficiente de Correlação & ,681(**) & 1,000 &, $622\left({ }^{* *}\right)$ \\
\hline & Sig, &, 000 & &, 000 \\
\hline & $\mathrm{N}$ & 204 & 204 & 204 \\
\hline $\mathrm{Rp}$ & Coeficiente de Correlação &, $725(* *)$ &, $622(* *)$ & 1,000 \\
\hline & Sig. &, 000 & ,000 & \\
\hline & $\mathrm{N}$ & 204 & 204 & 204 \\
\hline
\end{tabular}

${ }^{* *}$ A correlação é significante ao nível de 0,01 
Tabela 5.10 - Teste de correlação não-paramétrica de Spearman

\begin{tabular}{|c|c|c|c|c|}
\hline \multicolumn{2}{|c|}{ Correlação dos dados de T4A e T4B } & $\mathrm{Ra}$ & Rz & $\mathrm{Rp}$ \\
\hline $\mathrm{Ra}$ & Coeficiente de Correlação & 1,000 & ,681(**) &, $725(* *)$ \\
\hline & Sig. & . & ,000 &, 000 \\
\hline & $\mathrm{N}$ & 204 & 204 & 204 \\
\hline $\mathrm{Rz}$ & Coeficiente de Correlação & ,681(**) & 1,000 & ,622(**) \\
\hline & Sig, &, 000 & &, 000 \\
\hline & $\mathrm{N}$ & 204 & 204 & 204 \\
\hline Rp & Coeficiente de Correlação &, $725(* *)$ &, $622(* *)$ & 1,000 \\
\hline & Sig. &, 000 & 000 & . \\
\hline & $\mathrm{N}$ & 204 & 204 & 204 \\
\hline \multicolumn{2}{|c|}{ Correlação dos dados de T5A e T5B } & $\mathrm{Ra}$ & Rz & $\mathrm{Rp}$ \\
\hline $\mathrm{Ra}$ & Coeficiente de Correlação & 1,000 &, $358\left(^{* *}\right)$ &, $528\left({ }^{* *}\right)$ \\
\hline & Sig. & . &, 000 &, 000 \\
\hline & $\mathrm{N}$ & 204 & 204 & 204 \\
\hline $\mathrm{Rz}$ & Coeficiente de Correlação &, $358(* *)$ & 1,000 &, $676\left(^{* *}\right)$ \\
\hline & Sig, &, 000 & &, 000 \\
\hline & $\mathrm{N}$ & 204 & 204 & 204 \\
\hline $\mathrm{Rp}$ & Coeficiente de Correlação &, $528\left({ }^{* *}\right)$ &, $676\left({ }^{* *}\right)$ & 1,000 \\
\hline & Sig. &, 000 &, 000 & \\
\hline & $\mathrm{N}$ & 204 & 204 & 204 \\
\hline \multicolumn{2}{|c|}{ Correlação dos dados de T6A e T6B } & $\mathrm{Ra}$ & Rz & $\mathrm{Rp}$ \\
\hline $\mathrm{Ra}$ & Coeficiente de Correlação & 1,000 &, $508\left({ }^{* *}\right)$ &, $657(* *)$ \\
\hline & Sig. & &, 000 &, 000 \\
\hline & $\mathrm{N}$ & 204 & 204 & 204 \\
\hline $\mathrm{Rz}$ & Coeficiente de Correlação &, $508(* *)$ & 1,000 & ,681(**) \\
\hline & Sig, &, 000 & &, 000 \\
\hline & $\mathrm{N}$ & 204 & 204 & 204 \\
\hline $\mathrm{Rp}$ & Coeficiente de Correlação &, $657\left({ }^{* *}\right)$ &, $\left.6811^{* *}\right)$ & 1,000 \\
\hline & Sig. & ,000 & ,000 & . \\
\hline & $\mathrm{N}$ & 204 & 204 & 204 \\
\hline
\end{tabular}

${ }^{* *}$ A correlação é significante ao nível de 0,01 


\subsection{MEV}

As MEV dos grupos avaliados são apresentadas nas figuras 5.1 à 5.12.

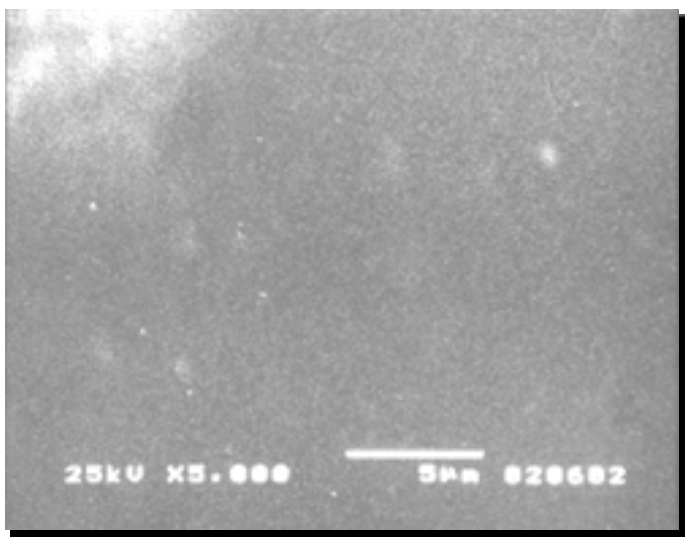

Figura 5.1 - Grupo T1A - "glaze"

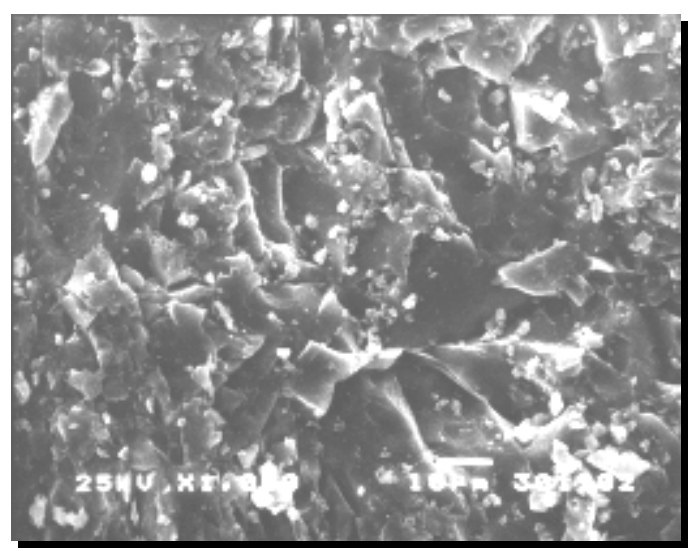

Figura 5.3 - Grupo T3A - desgaste com IADR

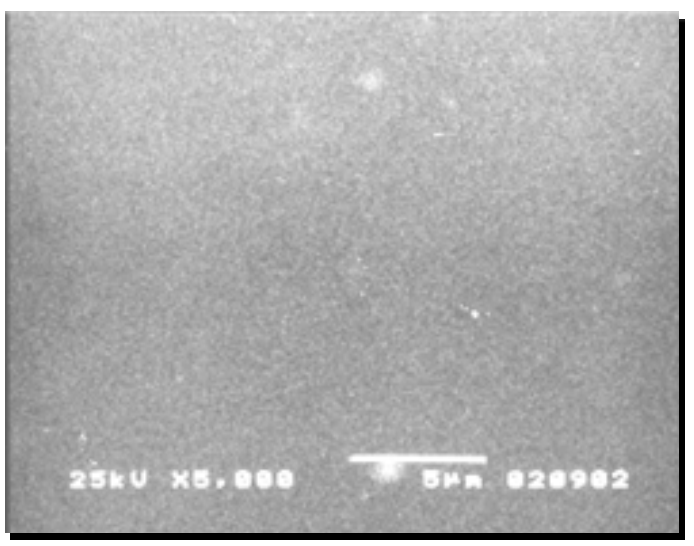

Figura 5.5 - Grupo T5A - polidores EVE Keramik

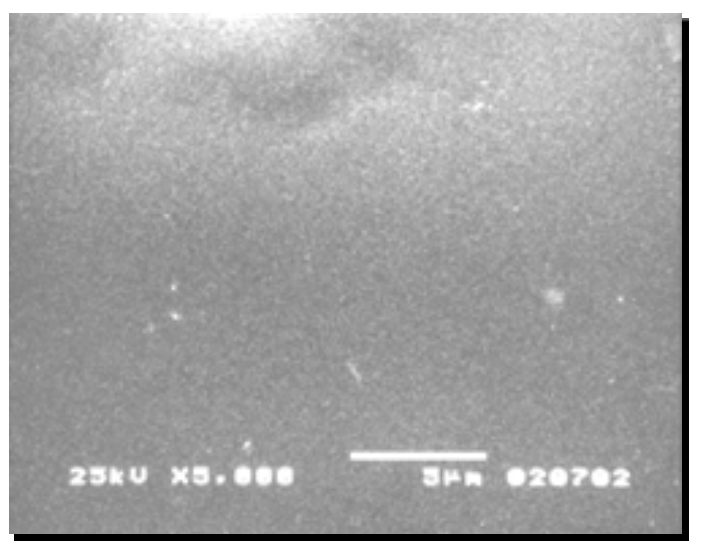

Figura 5.2 - Grupo T2A - "glaze"+ polimento com roda EVE R22NK

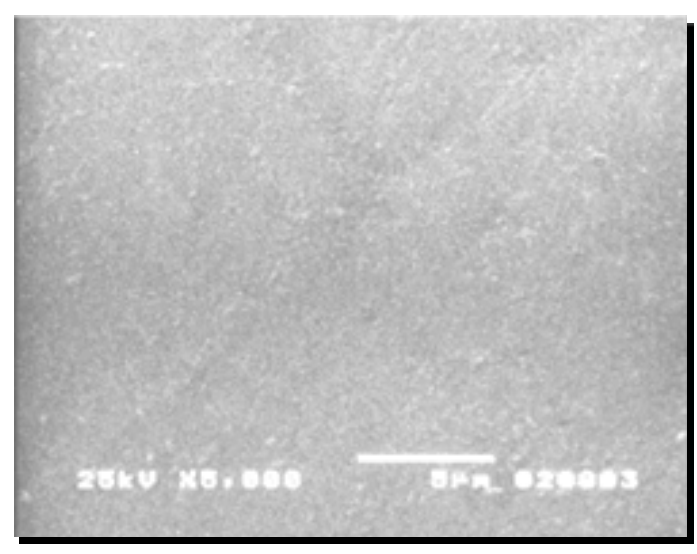

Figura 5.4 - Grupo T4A - ação dos polidores EDENTA

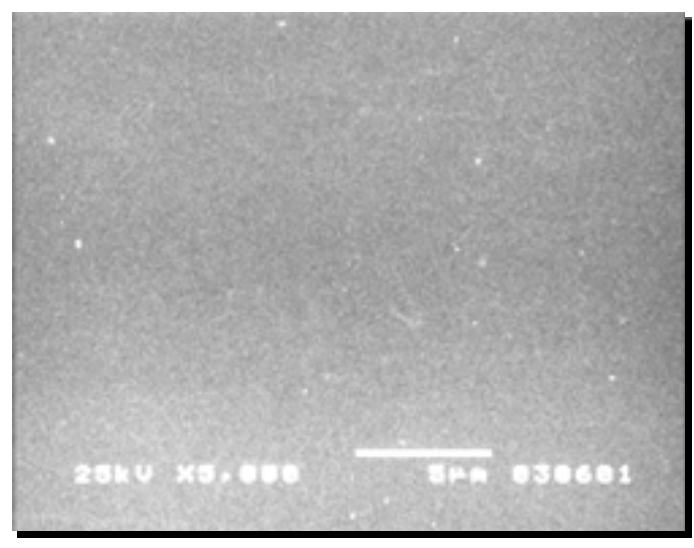

Figura 5.6 - Grupo T6A - polidores EVE Keramik + pasta CrystarPast 


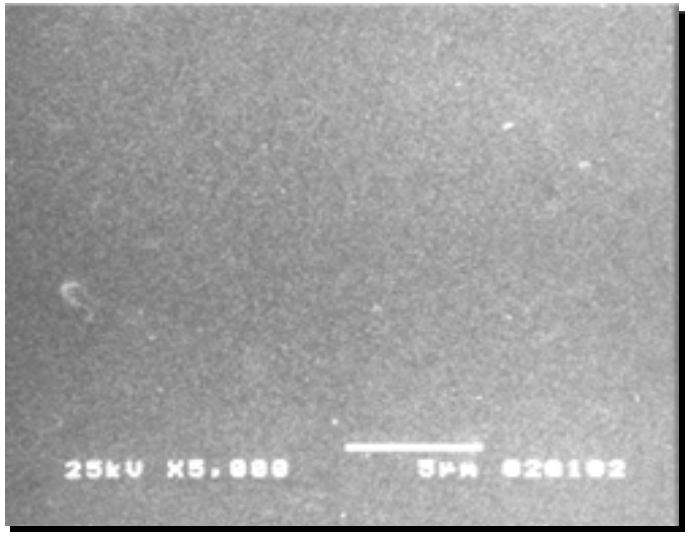

Figura 5.7 - Grupo T1B - "glaze"

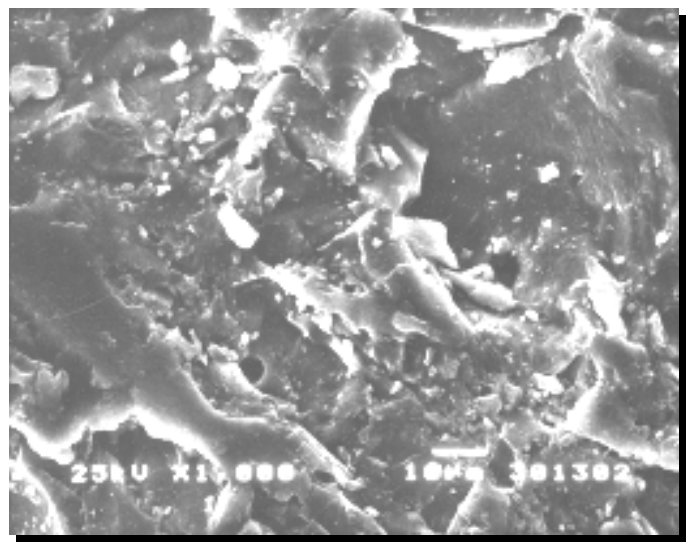

Figura 5.9 - Grupo T3B - desgaste com IADR

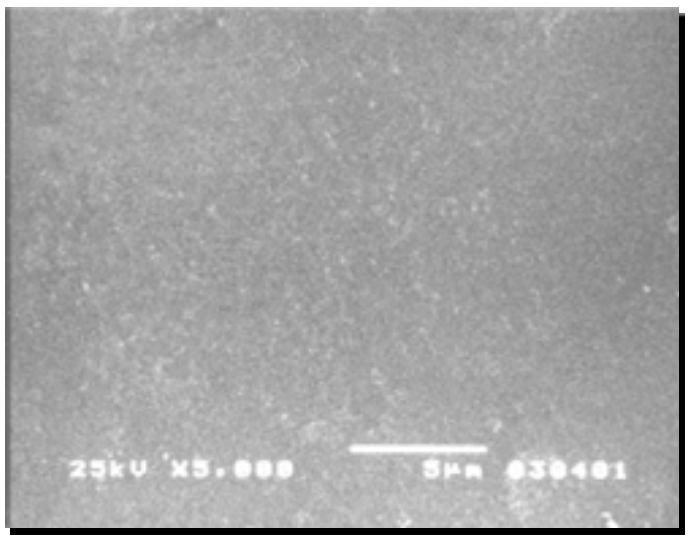

Figura 5.11 - Grupo T5B - polidores EVE Keramik

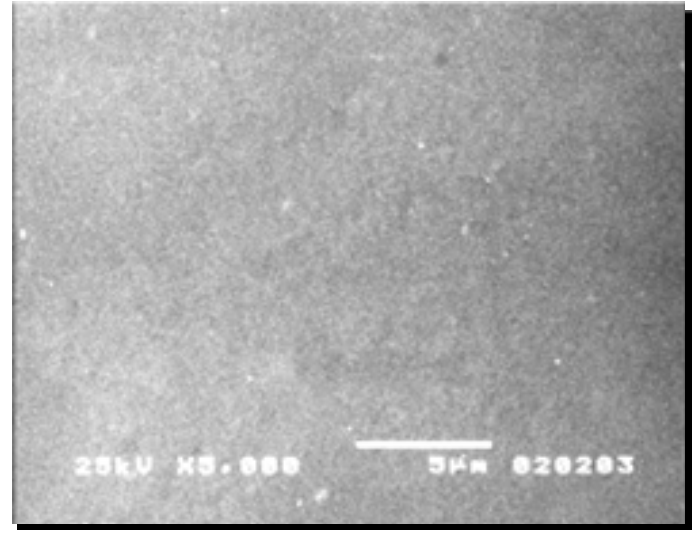

Figura 5.8 - Grupo T2B - "glaze"+ polimento com roda EVE R22NK

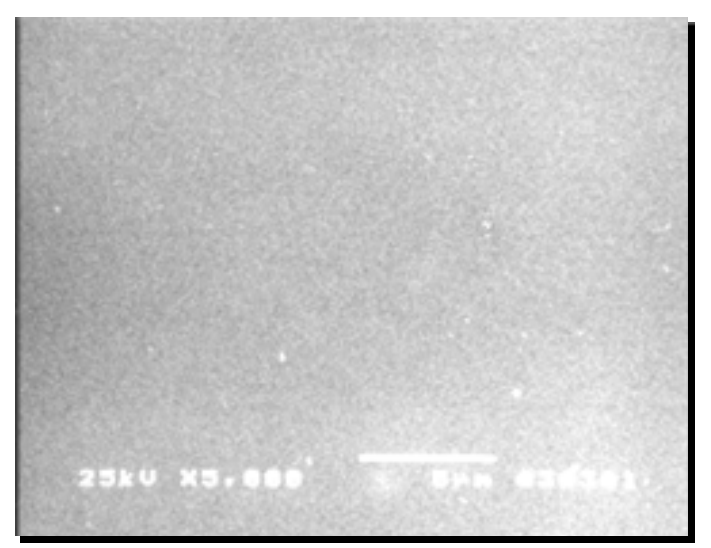

Figura 5.10 - Grupo T4B - ação dos polidores EDENTA

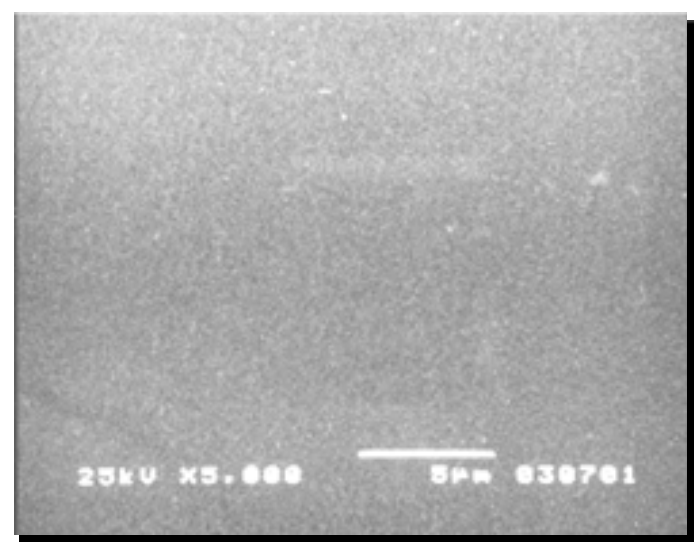

Figura 5.12 - Grupo T6B - polidores EVE Keramik + pasta CrystarPast 
A microscopia eletrônica de varredura foi realizada com uma ampliação de 1000 vezes para os grupos T3A e T3B, e de 5000 vezes para os demais grupos. A diferença de aumentos foi empregada para compatibilizar as dimensões expostas com algo próximo ao aferido na análise quantitativa. A tabela 5.11 apresenta os valores médios dos parâmetros em função dos tratamentos aplicados. Excetuando o tratamento T3A e T3B, houve dificuldade para focar as superfícies em função da lisura das mesmas. Os grupos T3A e T3B foram os que apresentaram maiores irregularidades. Entre os demais grupos não houve como identificar diferenças na rugosidade superficial.

Tabela 5.11 - Valores médios dos parâmetros em função dos tratamentos aplicados

\begin{tabular}{|r|c|c|c|}
\hline TRATAMENTOS/PARÂMETROS & $\mathrm{Ra}$ & $\mathrm{Rz}$ & $\mathrm{Rp}$ \\
\hline $\mathrm{T} 1$ & 1,30 & 5,05 & 2,48 \\
\hline $\mathrm{T} 2$ & 1,19 & 4,78 & 2,18 \\
\hline $\mathrm{T} 3$ & 6,16 & 33,26 & 14,92 \\
\hline $\mathrm{T} 4$ & 0,83 & 3,35 & 1,49 \\
\hline $\mathrm{T} 5$ & 1,05 & 4,38 & 1,84 \\
\hline $\mathrm{T} 6$ & 1,09 & 4,11 & 1,70 \\
\hline
\end{tabular}




\section{DISCUSSÃO}

A dentição natural está sujeita a um desgaste fisiológico que, progressivamente, implica em alteração das relações de contatos oclusais e proximais. A necessidade de restaurar os dentes implica na utilização de materiais que apresentam características mecânicas distintas das encontradas no esmalte e dentina. Quanto ao desgaste, há materiais que promovem maior ou menor desgaste que o esmalte. No entanto, ainda não há uma opção de material restaurador ideal, equivalente ao esmalte. Este comportamento distinto entre os dentes restaurados e os íntegros leva à ocorrência de desequilíbrios no processo natural de desgaste (WARD; TATE; POWERS, 1995).

O crescente interesse e emprego das restaurações cerâmicas devem-se à versatilidade das indicações clínicas e à superioridade estética deste material quanto à cor e a translucidez (VIEIRA; AGRA, 1998; VAN NOORT, 2002). Estão indicadas para as situações clínicas que demandam estética, em dentes que apresentam preparos cujas dimensões excedem o limite para a realização de uma restauração direta de resina composta.

Dentre as diversas técnicas e materiais que resultam em uma restauração cerâmica, a técnica de cocção de porcelanas feldspática é a que possibilita maior flexibilidade para a obtenção de um resultado individualizado e superior em relação à estética. A principal limitação das restaurações confeccionadas apenas com uma porcelana feldspática está relacionada à friabilidade deste material, o que determina extrema cautela no manuseio das mesmas. Tal friabilidade pode ser comparada à existente no esmalte. Sem a presença da dentina, que dá suporte e resistência 
mecânica, o esmalte torna-se sujeito a fratura ante a incidência das cargas presentes na cavidade oral. O emprego de uma resina composta como agente que viabiliza a união entre a porcelana e a estrutura do dente, provê suporte à porcelana, e torna este material resistente às cargas mastigatórias, se assemelhando em importância ao papel que a dentina tem relação ao esmalte.

A discussão sobre o potencial de desgaste de uma cerâmica ganha relevância proporcional ao emprego cada vez mais freqüente deste material. A lisura de superfície é o principal fator que condiciona o comportamento abrasivo de uma cerâmica, e é afetada pelo acabamento superficial, propriedades mecânicas e composição da cerâmica. Há consenso de que uma cerâmica que passou por ajuste com instrumento abrasivo ou cortante apresenta irregularidades danosas às superfícies antagonistas. Quando não há a possibilidade de se realizar um novo glaze antes da cimentação da restauração, deve-se executar um adequado polimento intra-oral que devolva lisura às superfícies desgastadas em função de ajustes de forma ou ajustes funcionais. As restaurações puras de porcelana que apresentam pequena espessura são susceptíveis à fratura se o ajuste de oclusão for executado antes da colagem. Mesmo quando a restauração apresenta volume que garanta resistência, discute-se a vantagem de realizar o ajuste antes da colagem, já que, excetuando a técnica da lâmina de platina e da porcelana de baixa fusão sobre uma de alta, o retorno da peça ao forno implicaria em deformação e conseqüente perda de adaptação.

Além do desgaste do antagonista, uma superfície rugosa favorece o acúmulo de placa bacteriana, trazendo efeitos indesejáveis aos tecidos gengivais circunvizinhos à restauração (CAMPBELL, 1989; JACOBI; SHILLINGBURG JR; 
DUNCANSON JR, 1991; EKFELDT; ÖILO, 1990; JAGGER; HARRISON, 1994; HACKER; WAGNER; RAZZOOG, 1996; KELLY; NISHIMURA; CAMPBELL, 1996).

Apesar do rugosímetro permitir que apenas uma pequena porção do material seja avaliada por vez, correspondente ao percurso da sonda apalpadora, este ainda é o instrumento mais prático e conveniente para avaliar a rugosidade de uma superfície. Os resultados da análise quantitativa com um rugosímetro podem ser influenciados por fatores como o posicionamento da superfície que será avaliada sob o sensor do aparelho, a calibragem do equipamento e a seleção dos parâmetros. Outro fator relevante, que é por vezes menosprezado, diz respeito ao modo de emprego de aparelhos que disponibilizam um filtro elétrico passa-alto. Deve-se compatibilizar o valor de "cut off" com a característica de rugosidade da superfície, realizando medidas e comparando os resultados com uma tabela de referência (NBR 6405; FERRARESI, 1977). Esta tabela está disponível em livros texto, normas e manuais de equipamentos, e apresenta os valores mínimos que devem ser selecionados como comprimento de amostragem. Poucas vezes vê-se referendada em artigos menção ao porque de eleger-se um ou outro valor de "cut off'. Pior, nota-se que em alguns trabalhos o valor do comprimento de amostragem é selecionado à conveniência do tamanho do corpo de prova confeccionado, ignorando totalmente os valores tabelados pré-estabelecidos. A seleção inadvertida de um valor de "cut off" alto em relação ao ideal pode resultar em valores de rugosidade também altos, frutos da inclusão de formas geométricas maiores, como as ondulações. Por outro lado, a atenuação excessiva com o emprego de um valor de corte inferior ao ideal também pode determinar uma leitura equivocada, já que uma supressão das irregularidades pode mascarar diferenças entre tratamentos dados a uma superfície (LEITÃO; HEGDAHL, 1981). 
Neste trabalho, a análise quantitativa revelou que o polimento foi capaz de estabelecer uma lisura superior à oferecida pelo "glaze". Os parâmetros avaliados ao rugosímetro apresentaram resultados não coincidentes, variando a ordenação existente entre os tratamentos que propiciam maior e menor lisura. Há trabalhos que empregam um determinado parâmetro para definir a rugosidade de um material, mas não explicam ou exploram o porquê da seleção destes. Devido à diversidade de parâmetros que a leitura com um rugosímetro pode propiciar, a exposição mais detalhada sobre o significado de cada parâmetro é de extrema importância para que os resultados obtidos possam ser avaliados. Apesar de o parâmetro Ra ser o mais empregado (PATTERSON et al., 1992; SCURRIA; POWERS, 1994; WHITEHEAD et al., 1995; WARD; TATE; POWERS 1995; CARPINNETTI, 1996), este descreve apenas a rugosidade média da superfície. Rp possibilita distinguir a altura média das maiores protusões a partir da linha média em cinco comprimentos de amostragem. Portanto, como meio de predizer o potencial de desgaste que uma superfície apresenta, Rp traz informações adicionais ao parâmetro Ra. Um valor de Rp proporcionalmente maior indica que as protusões presentes na superfície são mais projetadas e potencialmente mais danosas quanto ao potencial de desgaste. $\mathrm{O}$ coeficiente $\mathrm{Rp} / \mathrm{Rz}$ complementa a informação oferecida por $\mathrm{Rp}$, já que permite determinar se o perfil da superfície se apresenta arredondado ou agudo. Quando o valor deste coeficiente se aproxima de 1, a superfície apresenta projeções acentuadas e a linha média se encontra deslocada para baixo em relação ao perfil. Ao contrário, quando o valor aproxima-se de 0 , a superfície apresenta a linha média deslocada em direção à superfície, e resulta em um perfil de superfície mais arredondado, em que as depressões são mais acentuadas do que as protusões. 
Rz trouxe informações sobre a média das distâncias verticais entre a maior protusão e a maior depressão em cada um dos cinco comprimentos de amostragem. Neste trabalho, a avaliação do parâmetro Rz prestou-se essencialmente para obter o coeficiente Rp/Rz.

O coeficiente Rp/Rz foi usado para determinar, dentre os grupos que não apresentaram diferenças significativas, qual apresenta superfície menos abrasiva. Ordenar a lisura de diferentes superfícies levando em conta apenas o coeficiente Rp/Rz pode levar a conclusões errôneas. Por tratar-se de uma medida proporcional, não se pode afirmar que a existência de uma superfície com coeficiente mais baixo e maior valor de Rp seja melhor que outra com coeficiente mais alto e Rp significativamente menor. Pelo contrário, a existência de um valor de Rp mais alto sempre indica propriedades funcionais piores quanto ao desgaste. Por exemplo, ao compararem-se os valores médios de Rp dos grupos T4B (1,42 mícron) e de T3B (14,62 mícron) identificam-se duas situações extremas quanto à rugosidade. No entanto, o resultado do teste Mann-Whitney para o coeficiente Rp/Rz destes mesmos grupos apontou para a inexistência de diferença significativa. Conclui-se que a observação isolada deste coeficiente é inadequada. A tabela 6.1 apresenta a ordenação e o agrupamento dos resultados obtidos com o parâmetro Rp levando-se em conta o coeficiente Rp/Rz como critério de distinção entre os grupos que não apresentaram diferenças significativas. 
Tabela 6.1 - Resultado do teste Mann-Whitney para o parâmetro Rp, comparando os diferentes grupos e verificando diferenças significativas, mas considerando o coeficiente $R p / R z$ para distinguir grupos sem diferença significativa

\begin{tabular}{|c|c|c|c|c|c|c|c|c|}
\hline TRATAMENTO & 1 & 2 & 3 & 4 & 5 & 6 & 7 & 8 \\
\hline T4B & T4B & & & & & & & \\
\hline T6B & & T6B & & & & & & \\
\hline T4A & & & T4A & & & & & \\
\hline T5B & & & & T5B & & & & \\
\hline T6A & & & & & T6A & & & \\
\hline T5A & & & & & T5A & & & \\
\hline T2B & & & & & & T2B & & \\
\hline T2A & & & & & & & T2A & \\
\hline T1B & & & & & & & & T1B \\
\hline T1A & & & & & & & & T1A \\
\hline
\end{tabular}

O teste de correlação não-paramétrica de Spearman entre os parâmetros Ra, Rz e Rp mostrou resultados variados. Este teste determinou quão consistentemente os valores obtidos na análise dos parâmetros mudaram em conjunto. A correlação observada foi sempre positiva, e variou entre forte, média e fraca. Dos dezoito coeficientes de correlação observados, um foi classificado como fraco, quinze como médios e apenas dois como fortes. Estes resultados ajudam a explicar as variações nas ordenações dos grupos frente aos três parâmetros. 


\subsection{Comparativo entre os tratamentos realizados}

Para a porcelana Duceram Plus a melhor lisura foi obtida com os polidores da EDENTA (T4), e as duas piores, em ordem crescente, com os tratamentos T1A e T3A. Entre estes extremos, os parâmetros Rz e Rp apontaram em ordem crescente de rugosidade os grupos T6A, T5A e T2A, sendo que não houve diferença significativa entre T6A e T5A. O coeficiente Rp/Rz destes dois tratamentos também não apresentou diferença significativa. O parâmetro Ra apresentou ordenação diferente entre os tratamentos: T4A, T2A, T5A, T6A, T1A e T3A. Não houve diferença significativa entre T2A e T5A.

Para a cerâmica DuceraGold os três parâmetros apontaram o tratamento T4B como o que resultou em melhor lisura e o T3B como o que propiciou maior rugosidade. Entre estes extremos, os resultados apurados com Ra, Rz e Rp não foram coincidentes. Ra indicou a seguinte seqüência da menor para a maior rugosidade: T4B, T5B, T6B, T2B, T1B e T3B, sendo que não existiu diferença significativa entre T5B e T6B, e entre T2B e T1B. A seqüência apurada com Rz foi: T4B, T6B, T2B, T5B, T1B e T3B, sendo que não existiu diferença significativa entre T2B e T5B. A comparação dos coeficientes Rp/Rz destes dois tratamentos aponta vantagem do tratamento T5B. A seqüência apurada com Rp foi: T4B, T6B, T5B, T2B, T1B e T3B, sendo que não existiu diferença significativa entre T5B e T2B. A comparação dos coeficientes $R p / R z$ destes dois tratamentos aponta vantagem do tratamento T5B.

Portanto, dentre os métodos de polimento avaliados, os polidores da marca Edenta foram os que trouxeram melhores resultados com as duas cerâmicas 
avaliadas. A vantagem destes polidores não se restringe apenas à qualidade do polimento, mas também ao seu relativo baixo custo e ao fato das rodas poderem ser customizadas para que se adaptem às superfícies que necessitam polimento. As rodas podem ser facilmente diminuídas em seu diâmetro, e a superfície lateral pode ser adelgaçada de modo que alcance áreas de difícil acesso, como por exemplo, as vertetes internas da face oclusal dos dentes posteriores. Os polidores EVE apresentam vantagens semelhantes aos das EDENTA quanto ao custo e à possibilidade de customização. No entanto, promoveram lisura inferior aos da EDENTA. O uso da pasta CrystarPast após os polidores EVE trouxe melhor lisura à superfície. No entanto, tanto quando usados com ou sem a pasta contendo partículas de diamante, os polidores EVE promoveram lisura superior à observada apenas com o "glaze". O efeito do polimento sobre uma cerâmica que foi ajustada esta representado na figura 6.1 , onde metade da superfície do corpo de prova foi tratada com polidores EDENTA e a outra metade desgastada com um IADR (figura $6.2)$.

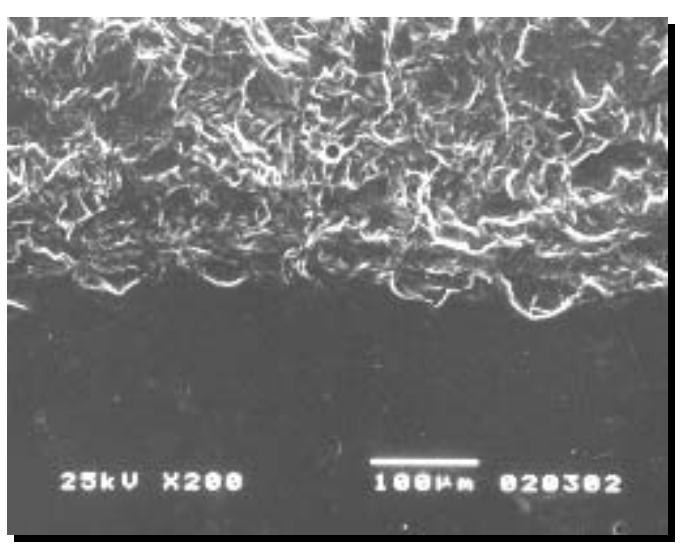

Figura 6.1 - Corpo de prova da cerâmica Duceragold. A metade superior da superfície foi mantida desgastada enquanto a inferior foi polida com os polidores EDENTA

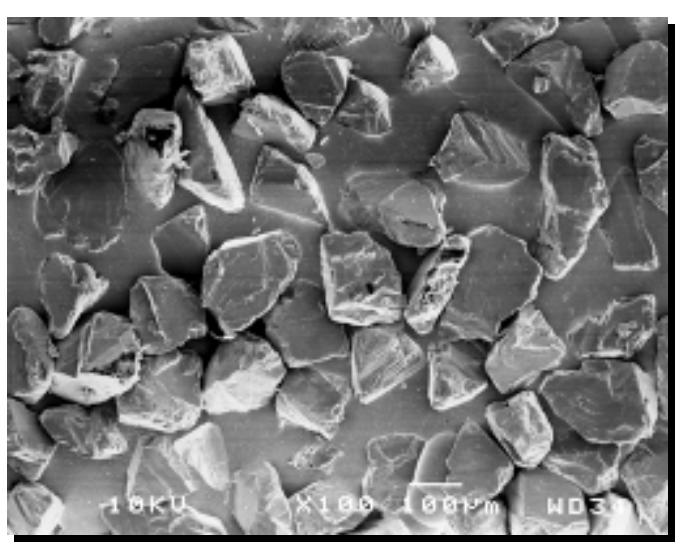

Figura 6.2 - Ampliação da superfície do IADR onde se observa $O$ aspecto irregular das partículas de diamante 


\subsection{Comparativo entre as cerâmicas Duceram Plus e Duceragold frente cada tratamento aplicado}

O parâmetro Ra apontou lisura superior da cerâmica Duceragold em quatro dos seis tratamentos (T3B, T4B, T5B e T6B). O tratamento T2B apresentou rugosidade maior que T2A. Entre T1A e T1B não existiu diferença significativa.

O parâmetro Rz indicou não existir diferença entre as duas cerâmicas em cinco dos seis tratamentos avaliados. $\mathrm{O}$ grupo T5A apresentou menor rugosidade que $\mathrm{O}$ T5B.

O parâmetro Rp não apontou diferenças significativas entre as cerâmicas em três dos seis tratamentos avaliados (T2, T3 e T5). Os valores apurados nos grupos T1B, T4B e T6B foram menores do que os observados respectivamente nos grupos T1A, T4A e T6A. A avaliação de Rp em conjunto com o coeficiente Rp/Rz para determinar vantagens entre grupos que não apresentaram diferenças significativas alterou o resultado da comparação, e colocou o grupo T5B em posição de superioridade em relação à T5A. Portanto, levando-se em consideração o coeficiente $\mathrm{Rp} / \mathrm{Rz}$, o número de grupos que apresentaram melhor resultado com a cerâmica DuceraGold sobe de três para quatro.

A vantagem da cerâmica Duceragold quanto ao polimento pode estar ligada à composição deste material, que apresenta matriz vítrea em proporção significativamente maior e com distribuição mais homogênea dos cristais de leucita do que a porcelana Duceram Plus (MEIER et al., 1993). Esta é ao mesmo tempo uma vantagem e uma desvantagem desta classe de materiais (vidros hidrotérmicos), já que a efetividade de uma colagem a estas cerâmicas é inferior à observada junto 
às porcelanas feldspáticas. Este fator limita a indicação da cerâmica Duceragold para aplicações sobre copings metálicos ou cerâmicos, e a contra-indica para a confecção de restaurações puras. Compondo uma coroa metalocerâmica ou reforçada por infra-estrutura cerâmica, a cerâmica Duceragold pode retornar ao forno para novo "glaze" após ajustes prévios à cimentação. No entanto, abrindo-se mão de técnicas de polimento como as avaliadas neste trabalho, pode-se dispensar o novo envio da restauração para o laboratório de .prótese. 


\subsection{Análise qualitativa}

A análise das imagens obtidas com a MEV trouxe uma classificação de lisura das superfícies distinta da observada através da análise quantitativa. A MEV não revelou diferenças significativas entre as duas cerâmicas avaliadas. As superfícies que foram facilmente identificadas como mais irregulares correspondem aos grupos T3A e T3B. Os valores médios destes dois grupos para os parâmetros avaliados foram de 33,25 mícron para Rz, 14,92 mícron para $\mathrm{Rp}$ e 6,16 mícron para Ra, valores que podem ser facilmente encaixados no aspecto revelado pela MEV. Nos demais grupos, apesar do aumento utilizado (5000 vezes), a MEV não propiciou a identificação de diferenças significativas que pudessem ser relacionadas aos achados quantitativos. 


\subsection{Considerações finais}

Os resultados qualitativos apresentaram-se diferentes dos quantitativos. A análise qualitativa possibilita a visualização efetiva de um quadro mostrado apenas por números através da análise quantitativa. Entretanto, a análise ao MEV envolve um aspecto subjetivo, que dificulta uma conclusão assertiva frente às superfícies que apresentam pequena variação de rugosidade. Neste trabalho, a análise quantitativa demonstrou a existência de diferenças que a MEV não foi capaz de traduzir.

$\mathrm{Na}$ comparação entre diferentes trabalhos, o tratamento "glaze" é o que apresenta maior disparidade de resultados. Sob a denominação de "glaze" há estudos que promovem tratamentos antes e durante a queima dos corpos de prova que por vezes se afastam da realidade observada na maioria dos laboratórios de prótese durante a confecção de restaurações de cerâmica. A tendência atual é a de prover as restaurações de um aspecto natural. Neste sentido, o uso de líquidos de "glaze" e/ou de temperaturas mais elevadas com tempo de manutenção nesta temperatura por um período prolongado promove alto brilho de superfície, por vezes muito maior que o desejável se comparado ao existente nos dentes naturais. Tempo de manutenção e temperatura elevada ("overglaze") também resultam em alteração na cor de algumas cerâmicas (VIEIRA et al., 2001). Van Noort (2002) prescreve que a sinterização dos materiais cerâmicos deva seguir estritamente as instruções de seus fabricantes, já que um tempo prolongado ou temperatura excessiva acarretam em deformação piroplástica (escoamento do vidro) e conseqüente alteração do brilho e perda de detalhes anatômicos. 
O equilíbrio entre o brilho das restaurações e o dos dentes naturais é um desafio constante durante a etapa de confecção laboratorial. Os corpos de prova confeccionados para a avaliação realizada neste trabalho passaram pelo processo de queima respeitando as indicações de tempo e temperatura estipuladas pelo fabricante. Esta queima sem excessos de tempo ou temperatura é chamada de "glaze" natural e, como o nome revela, resulta em um aspecto mais natural e menos brilhante da superfície.

Além da temperatura e tempo de manutenção da queima, há outros fatores que condicionam a qualidade final dos corpos de prova, como o uso de lixas e borrachas para regularizar a superfície antes do "glaze". Raimondo Jr, Richardson e Wiedner (1990) regularizaram os corpos de prova com IADR fino antes do "glaze". Os resultados da MEV demonstraram melhor superfície dos corpos de prova polidos (que neste trabalho não sofreram desgaste antes do polimento) em comparação com os que passaram apenas pelo "glaze". Rosentiel, Baiker e Johnston (1989) regularizaram os corpos de prova com lixas de granulosidade progressivamente mais fina antes do "glaze". Metade dos corpos de prova foi queimada enquanto a outra metade foi polida sem um desgaste prévio. Brewer, Garlapo e Chipps (1990) não executaram qualquer regularização de superfície ("autoglaze"). Fuzzi, Zaccheroni e Vallania (1996) empregaram na seqüência um IADR de 30 mícron, lixa de granulosidade 220, borracha Cerapearl e líquido de glaze. A análise ao MEV demonstrou que todas as técnicas de polimento avaliadas deixaram a superfície parcialmente porosa e com linhas de fratura. O "glaze" apresentou a melhor superfície. $\mathrm{Na}$ análise com o rugosímetro não houve distinção entre a rugosidade dos corpos polidos ou dos que passaram apenas pelo "glaze". Jagger e Harrison (1994) executaram o "glaze" sem regularização adicional dos corpos de prova. Os 
grupos que receberam o polimento foram queimados a uma temperatura inferior à final ("unglazed") antes do polimento com discos Sof-Lex ou borrachas Ceramisté (Shofu). Estes exemplos indicam a variedade de tratamentos que são denominados de "glaze" e como, muitas vezes, a base sobre a qual se parte para a realização do polimento é diversa da que acontece na clínica, quando há o desgaste da superfície antes de realizar-se o polimento. Neste trabalho, o protocolo de preparo dos corpos de prova buscou seguir a realidade de grande parte dos laboratórios de prótese, promovendo a regularização da superfície com uma pedra montada antes do "glaze". A pedra Dura-Green é largamente empregada nos laboratórios de prótese para ajustar os contatos oclusais durante a confecção, refinar a anatomia e para regularizar a superfície antes da queima final. Outro aspecto que deve ser ressaltado sobre este trabalho é o de que os corpos de prova polidos receberam desgaste prévio com um IADR (exceto os grupos T2A e T2B).

Depreende-se que a comparação entre os resultados obtidos por diferentes autores é crítica. Há significativa variação no modo de preparo dos corpos de prova. Há também diferenças significativas na composição das cerâmicas, o que torna precária a tentativa de generalizar resultados de um material para outro. $\mathrm{O}$ método quantitativo de aferição da rugosidade também é feito de modo não padronizado, na maioria das vezes sem justificativas ou menção à fatores como o comprimento de amostragem ou parâmetros selecionados. Os resultados observados na MEV também têm valor subjetivo a título de comparações, na medida em que é grande a variação de ampliações utilizadas (100x, 500x, 1000x, 5000x). Portanto, uma comparação segura entre resultados fica restrita aos trabalhos que seguem um protocolo semelhante e valendo-se das mesmas cerâmicas. 


\section{CONCLUSÕES}

Realizada a análise quantitativa dos corpos de prova com o rugosímetro e qualitativa com MEV verificou-se que:

- Houve uma atenuação acentuada na rugosidade superficial dos corpos de prova que foram submetidos ao desgaste com instrumento diamantado e depois polidos. O polimento resultou em lisura superior à obtida com o "glaze". O desgaste com instrumento diamantado determinou o pior quadro quanto à lisura de superfície.

- Na análise quantitativa, houve diferenças entre a rugosidade de superfície dos dois materiais cerâmicos em função do tratamento realizado e do parâmetro de rugosidade avaliado. Os parâmetros $\mathrm{Ra}$ e $\mathrm{Rp}$ apontaram menor rugosidade da cerâmica Duceragold na maioria dos tratamentos avaliados. O parâmetro Rz foi menos sensível para identificar diferenças entre os dois materiais. O parâmetro Rz não identificou diferenças entre as duas cerâmicas em cinco dos seis tratamentos realizados. A análise qualitativa não identificou diferenças entre as duas cerâmicas.

- Não houve correlação entre os resultados obtidos através do método quantitativo (rugosímetro) e qualitativo (MEV). Os achados ao MEV e ao rugosímetro foram coincidentes apenas na determinação de que o desgaste com o IADR representou a pior situação quanto à rugosidade de superfície. A análise quantitativa propiciou distinguir diferenças entre tratamentos e entre as cerâmicas que não foram observadas através da MEV.

- A análise estatística da correlação entre os diferentes parâmetros de rugosidade variou entre forte, média e fraca. Não foi observada uma correlação perfeita, o que explica as variações de resultados entre os parâmetros. A avaliação 
isolada do parâmetro Ra deve ser evitada, especialmente quando o objetivo é definir o potencial de desgaste que uma superfície apresenta. Rp e o coeficiente $R p / R z$ são úteis para determinar, dentro do perfil da superfície, a existência e magnitude de protusões.

- As seqüências, materiais e instrumentos empregados nas diferentes técnicas de polimento avaliadas foram efetivos para atenuar a rugosidade superficial após desgaste, e promoveram lisura de superfície superior à observada após o "glaze". Dentre os avaliados, o polimento com as borrachas EXACERAPOL foi a técnica que propiciou a menor rugosidade superficial. 


\section{REFERÊNCIAS ${ }^{1}$}

Agostinho OL, Rodrigues ACS, Lirani J. Tolerâncias, ajustes, desvios e análise de dimensões. Curitiba: Edgard Blücher; 1977.

Agra CM, Vieira GF. Quantitative analysis of dental porcelain surfaces following different treatments: correlation between parameters obtained by a surface profiling instrument. Dent Mater J 2002;221(1):44-52.

Albakry M, Guazzato, M, Swain MV. Effect of sandblasting, grinding, polishing and glazing on the flexural strength of two pressable all-ceramic dental materials.J Dent 2004;32(2):91-9.

Al-Hiyasat AS, Saunders WP, Sharkey SW, Smith GM, Gilmour WH. The abrasive effect of glazed, unglazed, and polished porcelain on the wear of human enamel, and the influence of carbonated soft drinks on the rate of wear. Int J Prosthodont 1997;10(3):269-82.

al-Wahadni A, Martin DM. Glazing and finishing dental porcelain: a literature review. J Can Dent Assoc 1998;64(8):580-3.

Ancowitz S, Torres T, Rostami H. Texturing and polishing. The final attempt at value control. Clin North Am 1998;42(4):607-12.

Anil N, Bolay S. Effect of toothbrushing on the material loss, roughness, and color of intrinsically and extrinsically stained porcelain used in metal-ceramic restorations: an in vitro study. Int J Prosthodont 2002;15(5):483-7.

Anusavice KJ. Degradability of dental ceramics. Adv Dent Res 1992;(6):82-9.

Associação Brasileira de Normas Técnicas. Rugosidade das superfícies: procedimentos. NBR 6405. 1988

\footnotetext{
${ }^{1}$ De acordo com Estilo Vancouver. Abreviatura de periódicos segundo base de dados MEDLINE.
} 
Attia A, Kern M. Fracture strength of all-ceramic crowns luted using two bonding methods. J Prosth Dent 2004;91(3):247-52.

Bessing C, Wiktorson A. Comparison of two different methods of polishing porcelain. Scandinavian Journal of Dental Research 1983;(91):482-7.

Bhamra G, Palin WM, Fleming GJP. The effect of surface roughness on the flexure strength of an alumina reinforced all-ceramic crown material J Dent 2002;30(4):15360

Brewer JD, Garlapo DA, Chipps EA, Tedesco LA. Clinical discrimination between autoglazed and polished porcelain surfaces. J Prosthet Dent 1990;64(6):631-4.

Burke FJT, Qualtrough AJE, Hale RW. The dentine bonded ceramic crown: an ideal restoration? Br Dent J 1995;(179):5863.

Burke FJT, Qualtrough AJE, Wilson NHF. A retrospective evaluation of a series of dentin-bonded ceramic crowns. Quintessence Int 1998;29(2):103-6.

Burke FJT, Watts DC. Fracture resistance of teeth restored with dentine-bonded crowns. Quintessence Int 1994;(25):335-40.

Butler CJ, Masri R, Driscoll CF, Thompson GA, Runyan DA, von Fraunhofer AJ. Effect of fluoride and $10 \%$ carbamide peroxide on the surface roughness of lowfusing and ultra low-fusing porcelain. J Prosthet Dent 2004;92(2):179-83.

Campbell SD. Evaluation of surface roughness and polishing techniques for new ceramic materials. J Prosthet Dent 1989;61(5):563-8.

Carpinnetti LCR. Rugosidade superficial: conceitos e princípios de medição. São Carlos: Seção de Publicações da EESC-USP; 1996.

Chen HY, Hickel R, Setcos JC, Kunzelmann KH. Effects of surface finish and fatigue testing on the fracture strength of CAD-CAM and pressed-ceramic crowns. J Prosthet Dent 1999;82(4):468-75.

Chiaverini V. Tecnologia Mecânica - processos de fabricação e tratamento. $2^{\mathrm{a}}$ ed. São Paulo: McGraw-Hill; 1995. 3v. 
Chu FC, Frankel N, Smales RJ. Surface roughness and flexural strength of selfglazed, polished, and reglazed In-Ceram/Vitadur Alpha porcelain laminates. Int J Prosthodont 2000;13(1):66-71.

Claus $\mathrm{H}$, Rauter $\mathrm{H}$. The structure and microstructure of dental porcelain in relation to the firing conditions. Int J Prosthodont 1989;(2):376-84.

Clelland NL, Agarwala V, Knobloch LA, Seghi RR. Relative wear of enamel opposing low-fusing dental porcelain. J Prosthodont 2003;12(3):168-75.

Correr Sobrinho L, Santos PH, Consani S, Spohr AM, Almeida MAB. Evaluation of Vickers hardness and roughness of the polished and glazed ceramic. In: IADR/AADR/CADR 80th General Session. March 6-9,2002. Res.1187.

Crinaldi AJ, Denry LL, Rosentiel SF. Strengthening of leucite-reinforced porcelain by double ion exchange. J Dent Res 1994;(73):135.

Cronin RJ, Cagna DR. An update on fixed prosthodontics. JADA 1997;(128):425-36.

Culp L. Empress 2. First year clinical results. J Dent Technol 1999;16(2):12-5.

Dalpino $\mathrm{PH}$, Francischone $\mathrm{CE}$, Ishikiriama A, Franco EB. Fracture resistance of teeth directly and indirectly restored with composite resin and indirectly restored with ceramic materials. Am J Dent 2002;15(6):389-94.

de Jager N, Feilzer AJ, Davidson CL. The influence of surface roughness on porcelain strength. Dent Mater 2000;16(6):381-8.

DeLong R, Sasik C, Pintado MR, Douglas WH. The wear of enamel when opposed by ceramic systems. Dent Mater 1989;5(4):266-71.

Denry IL. Recent advances in ceramics for dentistry. Crit Ver Oral Biol Med 1996; 8(2):134-43.

Dietschi D, Maeder M, Meyer J, Holz J. In vitro resistance to fracture of porcelain inlays bonded to tooth. Quintessence Int 1990;21(10):823-31.

Driscoll CF, Romberg E, Thompson GA, Runyan DA. Comparison of three porcelain polishing kits for ultra-low fusing dental porcelain. In:IADR/AADR/CADR 80th General Session. March 6-9, 2002. Res.3832 
Edelhoff $D$, Sorensen JA. Tooth structure removal associated with various preparation designs for anterior teeth. J Prosth Dent 2002; 87(5):503-9.

Edge MJ, Wagner WC. Surface cracking identified in polished and self-glazed dental porcelain. J Prosthodont. 1994;3(3):130-3.

Ekfeldt A, Fransson B, Söderlund B, Oilo G. Wear resistance of some prosthodontic materials in vivo. Acta Odontol Scand 1993; 51(2):99-107.

Ekfeldt A, Oilo G. Occlusal contact wear of prosthodontic materials. An in vivo study. Acta Odontol Scand 1988; 46(3):159-69.

Ekfeldt A, Oilo G. Wear of prosthodontic materials--an in vivo study. J Oral Rehabil 1990;17(2):117-29.

Ekfeldt A. Incisal and occlusal tooth wear and wear of some prosthodontic materials. An epidemiological and clinical study. Swed Dent J Suppl 1989;(65):1-62.

Estafan D, David A, David S, Calamia J. A new approach to restorative dentistry: fabricating ceramic restorations using CEREC CAD/CAM. Compend Contin Educ Dent 1999; 20(6):555-60.

Eustaquio R, Garner LD, Moore BK. Comparative tensile strengths of brackets bonded to porcelain with orthodontic adhesive and porcelain repair systems. Am J Orthod Dentofacial Orthop 1988;94(5):421-5.

Fairhurst CW, Lockwood PE, Ringle RD, Thompson WO. The effect of "glaze" on porcelain strength. Dent Mater 1992; 8(3):203-7.

Ferraresi, D. Usinagem dos Metais. Volume I - Fundamentos da Usinagem dos Metais. $1^{\mathrm{a}}$ ed.Curituba: Edgard Blücher; 1977.

Finger WJ, Noack MD Postadjustment polishing of CAD-CAM ceramic with luminescence diamond gel. Am J Dent 2000;13(1):8-12.

Fischer $\mathrm{H}$, Schafer M, Marx R. Effect of surface roughness on flexural strength of veneer ceramics. J Dent Res 2003;82(12):972-5.

Folwaczny M, Mehl A, Haffner C, Hickel R. Polishing and coating of dental ceramic materials with $308 \mathrm{~nm} \mathrm{XeCl} \mathrm{excimer} \mathrm{laser} \mathrm{radiation.} \mathrm{Dent} \mathrm{Mater} \mathrm{1998;14(3):186-93.}$ 
Fradeani M. The application of all-ceramic restorations in the anterior and posterior regions. Pract Proced Aesthet Dent 2003;Suppl:13-7.

Fuzzi M, Zaccheroni Z, Vallania G. Scanning electron microscopy and profilometer evaluation of glazed and polished dental porcelain. Int J Prosthodont 1996; 9(5):4528.

Geurtsen W, Garcia-Godoy F. Bonded restorations for the prevention and treatment of the cracked-tooth syndrome. Am J Dent 1999;12(6):266-70.

Giordano R, Campbell S, Pober R. Flexural strength of feldspathic porcelain treated with ion exchange, over"glaze", and polishing. J Prosthet Dent 1994;71(5):468-72.

Giordano R, Cima M, Pober R. Effect of surface finish on the flexural strength of feldspathic and aluminous dental ceramics. Int J Prosthodont 1995;8(4):311-9.

Glavina D, Skrinjaric I, Mahovic S, Majstorovic M. Surface quality of Cerec CAD/CAM ceramic veneers treated with four different polishing systems. Eur J Paediatr Dent 2004;5(1):30-4.

Goldstein GR, Barnhard BR, Penugonda B. Profilometer, SEM, and visual assessment of porcelain polishing methods. J Prosthet Dent 1991;65(5):627-34.

Gorucu J, Ozgunaltay G. Fracture resistance of teeth with Class II bonded amalgam and new tooth-colored restorations. Oper Dent. 2003;28(5):501-7.

Griggs JA, Thompson JY, Anusavice KJ. Effects of flaw size and auto-glaze treatment on porcelain strength. Journal of Dental Research 1996;(75):1414-7

Gürgan S, Bolay S, Alaçam R. In vitro adherence of bacteria to bleached or unbleached enamel surfaces. J Oral Rehabil 1997;24(8):624-7.

Hacker $\mathrm{CH}$, Wagner WC, Razzoog ME. An in vitro investigation of the wear of enamel on porcelain and gold and saliva. J Prosthet Dent 1996;75(1):14-7.

Hammad IA, Khalil AM. The effect of fluoride treatments on glazed and polished ceramic surfaces. Egypt Dent J 1994;40(3):757-64.

Haywood VB, Heymann HO, Scurria MS. Effects of water, speed, and experimental instrumentation on finishing and polishing porcelain intra-orally. Dent Mater 1989;5(3):15-8. 
Hulterström AK, Bergman M. Polishing systems for dental ceramics. Acta Odontol Scand 1993;51(4):229-34.

Jacobi R, Shillingburg HT JR, Duncanson MG JR. A comparison of the abrasiveness of six ceramic surfaces and gold. J Prosthet Dent 1991;66(3):303-9.

Jagger DC, Harrison A. An in vitro investigation into the wear effects of unglazed, glazed, and polished porcelain on human enamel. J Prosthet Dent 1994;72(3):320-3.

Jensen ME, Sheth JJ, Tolliver D. Etched-porcelain resin-bonded full-veneer crowns: in vitro fracture resistance. Compend Contin Educ 1989;(10):336-47.

Jung M. Finishing and polishing of a hybrid composite and a heat-pressed glass ceramic. Oper Dent 2002;27(2):175-83.

Kao EC, Boltz KC, Johnston WM. Direct bonding of orthodontic brackets to porcelain veneer laminates. Am J Orthod Dentofacial Orthop 1988;94(6):458-68.

Kawai K, Urano M, Ebisu S. Effect of surface roughness of porcelain on adhesion of bacteria and their synthesizing glucans. J Prosthet Dent 2000;83(6):664-7

Kelly JR, Nishimura I, Campbell SD. Ceramics in dentistry: historical roots and current perspectives. J Prosthet Dent 1996;75(1):18-32.

Kim IJ, Lee YK, Lim BS, Kim CW. Effect of surface topography on the color of dental porcelain. J Mater Sci Mater Med 2003;14(5):405-9.

Kitazaki $\mathrm{H}$, Takahashi $\mathrm{H}$, Hasegawa S, Nishimura F. Effect of amount of grinding on flexural strength of dental ceramics. J Med Dent Sci. 2001;48(1):7-13.

Komma O. Hydrothermal dental ceramic systems. Technical report. Rosbach, Germany, Ducera Dental Company, 1993.

Krejci I, Lutz F, Reimer M, Heinzmann JL. Wear of ceramic inlays, their enamel antagonists, and luting cements. J Prosthet Dent 1993;69(4):425-30.

Krejci I, Lutz F, Reimer M. Wear of CAD/CAM ceramic inlays: restorations, opposing cusps, and luting cements. Quintessence Int 1994;25(3):199-207. 
Lang H, Rampado M, Mullejans R, Raab WH. Determination of the dynamics of restored teeth by $3 \mathrm{D}$ electronic speckle pattern interferometry. Lasers Surg Med 2004;34(4):300-9.

Larsen-Basse J. Abrasive wear of ceramics. In: Jahanmir S., Friction and wear of ceramics. New York: Marcel Dekker; 1994.

Lee SY, Lai YL, Morgano SM. Effects of ultrasonic scaling and periodontal curettage on surface roughness of porcelain. J Prosthet Dent 1995;73(3):227-32.

Leitão J, Hegdahl T. On measuring of roughness. Acta Odontol Scand $1981 ;(39): 379-84$.

Lopes LMP, Leitão J, Douglas WH. Effect of a new resin inlay/onlay restorative material on cuspal reinforcement. Quintessence Int 1991;22(8):641-5.

Mackert JR Jr, Williams AL. Microcracks in dental porcelain and their behavior during multiple firing. J Dent Res 1996;75(7):1484-90.

Mackert JR Jr, Evans AL. Effect of cooling rate on leucite volume fraction in dental poncelains. J Dent Res 1991;(70):137-9.

Magne P, Belser U. Restaurações Adesivas de Porcelana na Dentição Anterior. São Paulo: Quintessence; 2003.

Magne P, Douglas WH. Porcelain veneers: dentin bonding optimization and biomimetic recovery of the crown. Int J Prosthodont 1999;(12):111-21.

Magne P, Oh WS, Pintado MR, DeLong R. Wear of enamel and veneering ceramics after laboratory and chairside finishing procedures. J Prosthet Dent 1999;82(6):66979.

Martinez-Gomis J, Bizar J, Anglada JM, Samso J, Peraire M. Comparative evaluation of four finishing systems on one ceramic surface. Int J Prosthodont 2003;16(1):74-7.

Mateos AG. Tolerâncias e Ajustes. São Paulo: Polígono; 1974.

McLean JW. Ceramics in dentistry. Br Dent J 1988;(164):187.

Meier B, Komma O, Kempf B, Weppler M, Frankfurt M. A New Metal-Ceramic System: Some Aspects of Materials Technology. 1993. Disponível em URL: 
http://www.goldengate-

system.de/Zahntechniker/Downloads/Pdf/Literatur/LaborMaterialtestSonderdruckDTS .pdf . [2004 Nov. 10]

Metzler KT, Woody RD, Miller AW 3RD, Miller BH. In vitro investigation of the wear of human enamel by dental porcelain. J Prosthet Dent 1999;81(3):356-64.

Nakazato T, Takahashi H, Yamamoto M, Nishimura F, Kurosaki N. Effect of polishing on cyclic fatigue strength of CAD/CAM ceramics. Dent Mater J 1999;18(4):395-402.

Palin WM, Fleming GJ, Marquis PM. An evaluation of the mechanical properties of 'hydrothermal' dental glass after water immersion and surface polishing. Dent Mater 2003;19(2):92-100.

Pallis K, Griggs JA, Woody RD, Guillen GE, Miller AW. Fracture resistance of three all-ceramic restorative systems for posterior applications. J Prosthet Dent 2004;91(6):561-9.

Patterson CJ, McLundie AC, Stirrups DR, Taylor WG. Efficacy of a porcelain refinishing system in restoring surface finish after grinding with fine and extra-fine diamond burs. J Prosthet Dent 1992;68(3):402-6.

Patterson CJ, McLundie AC, Stirrups DR, Taylor WG. Refinishing of porcelain by using a refinishing kit. J Prosthet Dent 1991; 65(3):383-8.

Piddock V, Qualtrough AJE. Dental ceramics - an update. J Dent 1990;(18):227-35.

Pober R, Giordano R. In-Vitro Wear Of Restorative Dental Materials In: IADR/AADR/CADR 80th General Session. March 6-9, 2002. Res. 1693

Proos KA, Swain MV, Ironside J, Steven GP. Influence of cement on a restored crown of a first premolar using finite element analysis. Int $\mathrm{J}$ Prosthodont 2003;16(1):82-90.

Qualtrough AJE, Piddock V. Ceramics update. J.Dent. 1997;25(2):91-5.

Raimondo RL JR, Richardson JT, Wiedner B. Polished versus autoglazed dental porcelain. J Prosthet Dent 1990; 64(5):3-7.

Ramfjord SP, Ash MM. Occlusion, $2^{\text {a }}$ ed. Philadelphia: W.B.Saunders Co.; 1971. 
Ramp MH, Suzuki S, Cox CF, Lacefield WR, Koth DL. Evaluation of wear: enamel opposing three ceramic materials and a gold alloy. J Prosthet Dent 1997;77(5):52330.

Ratledge DK, Smith BG, Wilson RF. The effect of restorative materials on the wear of human enamel. J Prosthet Dent 1994;72(2):194-203.

Richter KH, Blencke B, Deutscher KK, Brömer H. Surface nature of implant material and its effect on the profileration of cells in culture. In: Winter GD, Leray JL, de Groot K. Evaluation of Biomaterials. New York: John Wiley \& Sons; 1980.

Rosenblum MA, Schulman A. A review of all-ceramic restorations. J Am Dent Assoc 1997;128(3):297-307

Rosenstiel SF, Baiker MA, Johnston WM. Comparison of glazed and polished dental porcelain. Int J Prosthodont 1989;2(6):524-9.

Roulet JF, Herder S. Bonded Ceramic Inlays. Chicago: Quintessence Publishing Co.; 1991.

Rykke M. Dental materials for posterior restorations. Endod Dent Traumatol 1992;8(4):139-48.

Salthouse TN, Matlaga RF. Effects of implant surface on cellular activity and evaluation of histocompatibility. In: Winter GD, Leray JL de Groot K. Evaluation of Biomaterials. New York: John Wiley \& Sons; 1980.

Schmidlin PR, Gohring TN. Finishing tooth-colored restorations in vitro: an index of surface alteration and finish-line destruction. Oper Dent 2004;29(1):80-6.

Scurria MS, Powers JM. Surface roughness of two polished ceramic materials. J Prosthet Dent 1994;71(2):174-7.

Seghi RR, Rosenstiel SF, Bauer P. Abrasion of human enamel by different dental ceramics in vitro. J Dent Res 1991;70(3):221-5.

Shearer AC, Kusy RP, Whitley JQ, Heymann HO, Wilson NH. Finishing of MGC Dicor material. Int J Prosthodont 1994;7(2):167-73. 
Shor A, Nicholls JI, Phillips KM, Libman WJ. Fatigue load of teeth restored with bonded direct composite and indirect ceramic inlays in MOD class II cavity preparations. Int J Prosthodont 2003;16(1):64-9.

Smales RJ, Etemadi S. Survival of ceramic onlays placed with and without metal reinforcement. J Prosthet Dent 2004;91(6): 548-53.

Stewart GP, Jain P, Hodges J. Shear bond strength of resin cements to both ceramic and dentin. J Prosthet Dent 2002;88(3):277-84.

Ubassy G. Shape and Color. The key to successful Ceramic Restorations. Chicago: Quintessence Publishing; 1993.

Van Noort R. Introduction to Dental Materials, 2a ed. Londres: Mosby; 2002.

Vermilyea SG, Prasanna MK, Agar JR. Effect of ultrasonic cleaning and air polishing on porcelain labial margin restorations. J Prosthet Dent 1994; 71(5):447-52.

Vieira GF, Ferreira ATM, Garofalo JC, Agra CM. Restaurações estéticas indiretas em dentes posteriores Inlay/Onlay. São Paulo: Santos; 1995.

Vieira GF, Agra CM. Atlas de Facetas Laminadas. São Paulo: Santos; 1998.

Vieira GF, Agra CM. Influência da textura de superfície na cor. Estética Contemporânea 1999;1(1):45-50.

Vieira GF, De Caroli A, Amorim JC, Matson E. The influence of the surface treatment and saliva on the color of two porcelains. Dent Mater J 2001;20(2):127-34.

Wang YN, Wen GJ, Shi B, Pan XH. Adhesion of oral microorganisms on dental porcelain polished and glazed. Zhonghua Kou Qiang Yi Xue Za Zhi. 2003;38(5):3424.

Ward MT, Tate WH, Powers JM. Surface roughness of opalescent porcelains after polishing. Oper Dent 1995;20(3):106-10.

Wardak D, Wirz J, Schmidli F. The influence of different polishing systems on dental veneering materials. Schweiz Monatsschr Zahnmed 2001;111(3):282-91.

Whitehead AS, Shearer AC, Watts DC, Wilson NH. Comparison of methods for measuring surface roughness of ceramic. J Oral Rehabil 1995;22(6):421-7. 
Williamson RT, Kovarik RE, Mitchell RJ. Effects of grinding, polishing, and overglazing on the flexure strength of a high-leucite feldspathic porcelain. Int $\mathrm{J}$ Prosthodont 1996;9(1):30-7.

Wilson NHF. The evaluation of materials: relationships between laboratory investigations and clinical studies. Oper Dent 1990;(15):149-55.

Winchester L. Direct orthodontic bonding to porcelain: an in vitro study. $\mathrm{Br} \mathrm{J}$ Orthod 1991;18(4):299-308.

Wright MD, Masri R, Driscoll CF, Romberg E, Thompson GA, Runyan DA. Comparison of three systems for the polishing of an ultra-low fusing dental porcelain. J Prosthet Dent 2004;92(5):486-90.

Yamamoto M, Miyoshi Y, Kataoka S. Fundamentals of esthetics: contouring techniques for metal ceramic restorations. QDT 1990/1991;(14):10-81.

Yamamoto M. Metal-Ceramics: principles and methods of Makoto Yamamoto. Chicago: Quintessence Publishing Co.; 1985.

Zanetti JJ. Mecânica Geral - acabamento superficial. CFP SENAI Artes Gráficas, 1994, p.35-67.

Zhang Y, Griggs JA, Benham AW. Influence of powder/liquid mixing ratio on porosity and translucency of dental porcelains. J Prosthet Dent 2004;91(2):128-35. 
APÊNDICE A - Valores apurados com o rugosímetro (mícron).

\begin{tabular}{|c|c|c|c|c|c|c|c|c|c|c|c|c|c|c|}
\hline & $\mathbf{R a}$ & Rz & $\mathbf{R p}$ & Rp/Rz & & $\mathbf{R a}$ & Rz & $\mathrm{Rp}$ & Rp/Rz & & $\mathbf{R a}$ & Rz & $\mathrm{Rp}$ & Rp/Rz \\
\hline T1A & 1,11 & 4,74 & 2,15 & 0,45 & T1B & 1,11 & 3,38 & 1,62 & 0,48 & T2A & 1,27 & 3,71 & 1,72 & 0,46 \\
\hline$\Gamma 1 \mathrm{~A}$ & 1,13 & 4,52 & 2,49 & 0,55 & T1B & 1,29 & 4,13 & 1,94 & 0,47 & T2A & 1,55 & 4,90 & 2,13 & 0,43 \\
\hline $11 \mathrm{~A}$ & 1,63 & 5,89 & 2,97 & 0,50 & T1B & 1,60 & 4,27 & 2,16 & 0,51 & T2A & 1,01 & 3,50 & 1,58 & 0,45 \\
\hline T1A & 0,95 & 4,41 & 1,82 & 0,41 & T1B & 1,19 & 4,89 & 2,39 & 0,49 & T2A & 1,05 & 3,13 & 1,66 & 0,53 \\
\hline T1A & 1,13 & 5,52 & 2,48 & 0,45 & T1B & 0,86 & 3,20 & 1,70 & 0,53 & T2A & 0,89 & 3,41 & 1,45 & 0,43 \\
\hline T1A & 1,10 & 5,05 & 2,48 & 0,49 & T1B & 0,95 & 3,63 & 1,81 & 0,50 & T2A & 0,88 & 3,02 & 1,27 & 0,42 \\
\hline $1 \mathrm{~A}$ & 1,10 & 6,15 & 2,69 & 0,44 & T1B & 1,16 & 3,66 & 1,77 & 0,48 & T2A & 1,06 & 3,89 & 1,86 & 0,48 \\
\hline $1 \mathrm{~A}$ & 1,03 & 4,67 & 2,66 & 0,57 & T1B & 0,93 & 2,74 & 1,22 & 0,45 & T2A & 0,91 & 4,26 & 2,03 & 0,48 \\
\hline T1A & 1,15 & 5,14 & 2,41 & 0,47 & T1B & 1,03 & 3,59 & 1,66 & 0,46 & T2A & 0,71 & 2,54 & 1,16 & 0,46 \\
\hline T1A & 1,14 & 5,47 & 2,50 & 0,46 & T1B & 1,09 & 3,49 & 1,52 & 0,44 & T2A & 0,90 & 4,16 & 1,80 & 0,43 \\
\hline $1 \mathrm{~A}$ & 1,41 & 9,84 & 3,22 & 0,33 & T1B & 0,89 & 2,91 & 1,39 & 0,48 & T2A & 0,75 & 3,42 & 1,87 & 0,55 \\
\hline $1 \mathrm{~A}$ & 1,19 & 6,24 & 2,72 & 0,44 & T1B & 1,07 & 4,41 & 2,46 & 0,56 & T2A & 1,36 & 8,62 & 2,22 & 0,26 \\
\hline $1 \mathrm{~A}$ & 0,98 & 5,67 & 2,18 & 0,38 & T1B & 1,02 & 3,82 & 1,94 & 0,51 & T2A & 1,20 & 3,9 & 1,80 & 0,45 \\
\hline T1A & 0,84 & 5,32 & 2,35 & 0,44 & T1B & 0,90 & 2,90 & 1,54 & 0,53 & T2A & 1,09 & 4,47 & 2,38 & 0,53 \\
\hline $\mathrm{T} 1 \mathrm{~A}$ & 1,00 & 5,47 & 2,29 & 0,42 & T1B & 0,92 & 3,25 & 1,93 & 0,59 & T2A & 0,99 & 3,76 & 1,83 & 0,49 \\
\hline T1A & 0,98 & 4,71 & 2,08 & 0,44 & T1B & 1,05 & 4,28 & 2,12 & 0,50 & T2A & 0,73 & 3,69 & 1,92 & 0,52 \\
\hline T1A & 1,16 & 4,95 & 2,56 & 0,52 & T1B & 1,07 & 4,23 & 2,13 & 0,50 & T2A & 0,80 & 2,81 & 1,52 & 0,54 \\
\hline T1A & 1,73 & 5,35 & 3,28 & 0,61 & T1B & 0,99 & 3,22 & 1,68 & 0,52 & T2A & 1,11 & 3,62 & 1,51 & 0,42 \\
\hline T1A & 1,60 & 5,51 & 3,36 & 0,61 & T1B & 1,56 & 6,30 & 3,32 & 0,53 & T2A & 1,34 & 5,00 & 2,35 & 0,47 \\
\hline T1A & 1,64 & 5,35 & 3,27 & 0,61 & T1B & 1,69 & 6,57 & 3,06 & 0,47 & T2A & 1,33 & 4,57 & 2,21 & 0,48 \\
\hline T1A & 1,67 & 4,51 & 2,03 & 0,45 & T1B & 1,49 & 5,73 & 3,01 & 0,53 & T2A & 1,21 & 5,36 & 2,57 & 0,48 \\
\hline $\mathrm{T} 1 \mathrm{~A}$ & 1,44 & 6,60 & 3,76 & 0,57 & T1B & 1,39 & 7,92 & 4,22 & 0,53 & T2A & 0,87 & & 1,73 & 0,42 \\
\hline T1A & 1,57 & 5,65 & 2,88 & 0,51 & T1B & 2,15 & 10,21 & 4,56 & 0,45 & T2A & 0,97 & 4,10 & 1,90 & 0,46 \\
\hline T1A & 1,76 & 5,48 & 2,81 & 0,51 & T1B & 1,52 & 4,31 & 1,85 & 0,43 & T2A & 0,96 & 4,40 & 1,73 & 0,39 \\
\hline T1A & 1,77 & 5,67 & 2,38 & 0,42 & T1B & 1,48 & 5,28 & 3,21 & 0,61 & T2A & 1,24 & 5,73 & 2,40 & 0,42 \\
\hline T1A & 1,13 & 4,37 & 2,67 & 0,61 & T1B & 2,14 & 8,20 & 3,89 & 0,47 & T2A & 1,14 & 3,63 & 1,55 & 0,43 \\
\hline T1A & 1,51 & 5,34 & 2,63 & 0,49 & T1B & 1,97 & 11,18 & 3,98 & 0,36 & T2A & 1,38 & & & 0,41 \\
\hline T1A & 1,09 & 4,27 & 2,56 & 0,60 & T1B & 1,87 & 6,05 & 2,83 & 0,47 & T2A & 0,93 & 3,96 & 1,52 & 0,38 \\
\hline T1A & 1,16 & 4,31 & 2,23 & 0,52 & T1B & 1,71 & 5,78 & 2,47 & 0,43 & T2A & 1,34 & 6,40 & 2,81 & 0,44 \\
\hline $\mathrm{T} 1 \mathrm{~A}$ & 1,11 & 3,96 & 2,23 & 0,56 & T1B & 1,63 & 7,02 & 3,80 & 0,54 & T2A & 1,46 & 5,41 & 2,62 & 0,48 \\
\hline T1A & 1,15 & 4,27 & 2,52 & 0,59 & T1B & 1,64 & 6,16 & 2,91 & 0,47 & T2A & 1,19 & 5,33 & 2,51 & 0,47 \\
\hline T1A & 1,10 & 3,42 & 1,91 & 0,56 & T1B & 1,44 & 6,05 & 2,86 & 0,47 & T2A & 1,26 & 4,46 & 2,45 & 0,55 \\
\hline T1A & 1,51 & 5,63 & 3,08 & 0,55 & T1B & 1,43 & 5,96 & 3,02 & 0,51 & T2A & 1,14 & 3,79 & 1,74 & 0,46 \\
\hline $\mathrm{T} 1 \mathrm{~A}$ & 1,11 & 3,88 & 2,16 & 0,56 & T1B & 1,46 & 5,86 & 3,09 & 0,53 & T2A & 0,97 & 3,58 & 1,46 & 0,41 \\
\hline $\mathrm{T} 1 \mathrm{~A}$ & 0,97 & 5,26 & 2,69 & 0,51 & T1B & 1,54 & 5,26 & 2,92 & 0,56 & T2A & 0,90 & 2,92 & 1,22 & 0,42 \\
\hline T1A & 0,91 & 3,85 & 1,85 & 0,48 & T1B & 1,56 & 6,69 & 3,86 & 0,58 & T2A & 1,14 & 4,43 & 2,41 & 0,54 \\
\hline T1A & 0,76 & 3,63 & 1,59 & 0,44 & T1B & 1,69 & 5,63 & 2,85 & 0,51 & T2A & 0,87 & 3,84 & 1,68 & 0,44 \\
\hline $1 \mathrm{~A}$ & 1,39 & 4,81 & 2,54 & 0,53 & T1B & 1,21 & 4,92 & 2,69 & 0,55 & T2A & 1,22 & 4,56 & 2,48 & 0,54 \\
\hline $1 \mathrm{~A}$ & 1,15 & 5,43 & 3,09 & 0,57 & T1B & 1,79 & 3,82 & 1,96 & 0,51 & T2A & 0,96 & 4,53 & 2,45 & 0,54 \\
\hline
\end{tabular}


continuação

\begin{tabular}{|c|c|c|c|c|c|c|c|c|c|c|c|c|c|c|}
\hline & $\mathbf{R a}$ & Rz & $\mathrm{Rp}$ & Rp/Rz & & $\mathbf{R a}$ & Rz & $R p$ & Rp/Rz & & $\mathbf{R a}$ & Rz & $R p$ & Rp/Rz \\
\hline T1A & 1,11 & 4,67 & 2,27 & 0,49 & T1B & 1,41 & 4,22 & 2,16 & 0,51 & T2A & 0,94 & 4,70 & 2,03 & 0,43 \\
\hline$\Gamma 1 \mathrm{~A}$ & 0,87 & 4,21 & 1,89 & 0,45 & T1B & 1,55 & 5,49 & 3,03 & 0,55 & T2A & 1,46 & 6,58 & 2,27 & 0,34 \\
\hline $1 \mathrm{~A}$ & 1,17 & 5,42 & 2,40 & 0,44 & T1B & 1,93 & 7,39 & 3,48 & 0,47 & T2A & 1,48 & 4,64 & 2,45 & 0,53 \\
\hline $1 \mathrm{~A}$ & 1,11 & 4,49 & 1,81 & 0,40 & T1B & 1,71 & 5,75 & 3,37 & 0,59 & T2A & 1,74 & 5,48 & 2,95 & 0,54 \\
\hline $1 \mathrm{~A}$ & 1,21 & 4,93 & 2,26 & 0,46 & T1B & 1,37 & 5,66 & 2,77 & 0,49 & T2A & 1,48 & 4,35 & 2,39 & 0,55 \\
\hline $1 \mathrm{~A}$ & 1,16 & 4,98 & 2,38 & 0,48 & T1B & 1,32 & 5,71 & 2,46 & 0,43 & T2A & 1,36 & 5,77 & 2,74 & 0,47 \\
\hline $1 \mathrm{~A}$ & 1,13 & 4,47 & 2,13 & 0,48 & T1B & 1,06 & 4,66 & 2,16 & 0,46 & T2A & 0,98 & 4,21 & 2,43 & 0,58 \\
\hline T1A & 1,36 & 5,10 & 2,83 & 0,55 & T1B & 1,50 & 6,77 & 2,79 & 0,41 & T2A & 1,33 & 5,79 & 2,56 & 0,44 \\
\hline $1 \mathrm{~A}$ & 1,73 & 6,05 & 2,77 & 0,46 & T1B & 1,12 & 5,53 & 2,80 & 0,51 & T2A & 0,88 & 3,35 & 1,54 & 0,46 \\
\hline $1 \mathrm{~A}$ & 0,80 & 3,41 & 1,93 & 0,57 & T1B & 1,43 & 5,90 & 3,00 & 0,51 & T2A & 1,14 & 5,34 & 2,06 & 0,39 \\
\hline $1 \mathrm{~A}$ & 1,80 & 7,89 & 4,38 & 0,56 & T1B & 1,27 & 5,69 & 2,46 & 0,43 & T2A & 1,64 & 7,10 & 3,56 & 0,50 \\
\hline T1A & 1,18 & 5,91 & 2,18 & 0,37 & T1B & 1,40 & 5,33 & 2,72 & 0,51 & T2A & 1,10 & 5,18 & 1,86 & 0,36 \\
\hline $1 \mathrm{~A}$ & 1,57 & 5,30 & 2,60 & 0,49 & T1B & 1,43 & 6,35 & 3,63 & 0,57 & T2A & 0,98 & 4,43 & 1,81 & 0,41 \\
\hline $1 \mathrm{~A}$ & 1,52 & 5,43 & 2,36 & 0,43 & T1B & 1,63 & 6,35 & 2,82 & 0,44 & T2A & 1,18 & 4,28 & 2,02 & 0,47 \\
\hline $1 \mathrm{~A}$ & 1,43 & 4,60 & 2,10 & 0,46 & T1B & 1,54 & 5,21 & 2,69 & 0,52 & T2A & 1,12 & 7,84 & 5,01 & 0,64 \\
\hline $1 \mathrm{~A}$ & 1,46 & 4,73 & 2,28 & 0,48 & T1B & 1,63 & 5,61 & 2,58 & 0,46 & T2A & 1,14 & 5,71 & 2,85 & 0,50 \\
\hline T1A & 1,51 & 5,98 & 2,52 & 0,42 & T1B & 1,69 & 7,14 & 3,13 & 0,44 & T2A & 1,05 & 5,42 & 3,01 & 0,56 \\
\hline $1 \mathrm{~A}$ & 1,38 & 5,13 & 2,36 & 0,46 & T1B & 1,11 & 4,66 & 2,29 & 0,49 & T2A & 0,81 & 3,85 & 1,63 & 0,42 \\
\hline $1 \mathrm{~A}$ & 1,12 & 4,75 & 2,09 & 0,44 & T1B & 2,09 & 6,72 & 3,39 & 0,50 & T2A & 0,87 & 5,01 & 2,33 & 0,47 \\
\hline $1 \mathrm{~A}$ & 1,48 & 4,31 & 1,92 & 0,45 & T1B & 1,09 & 5,53 & 2,41 & 0,44 & T2A & 1,00 & 5,48 & 3,10 & 0,57 \\
\hline T1A & 1,54 & 4,70 & 2,22 & 0,47 & T1B & 1,46 & 5,75 & 3,00 & 0,52 & T2A & 1,13 & 4,94 & 2,58 & 0,52 \\
\hline $1 \mathrm{~A}$ & 1,79 & 5,62 & 2,19 & 0,39 & T1B & 1,19 & 4,33 & 2,23 & 0,52 & T2A & 0,98 & 5,70 & 2,72 & 0,48 \\
\hline $1 \mathrm{~A}$ & 1,52 & 4,89 & 2,35 & 0,48 & T1B & 1,18 & 4,33 & 2,20 & 0,51 & T2A & 1,11 & 4,42 & 2,26 & 0,51 \\
\hline $1 \mathrm{~A}$ & 1,54 & 4,86 & 2,32 & 0,48 & T1B & 1,31 & 6,80 & 2,82 & 0,41 & T2A & 0,85 & & & 0,41 \\
\hline $1 \mathrm{~A}$ & 1,15 & 4,68 & 2,42 & 0,52 & T1B & 1,38 & 7,61 & 3,58 & 0,47 & T2A & 0,94 & 5,43 & 2,45 & 0,45 \\
\hline $1 \mathrm{~A}$ & 1,11 & 5,32 & 2,87 & 0,54 & T1B & 1,44 & 6,10 & 2,64 & 0,43 & T2A & 1,21 & 5,50 & 3,21 & 0,58 \\
\hline $1 \mathrm{~A}$ & 1,10 & 4,92 & 2,58 & 0,52 & T1B & 1,10 & 3,03 & 1,51 & 0,50 & T2A & 0,82 & 4,64 & 2,42 & 0,52 \\
\hline $1 \mathrm{~A}$ & 1,08 & 3,91 & 2,22 & 0,57 & T1B & 1,29 & 4,76 & 2,06 & 0,43 & T2A & 1,11 & 5,50 & 3,17 & 0,58 \\
\hline $1 \mathrm{~A}$ & 1,38 & 4,95 & 2,31 & 0,47 & T1B & 1,26 & 4,52 & 2,54 & 0,56 & T2A & 1,04 & 6,86 & 3,29 & 0,48 \\
\hline $1 \mathrm{~A}$ & 1,26 & 4,39 & 2,07 & 0,47 & T1B & 1,40 & 5,78 & 3,18 & 0,55 & T2A & 0,99 & 3,61 & 1,80 & 0,50 \\
\hline $1 \mathrm{~A}$ & 1,09 & 4,61 & 2,36 & 0,51 & T1B & 1,39 & 5,29 & 2,91 & 0,55 & $\mathrm{~T} 2 \mathrm{~A}$ & 0,98 & 4,16 & 2,20 & 0,53 \\
\hline $1 \mathrm{~A}$ & 1,22 & 5,72 & 2,75 & 0,48 & T1B & 1,20 & 5,01 & 2,68 & 0,53 & T2A & 1,15 & 4,81 & 2,81 & 0,58 \\
\hline $1 \mathrm{~A}$ & 1,16 & 5,59 & 2,48 & 0,44 & $\mathrm{~T} 1 \mathrm{~B}$ & & 5,36 & 2,74 & 0,51 & T2A & 1,10 & & & 0,57 \\
\hline $1 \mathrm{~A}$ & 1,12 & 4,09 & 2,26 & 0,55 & T1B & 1,32 & 6,34 & 3,69 & 0,58 & T2A & 0,95 & 3,83 & 2,11 & 0,55 \\
\hline $1 \mathrm{~A}$ & 1,08 & 3,71 & 1,80 & 0,49 & T1B & 1,28 & 4,63 & 2,02 & 0,44 & T2A & 0,87 & 3,88 & 2,22 & 0,57 \\
\hline T1A & 1,27 & 4,50 & 2,07 & 0,46 & T1B & 1,29 & 5,35 & 2,98 & 0,56 & T2A & 1,18 & 4,81 & 2,90 & 0,60 \\
\hline $1 \mathrm{~A}$ & 1,39 & 9,00 & 3,35 & 0,37 & T1B & 1,29 & 5,09 & 2,42 & 0,48 & T2A & 1,16 & 4,44 & 2,24 & 0,50 \\
\hline T1A & 1,12 & 5,62 & 2,50 & 0,44 & T1B & 1,36 & 5,22 & 2,82 & 0,54 & T2A & 1,29 & 5,69 & & 0,44 \\
\hline T1A & 1,16 & 4,43 & 2,52 & 0,57 & T1B & 1,26 & 4,78 & 2,18 & 0,46 & T2A & 1,25 & 4,79 & 2,44 & 0,51 \\
\hline T1A & 1,21 & 5,44 & 2,70 & 0,50 & T1B & 1,49 & 4,65 & 2,40 & 0,52 & T2A & 1,24 & 4,19 & 2,19 & 0,52 \\
\hline $1 \mathrm{~A}$ & 1,17 & 4,12 & 1,99 & 0,48 & T1B & 1,71 & 4,75 & 2,69 & 0,57 & T2A & 1,12 & 4,15 & 1,73 & 0,42 \\
\hline T1A & 1,46 & 7,14 & 2,81 & 0,39 & T1B & 1,58 & 5,25 & 2,21 & 0,42 & T2A & 1,22 & 4,21 & 2,03 & 0,48 \\
\hline $\mathrm{T} 1 \mathrm{~A}$ & 1,15 & 4,23 & 2,04 & 0,48 & T1B & 0,84 & 3,74 & 1,65 & 0,44 & T2A & 0,90 & 3,10 & 1,52 & 0,49 \\
\hline $\mathrm{T} 1 \mathrm{~A}$ & 1,15 & 4,04 & 1,71 & 0,42 & $\mathrm{~T} 1 \mathrm{~B}$ & 1,03 & 4,36 & 2,15 & 0,49 & T2A & 1,10 & 4,05 & 1,72 & 0,42 \\
\hline T1A & 1,21 & 3,41 & 1,62 & 0,48 & T1B & 0,90 & 3,65 & 1,80 & 0,49 & T2A & 1,41 & 5,30 & 2,93 & 0,55 \\
\hline T1A & 1,52 & 7,91 & 3,72 & 0,47 & T1B & 1,07 & 3,04 & 1,70 & 0,56 & T2A & 1,11 & 4,37 & 2,46 & 0,56 \\
\hline T1A & 1,29 & 5,30 & 1,85 & 0,35 & T1B & 1,39 & 6,32 & 3,17 & 0,50 & T2A & 0,98 & 4,80 & 2,25 & 0,47 \\
\hline 4 & 0,99 & 3,31 & 1,47 & 0,44 & T1B & 1,10 & 5,42 & 3,33 & 0,61 & T2A & 1,18 & 6,38 & 2,57 & 0,40 \\
\hline $1 \mathrm{~A}$ & 1,70 & 5,24 & 2,72 & 0,52 & T1B & 1,45 & 5,14 & 1,94 & 0,38 & T2A & 0,91 & 4,49 & 1,98 & 0,44 \\
\hline
\end{tabular}


continuação

\begin{tabular}{|c|c|c|c|c|c|c|c|c|c|c|c|c|c|c|}
\hline & $\mathbf{R a}$ & Rz & $\mathrm{Rp}$ & Rp/Rz & & $\mathbf{R a}$ & $\mathbf{R z}$ & $\mathrm{Rp}$ & Rp/Rz & & $\mathbf{R a}$ & Rz & $\mathrm{Rp}$ & Rp/Rz \\
\hline$\Gamma 1 \mathrm{~A}$ & 1,63 & 5,26 & 2,47 & 0,47 & T1B & 0,96 & 3,24 & 1,88 & 0,58 & $\mathrm{~T} 2 \mathrm{~A}$ & 1,04 & 4,30 & 2,22 & 0,52 \\
\hline $1 \mathrm{~A}$ & ,70 & 68 & ,40 & 0,51 & T1B & ,98 & 3,46 & 1,85 & 0,53 & $\mathrm{~T} 2 \mathrm{~A}$ & 1,08 & 5,21 & 2,34 & 0,45 \\
\hline $1 \mathrm{~A}$ & 1,35 & 5,37 & 3,42 & 0,64 & T1B & 0,92 & & 1,67 & 0,51 & $\mathrm{~T} 2 \mathrm{~A}$ & 0,95 & 4,36 & 2,35 & 054 \\
\hline $1 \mathrm{~A}$ & 1,60 & 4,58 & 2,36 & 0,52 & T1B & 132 & 6,02 & 2,91 & 0,48 & $\mathrm{~T} 2 \mathrm{~A}$ & 0,86 & 4,18 & 2,08 & 0,50 \\
\hline $1 \mathrm{~A}$ & 1,37 & 4,58 & 2,19 & 0,48 & T1B & 0,93 & 3,09 & 1,53 & 0,50 & $\mathrm{~T} 2 \mathrm{~A}$ & 1,20 & 6,79 & 2,76 & 0,41 \\
\hline $1 \mathrm{~A}$ & 1,27 & 4,70 & 2,53 & 0,54 & T1B & 0,90 & 2,99 & 1,46 & 0,49 & $\mathrm{~T} 2 \mathrm{~A}$ & 1,01 & 4,39 & 2,13 & 0,49 \\
\hline $1 \mathrm{~A}$ & 0,95 & 3,88 & 1,85 & 0,48 & T1B & 1,19 & 4,04 & 1,93 & 0,48 & $\mathrm{~T} 2 \mathrm{~A}$ & 1,05 & & 3,00 & 0,56 \\
\hline $1 \mathrm{~A}$ & 1,18 & 4,30 & 2,13 & 0,50 & T1B & 1,29 & 5,46 & 2,48 & 0,45 & $\mathrm{~T} 2 \mathrm{~A}$ & 1,01 & & 1,89 & 0,48 \\
\hline $1 \mathrm{~A}$ & 1,23 & 5,02 & 2,37 & 0,47 & T1B & 0,94 & 2,76 & 1,59 & 0,58 & $\mathrm{~T} 2 \mathrm{~A}$ & 1,03 & 5,73 & 2,61 & 0,46 \\
\hline $1 \mathrm{~A}$ & 1,78 & 6,81 & 3,57 & 0,52 & T1B & 0,96 & 2,68 & 1,45 & 0,54 & $\mathrm{~T} 2 \mathrm{~A}$ & 1,02 & 3,94 & 1,77 & 0,45 \\
\hline $1 \mathrm{~A}$ & 1,40 & 5,49 & 3,16 & 0,58 & T1B & 0,63 & 2,89 & 1,77 & 0,61 & $\mathrm{~T} 2 \mathrm{~A}$ & 1,02 & 5,80 & 2,71 & 0,47 \\
\hline $1 \mathrm{~A}$ & 1,48 & 5,18 & 2,49 & 0,48 & T1B & 0,89 & 3,51 & 1,90 & 0,54 & $\mathrm{~T} 2 \mathrm{~A}$ & 1,05 & 5,40 & 2,28 & 0,42 \\
\hline $1 \mathrm{~A}$ & 1,46 & 4,42 & 2,31 & 0,52 & T1B & 0,92 & 3,35 & 1,30 & 0,39 & $\mathrm{~T} 2 \mathrm{~A}$ & 0,85 & & & 0,51 \\
\hline $1 \mathrm{~A}$ & 1,34 & 3,65 & 1,90 & 0,52 & T1B & 1,32 & 4,74 & 2,36 & 0,50 & $\mathrm{~T} 2 \mathrm{~A}$ & 1,08 & 4,89 & 2,67 & 0,55 \\
\hline $2 \mathrm{~B}$ & 1,41 & 5,08 & 2,12 & 0,42 & T3A & 6,57 & 33,60 & 16,07 & 0,48 & T3B & 5,56 & 33,95 & 1,63 & 0,34 \\
\hline $2 \mathrm{~B}$ & 1,22 & 5,25 & 2,48 & 0,47 & T3A & 6,52 & 34,20 & 15,94 & 0,47 & T3B & 6,02 & 41,55 & 13,65 & 0,33 \\
\hline $2 B$ & 1,00 & 4,85 & 1,83 & 0,38 & T3A & 5,91 & 5,95 & 16,72 & 0,47 & T3B & 5,42 & 9,13 & & 0,29 \\
\hline T2B & 1,03 & 4,40 & 2,07 & 47 & T3А & 6,7 & & & 49 & Т3В & & & & 0,37 \\
\hline T2B & 1,26 & 6,08 & 2,01 & 0,33 & T3A & 6,22 & 34,43 & 16,77 & 0,49 & T3B & 5,85 & 40,32 & 12,80 & 0,32 \\
\hline $2 \mathrm{~B}$ & 1,04 & 4,44 & 2,00 & 0,45 & T3A & 7,34 & 39,23 & 20,25 & 0,52 & T3B & 5,75 & 36,23 & 14,09 & 0,39 \\
\hline $2 B$ & 1,20 & 4,34 & 1,97 & 0,45 & T3A & 7,10 & 35,06 & 15,19 & 0,43 & T3B & 5,89 & 32,42 & 3,50 & 0,42 \\
\hline Г2B & & & & & & & & & & Т3В & & & & 0,34 \\
\hline T2B & 1,30 & 7,53 & 2,09 & 0,28 & T3A & 7,23 & 38,88 & 18,92 & 0,49 & T3B & 5,54 & 44,30 & 13,96 & 0,32 \\
\hline $2 \mathrm{~B}$ & 1,17 & 4,77 & 1,94 & 0,41 & T3A & 6,24 & 35,34 & 17,23 & 0,49 & T3B & 6,54 & 41,14 & 15,46 & 0,38 \\
\hline $2 \mathrm{~B}$ & 1,30 & 4,88 & 2,17 & 0,44 & T3A & 6,19 & 37,35 & 17,09 & 0,46 & T3B & 4,61 & 41,16 & 13,64 & 0,33 \\
\hline T2B & & 4,23 & 1,83 & & T3A & & & & & T3B & 5,20 & & & 0,39 \\
\hline T2B & 1,19 & 4,09 & 1,93 & 0,47 & T3A & 6,91 & 35,17 & 16,95 & 0,48 & T3B & 4,88 & 34, & & 0,37 \\
\hline Г2B & 0,86 & 3,30 & 1,53 & 0,46 & T3A & 6,59 & 35,85 & 15,85 & 0,44 & Т3В & 4,95 & 38,18 & 13,02 & 0,34 \\
\hline $2 \mathrm{~B}$ & 1,45 & 4,97 & 2,31 & 0,46 & T3A & 6,88 & 35,31 & 14,85 & 0,42 & T3B & 5,23 & 39,76 & 14,15 & 0,36 \\
\hline Г2B & 1,20 & 4,18 & 1,99 & 0,48 & T3A & 7,10 & & & 45 & T3B & 36 & & & 0,33 \\
\hline Г2B & 1,15 & 4,67 & 1,94 & 0,42 & T3A & & & & 0,50 & Т3В & & & & 0,48 \\
\hline T2B & 1,35 & 5,12 & 2,60 & 0,51 & T3A & 6,91 & 36,07 & 16,51 & 0,46 & Т3В & 7,36 & 38,24 & 17,60 & 0,46 \\
\hline T2B & 1,65 & 7,80 & 3,12 & 0,40 & T3A & 6,37 & 30,77 & 14,03 & 0,46 & T3B & 6,65 & 35,73 & 16,41 & 0,46 \\
\hline T2B & 1,92 & 7,53 & 3,48 & 0,46 & T3A & 5,14 & 26,98 & 93 & 44 & Т3В & 7,34 &, 67 & & 0,52 \\
\hline T2B & 1,32 & 6,29 & & & T3A & & & & & Т3В & & & & 0,50 \\
\hline T2B & 1,79 & 6,04 & 3,81 & 0,63 & T3A & 6,67 & 32,92 & & 0,47 & Т3В & 7,15 & 33,74 & & 0,44 \\
\hline T2B & 1,64 & 7,64 & 3,95 & 0,52 & T3A & 4,89 & 25,19 & 10,23 & 0,41 & T3B & 7,55 & 39,45 & 18,04 & 0,46 \\
\hline T2B & 1,90 & 5,46 & & 0,58 & T3A & 5,98 & 31,53 & & ,46 & Т3В & 6,98 & 32,05 & 18,07 & 0,56 \\
\hline T2B & 2,03 & 8,57 & 3,07 & 0,36 & T3A & 6,05 & & & 0,48 & T3B & 7,11 & & & 0,43 \\
\hline T2B & 1,73 & 6,97 & 3,61 & 0,52 & T3A & 5,33 & & & & Т3В & 6,80 & & & 0,50 \\
\hline T2B & 1,79 & 6,47 & 3,73 & 0,58 & T3A & 6,06 & 28,59 & 12,33 & 0,43 & T3B & 6,93 & 39,07 & 19,98 & 0,51 \\
\hline T2B & 1,49 & 5,86 & 2,70 & 0,46 & T3A & 6,53 & 34,72 & & 0,43 & T3B & 6,67 & 34,88 & 18,93 & 0,54 \\
\hline T2B & 1,41 & 5,53 & 2,63 & 0,48 & T3A & 6,17 & 32,21 & 15,05 & 0,47 & Т3В & 6,92 & 32,80 & 17,43 & 0,53 \\
\hline T2B & 1,92 & 8,75 & 4,12 & 0,47 & T3A & 6,63 & & & 0,44 & Т3В & 7,22 & 38,04 & & 0,50 \\
\hline T2B & 2,05 & 8,31 & 4,47 & 0,54 & T3A & 6,54 & 33,62 & 13,60 & 0,40 & T3B & 6,75 & 32,87 & 16,38 & 0,50 \\
\hline T2B & 1,98 & 7,02 & 3,26 & 0,46 & T3A & 6,15 & 31,07 & & 0,41 & T3B & 6,36 & 34,64 & & 0,50 \\
\hline T2B & 1,98 & 7,56 & 2,55 & 0,34 & T3A & 6,75 & 35,51 & 15,92 & 0,45 & Т3В & 6,78 & 39,31 & 20,38 & 0,52 \\
\hline T2B & 1,49 & 5,86 & 3,02 & 0,52 & T3A & 5,84 & 30,82 & 12,81 & 0,42 & Т3В & 7,10 & 37,65 & 15,75 & 0,42 \\
\hline T2B & 1,94 & 5,26 & 1,96 & 0,37 & T3A & 6,36 & 28,55 & 13,30 & 0,47 & T3B & 5,90 & 30,12 & 14,35 & 0,48 \\
\hline T2B & 1,96 & 8,46 & 3,11 & 0,37 & T3A & 6,22 & & & 0,45 & Т3В & 6,31 & 33,84 & 16,35 & 0,48 \\
\hline T2B & 0,95 & 7,45 & 2,00 & 0,27 & T3A & 5,72 & 28,95 & 14,78 & 0,51 & T3B & 5,83 & 30,37 & 14,36 & 0,47 \\
\hline
\end{tabular}

continua 
continuação

\begin{tabular}{|c|c|c|c|c|c|c|c|c|c|c|c|c|c|c|}
\hline & $\mathbf{R a}$ & $\mathbf{R z}$ & $R p$ & Rp/Rz & & $\mathbf{R a}$ & Rz & $R p$ & Rp/Rz & & $\mathbf{R a}$ & Rz & $\mathrm{Rp}$ & Rp/Rz \\
\hline T2B & 0,98 & 5,81 & 2,30 & 0,40 & T3A & 5,52 & 27,75 & 13,29 & 0,48 & T3B & 6,60 & 32,73 & 15,75 & 0,48 \\
\hline T2B & 1,49 & 8,67 & 2,75 & 0,32 & T3A & 6,00 & 31,48 & 15,07 & 0,48 & T3B & 6,05 & 32,48 & 14,23 & 0,44 \\
\hline T2B & 1,25 & 7,48 & 2,59 & 0,35 & T3A & 5,52 & 30,11 & 14,82 & 0,49 & T3B & 6,16 & 31,77 & 15,16 & 0,48 \\
\hline T2B & 1,59 & 5,01 & 2,06 & 0,41 & T3A & 5,63 & 29,11 & 12,51 & 0,43 & T3B & 6,37 & 30,48 & 12,68 & 0,42 \\
\hline T2B & 1,80 & 4,34 & 2,15 & 0,50 & T3A & 6,01 & 29,68 & 14,74 & 0,50 & T3B & 6,08 & 32,55 & 14,60 & 0,45 \\
\hline T2B & 0,80 & 4,75 & 1,87 & 0,39 & T3A & 5,42 & 28,84 & 14,58 & 0,51 & T3B & 5,58 & 31,93 & 13,48 & 0,42 \\
\hline T2B & 1,36 & 9,52 & 2,95 & 0,31 & T3A & 6,16 & 31,34 & 13,88 & 0,44 & T3B & 6,30 & 31,25 & 15,55 & 0,50 \\
\hline T2B & 0,95 & 4,80 & 2,85 & 0,59 & T3A & 5,90 & 29,37 & 14,66 & 0,50 & Т3В & 5,53 & 29,73 & 14,17 & 0,48 \\
\hline T2B & 1,46 & 5,72 & 2,98 & 0,52 & T3A & 5,87 & 31,08 & 15,08 & 0,49 & T3B & 5,70 & 33,60 & 15,09 & 0,45 \\
\hline T2B & 1,72 & 9,42 & 3,89 & 0,41 & T3A & 6,04 & 28,61 & 14,48 & 0,51 & T3B & 5,67 & 37,16 & 15,01 & 0,40 \\
\hline T2B & 1,11 & 5,46 & 2,58 & 0,47 & T3A & 6,42 & 30,58 & 12,86 & 0,42 & T3B & 6,36 & 33,85 & 16,73 & 0,49 \\
\hline T2B & 1,64 & 7,12 & 4,65 & 0,65 & T3A & 5,86 & 26,55 & 13,61 & 0,51 & T3B & 6,46 & 34,49 & 17,49 & 0,51 \\
\hline T2B & 2,08 & 4,84 & 2,44 & 0,50 & T3A & 5,73 & 28,48 & 14,62 & 0,51 & T3B & 6,20 & 33,39 & 16,33 & 0,49 \\
\hline T2B & 1,92 & 4,47 & 2,10 & 0,47 & T3A & 5,68 & 29,81 & 15,19 & 0,51 & T3B & 6,07 & 32,30 & 14,46 & 0,45 \\
\hline T2B & 1,77 & 4,52 & 1,93 & 0,43 & T3A & 5,68 & 30,35 & 13,46 & 0,44 & T3B & 6,66 & 43,72 & 16,31 & 0,37 \\
\hline T2B & 0,74 & 2,66 & 1,26 & 0,47 & T3A & 6,90 & 36,08 & 15,98 & 0,44 & T3B & 7,31 & 37,05 & 18,33 & 0,49 \\
\hline T2B & 0,97 & 2,59 & 1,14 & 0,44 & T3A & 6,45 & 31,80 & 14,83 & 0,47 & T3B & 6,55 & 35,55 & 16,88 & 0,47 \\
\hline T2B & 0,88 & 2,87 & 1,35 & 0,47 & T3A & 5,37 & 30,44 & 12,55 & 0,41 & Т3В & 6,09 & 33,60 & 17,65 & 0,53 \\
\hline T2B & 1,03 & 2,65 & 1,25 & 0,47 & T3A & 5,66 & 32,56 & 15,46 & 0,47 & T3B & 6,86 & 35,88 & 16,66 & 0,46 \\
\hline T2B & 0,92 & 3,26 & 1,44 & 0,44 & T3A & 6,48 & 35,67 & 17,67 & 0,50 & T3B & 7,56 & 39,64 & 19,61 & 0,49 \\
\hline T2B & 0,64 & 2,63 & 1,22 & 0,46 & T3A & 6,57 & 41,28 & 19,33 & 0,47 & T3B & 6,89 & 36,87 & 17,98 & 0,49 \\
\hline T2B & 0,81 & 2,77 & 1,17 & 0,42 & T3A & 5,41 & 29,24 & 12,17 & 0,42 & T3B & 7,58 & 39,91 & 19,96 & 0,50 \\
\hline T2B & 0,77 & 2,77 & 1,16 & 0,42 & T3A & 5,65 & 30,18 & 13,29 & 0,44 & T3B & 7,34 & 38,65 & 18,67 & 0,48 \\
\hline T2B & 0,71 & 3,22 & 1,31 & 0,41 & T3A & 5,78 & 31,12 & 13,96 & 0,45 & T3B & 6,26 & 33,80 & 17,02 & 0,50 \\
\hline T2B & 0,62 & 2,72 & 1,22 & 0,45 & T3A & 5,86 & 32,21 & 14,55 & 0,45 & T3B & 6,16 & 35,60 & 16,98 & 0,48 \\
\hline T2B & 0,77 & 3,42 & 1,45 & 0,42 & T3A & 6,04 & 31,60 & 14,68 & 0,46 & T3B & 6,97 & 33,77 & 15,52 & 0,46 \\
\hline T2B & 1,00 & 3,10 & 1,36 & 0,44 & T3A & 6,15 & 31,23 & 14,45 & 0,46 & T3B & 6,56 & 34,67 & 14,78 & 0,43 \\
\hline T2B & 0,85 & 4,40 & 1,58 & 0,36 & T3A & 6,86 & 34,14 & 16,32 & 0,48 & T3B & 6,12 & 31,36 & 14,10 & 0,45 \\
\hline T2B & 1,08 & 3,05 & 1,08 & 0,35 & T3A & 5,30 & 32,51 & 15,99 & 0,49 & T3B & 6,57 & 33,54 & 15,60 & 0,47 \\
\hline T2B & 0,80 & 3,15 & 1,23 & 0,39 & T3A & 5,71 & 32,58 & 14,98 & 0,46 & T3B & 7,22 & 33,46 & 15,83 & 0,47 \\
\hline T2B & 0,90 & 4,13 & 1,32 & 0,32 & T3A & 6,01 & 35,88 & 16,25 & 0,45 & T3B & 6,87 & 33,18 & 14,89 & 0,45 \\
\hline T2B & 0,80 & 3,29 & 1,11 & 0,34 & T3A & 7,12 & 35,77 & 15,95 & 0,45 & T3B & 7,22 & 35,09 & 16,62 & 0,47 \\
\hline T2B & 1,34 & 4,14 & 1,93 & 0,47 & T3A & 5,75 & 30,28 & 14,34 & 0,47 & T3B & 5,55 & 31,22 & 13,80 & 0,44 \\
\hline T2B & 1,06 & 4,43 & 1,60 & 0,36 & T3A & 6,12 & 31,46 & 15,44 & 0,49 & T3B & 5,87 & 33,29 & 16,30 & 0,49 \\
\hline T2B & 1,60 & 4,01 & 1,88 & 0,47 & T3A & 6,33 & 33,67 & 16,51 & 0,49 & T3B & 4,46 & 24,84 & 12,03 & 0,48 \\
\hline T2B & 1,90 & 3,97 & 1,95 & 0,49 & T3A & 7,37 & 34,80 & 14,09 & 0,40 & T3B & 4,29 & 22,88 & 10,18 & 0,44 \\
\hline T2B & 1,21 & 4,36 & 1,78 & 0,41 & T3A & 6,38 & 34,69 & 16,77 & 0,48 & T3B & 4,32 & 23,12 & 11,87 & 0,51 \\
\hline T2B & 1,74 & 4,32 & 2,04 & 0,47 & T3A & 6,90 & 35,72 & 17,95 & 0,50 & T3B & 3,46 & 19,37 & 8,85 & 0,46 \\
\hline T2B & 1,78 & 3,93 & 1,92 & 0,49 & T3A & 6,50 & 34,39 & 15,03 & 0,44 & T3B & 4,32 & 21,19 & 10,35 & 0,49 \\
\hline T2B & 1,67 & 5,66 & 2,39 & 0,42 & T3A & 7,63 & 43,86 & 24,77 & 0,56 & T3B & 4,23 & 24,41 & 11,68 & 0,48 \\
\hline T2B & 1,19 & 5,59 & 2,69 & 0,48 & T3A & 6,79 & 32,95 & 15,26 & 0,46 & T3B & 4,48 & 23,89 & 12,10 & 0,51 \\
\hline T2B & 1,90 & 4,02 & 2,11 & 0,52 & T3А & 6,64 & 34,82 & 17,48 & 0,50 & T3B & 4,48 & 21,53 & 9,56 & 0,44 \\
\hline T2B & 0,77 & 3,05 & 1,57 & 0,51 & T3A & 6,74 & 32,45 & 14,83 & 0,46 & T3B & 4,32 & 20,19 & 10,19 & 0,50 \\
\hline T2B & 0,90 & 4,06 & 1,38 & 0,34 & T3A & 6,26 & 34,60 & 15,24 & 0,44 & T3B & 4,24 & 23,38 & 10,66 & 0,46 \\
\hline T2B & 0,86 & 3,43 & 1,24 & 0,36 & T3A & 6,88 & 33,12 & 15,18 & 0,46 & T3B & 4,12 & 22,51 & 11,26 & 0,50 \\
\hline T2B & 1,13 & 4,20 & 1,65 & 0,39 & T3А & 6,39 & 34,26 & 15,26 & 0,45 & T3B & 4,38 & 23,27 & 9,87 & 0,42 \\
\hline T2B & 0,81 & 3,95 & 1,46 & 0,37 & T3A & 6,92 & 33,19 & 15,50 & 0,47 & T3B & 4,19 & 22,76 & 10,16 & 0,45 \\
\hline T2B & 1,77 & 5,75 & 2,40 & 0,42 & T3A & 7,17 & 39,82 & 16,51 & 0,41 & T3B & 4,18 & 21,81 & 8,28 & 0,38 \\
\hline T2B & 1,97 & 6,90 & 2,95 & 0,43 & T3A & 6,69 & 31,45 & 14,33 & 0,46 & T3B & 4,08 & 21,89 & 9,87 & 0,45 \\
\hline T2B & 1,65 & 9,67 & 3,19 & 0,33 & T3A & 6,90 & 35,22 & 18,06 & 0,51 & T3B & 4,15 & 24,23 & 10,74 & 0,44 \\
\hline T2B & 1,10 & 5,25 & 1,99 & 0,38 & T3A & 7,11 & 38,05 & 14,94 & 0,39 & T3B & 4,09 & 22,78 & 9,65 & 0,42 \\
\hline
\end{tabular}


continuação

\section{$\begin{array}{llll}\mathbf{R a} & \mathbf{R z} & \mathbf{R p} & \mathbf{R p} / \mathbf{R z}\end{array}$}

$\begin{array}{llll}\text { T2B } & 1,21 & 3,08 & 1,52\end{array}$

$\begin{array}{llll}\text { T2B } & 1,19 & 3,08 & 1,53\end{array}$

Т2В $\quad 1,19 \quad 3,22 \quad 1,46$

$\begin{array}{llll}\text { T2B } & 0,99 & 3,15 & 1,24\end{array}$

$\begin{array}{llll}\text { T2B } & 1,20 & 3,20 & 1,57\end{array}$

$\begin{array}{llll}\text { T2B } & 1,03 & 3,03 & 1,46\end{array}$

$\begin{array}{llll}\text { Т2В } & 1,04 & 3,52 & 1,50\end{array}$

$\begin{array}{llll}\text { T2B } & 1,19 & 2,95 & 1,38\end{array}$

$\begin{array}{llll}\text { T2B } & 0,96 & 2,69 & 1,22\end{array}$

$\begin{array}{llll}\text { T2B } & 0,84 & 2,94 & 1,28\end{array}$

$\begin{array}{llll}\text { T2B } & 0,92 & 3,53 & 1,49\end{array}$

$\begin{array}{llll}\text { T2B } & 0,76 & 3,08 & 1,49\end{array}$

$\begin{array}{llll}\text { T2B } & 0,81 & 3,71 & 1,31\end{array}$

$\begin{array}{llll}\text { T2B } & 0,93 & 3,41 & 1,25\end{array}$

$\begin{array}{llll}\text { T4A } & 1,59 & 5,04 & 2,65\end{array}$

$\begin{array}{llll}\text { T4A } & 1,55 & 4,63 & 2,29\end{array}$

$\begin{array}{llll}\text { T4A } & 1,13 & 4,59 & 1,77\end{array}$

$\begin{array}{llll}\text { T4A } & 1,09 & 4,78 & 2,02\end{array}$

T4A $\quad 1,15 \quad 5,02 \quad 1,81$

$\begin{array}{llll}\text { T4A } & 0,95 & 4,44 & 1,96\end{array}$

T4A $\quad 1,41 \quad 4,86 \quad 2,33$

T4A $\quad 1,16 \quad 4,47 \quad 1,94$

$\begin{array}{llll}\text { T4A } & 1,01 & 4,87 & 2,05\end{array}$

$\begin{array}{llll}\text { T4A } & 0,97 & 4,06 & 1,88\end{array}$

$\begin{array}{llll}\text { T4A } & 1,08 & 5,14 & 1,88\end{array}$

$\begin{array}{llll}\text { T4A } & 0,98 & 5,33 & 2,2\end{array}$

$\begin{array}{llll}\text { T4A } & 1,14 & 4,94 & 1,98\end{array}$

$\begin{array}{llll}\text { T4A } & 1,01 & 4,78 & 1,99\end{array}$

$\begin{array}{llll}\text { T4A } & 1,24 & 3,79 & 1,78\end{array}$

$\begin{array}{llll}\text { T4A } & 0,85 & 4,27 & 1,96\end{array}$

$\begin{array}{llll}\text { T4A } & 1,26 & 5,56 & 2,35\end{array}$

$\begin{array}{llll}\text { T4A } & 0,89 & 4,06 & 1,86\end{array}$

$\begin{array}{llll}\text { T4A } & 1,30 & 6,72 & 2,02\end{array}$

$\begin{array}{llll}\text { T4A } & 1,18 & 3,80 & 1,84\end{array}$

$\begin{array}{llll}\text { T4A } & 1,37 & 5,36 & 1,89\end{array}$

$\begin{array}{llll}\text { T4A } & 1,07 & 3,47 & 1,87\end{array}$

$\begin{array}{llll}\text { T4A } & 1,12 & 3,66 & 1,73\end{array}$

$\begin{array}{llll}\text { T4A } & 1,11 & 3,28 & 1,68\end{array}$

$\begin{array}{llll}\text { T4A } & 1,16 & 3,56 & 1,84\end{array}$

$\begin{array}{llll}\text { T4A } & 1,15 & 3,28 & 1,68\end{array}$

$\begin{array}{llll}\text { T4A } & 1,11 & 3,23 & 1,8\end{array}$

$\begin{array}{llll}\text { T4A } & 1,10 & 3,53 & 1,35\end{array}$

$\begin{array}{llll}\text { T4A } & 1,32 & 4,24 & 1,84\end{array}$

$\begin{array}{llll}\text { T4A } & 1,22 & 4,10 & 2,17\end{array}$

$\begin{array}{llll}\text { T4A } & 1,17 & 3,94 & 1,68\end{array}$

T4A $\quad 1,26 \quad 4,39 \quad 1,96$

$\begin{array}{llll}\text { T4A } & 1,15 & 3,54 & 1,48\end{array}$

$\begin{array}{llll}\text { T4A } & 1,06 & 3,59 & 1,37\end{array}$

$\begin{array}{llll}\text { T4A } & 1,33 & 3,89 & 1,73\end{array}$

$\begin{array}{llll}\text { T4A } & 1,04 & 3,97 & 1,5\end{array}$

T4A $\quad 1,05 \quad 3,49 \quad 1,42$
Rp/Rz

Ra

$\begin{array}{lllll}0,49 & \text { T3A } & 7,15 & 39,18 & 14,72\end{array}$

$\begin{array}{lllll}0,50 & \text { ТЗА } & 7,01 & 37,81 & 13,76\end{array}$

$\begin{array}{lllll}0,45 & \text { Т3A } & 7,05 & 40,48 & 14,54\end{array}$

$\begin{array}{llllll}0,39 & \text { ТЗА } & 7,15 & 40,36 & 15,56\end{array}$

$\begin{array}{lllll}0,49 & \text { T3A } & 7,00 & 39,11 & 14,15\end{array}$

$\begin{array}{lllll}0,48 & \text { T3A } & 7,24 & 40,89 & 13,37\end{array}$

$\begin{array}{lllll}0,43 & \text { ТЗА } & 6,98 & 39,61 & 14,77\end{array}$

$\begin{array}{lllll}0,47 & \text { ТЗА } & 7,35 & 41,85 & 15,91\end{array}$

$\begin{array}{lllll}0,45 & \text { ТЗА } & 7,27 & 38,12 & 15,28\end{array}$

$\begin{array}{lllll}0,44 & \text { T3A } & 6,98 & 39,38 & 15,04\end{array}$

$\begin{array}{lllll}0,42 & \text { ТЗА } & 7,35 & 41,45 & 15,32\end{array}$

$\begin{array}{lllll}0,48 & \text { ТЗА } & 7,07 & 38,84 & 14,34\end{array}$

$\begin{array}{lllll}0,35 & \text { ТЗА } & 7,16 & 38,62 & 15,14\end{array}$

$\begin{array}{lllll}0,37 & \text { T3A } & 7,04 & 38,87 & 14,92\end{array}$

$\begin{array}{lllll}0,53 & \text { Т4В } & 0,94 & 3,38 & 1,6\end{array}$

$\begin{array}{lllll}0,49 & \text { Т4В } & 1,14 & 5,76 & 1,94\end{array}$

$\begin{array}{lllll}0,39 & \text { T4B } & 0,93 & 4,68 & 1,37\end{array}$

$\begin{array}{lllll}0,42 & \text { T4B } & 0,98 & 4,31 & 1,96\end{array}$

$0,36 \quad$ T4B $\quad 1,11 \quad 3,81 \quad 1,86$

$\begin{array}{lllll}0,44 & \text { T4B } & 1 & 5,14 & 1,94\end{array}$

$\begin{array}{lllll}0,48 & \text { T4B } & 0,83 & 3,65 & 1,54\end{array}$

$0,43 \quad$ T4B 1,11

$0,42 \quad$ T4B $\quad 0,99$

$0,46 \quad$ T4B $\quad 0,68$

$0,37 \quad$ T4B $\quad 0,97$

$0,41 \quad$ T4B $\quad 0,87$

$0,40 \quad$ T4B $\quad 1,15$

$0,42 \quad$ T4B $\quad 0,83$

$0,47 \quad$ T4B $\quad 0,89$

$0,46 \quad$ T4B $\quad 0,86$

$0,42 \quad$ T4B 1,18

$0,46 \quad$ T4B 1,16

$0,30 \quad$ Т4В 0,86

$0,48 \quad$ T4B 0,93

$0,35 \quad$ T4B $\quad 0,78$

$0,54 \quad$ T4B $\quad 0,76$

$0,47 \quad$ T4B $\quad 0,92$

$0,51 \quad$ T4B $\quad 0,8$

$0,52 \quad$ T4B $\quad 1,22$

$0,51 \quad$ T4B $\quad 0,69$

$0,56 \quad$ T4B $\quad 1,08$

$0,38 \quad$ T4B $\quad 0,95$

$0,43 \quad$ T4B 1,04

$0,53 \quad$ T4B 1,16

$0,43 \quad$ T4B $\quad 0,96$

$0,45 \quad$ T4B 1,18

$0,42 \quad$ T4B 1,15

$0,38 \quad$ T4B $\quad 1,3$

$0,44 \quad$ Т4В 1,19

$0,38 \quad$ Т4В 0,99

0,41 T4B 1,01
$5,56 \quad 2$

$4,43 \quad 1,7$

$3,75 \quad 1,39$

$4,14 \quad 2,1$

$4,01 \quad 1,65$

$6,14 \quad 2,15$

$5,02 \quad 1,82$

$3,98 \quad 1,84$

$3,65 \quad 1,57$

$6,23 \quad 2,11$

$3,61 \quad 1,44$

$3,51 \quad 1,98$

$3,67 \quad 1,65$

$3,3 \quad 1,46$

$3,64 \quad 1,73$

$3,46 \quad 1,73$

$5,76 \quad 1,78$

$3,84 \quad 1,53$

$3,77 \quad 1,72$

$3,31 \quad 1,53$

$3,12 \quad 1,55$

$3,22 \quad 1,55$

$3,51 \quad 1,64$

$4,19 \quad 1,56$

$3,38 \quad 1,58$

$4,39 \quad 1,74$

$5,32 \quad 1,91$

$3,35 \quad 1,37$

$3,99 \quad 2,22$

$4,61 \quad 2,4$
Rp/Rz

$\begin{array}{llll}\text { Ra } & \text { Rz } & \mathbf{R p} & \mathbf{R p} / \mathbf{R z}\end{array}$

$\begin{array}{llllll}0,38 & \text { T3B } & 6,71 & 34,51 & 15,96 & 0,46\end{array}$

$\begin{array}{llllll}0,36 & \text { Т3В } & 6,84 & 33,09 & 14,87 & 0,45\end{array}$

$\begin{array}{llllll}0,36 & \text { Т3В } & 6,72 & 34,24 & 16,39 & 0,48\end{array}$

$\begin{array}{llllll}0,39 & \text { ТЗВ } & 6,54 & 31,01 & 15,34 & 0,49\end{array}$

$\begin{array}{llllll}0,36 & \text { Т3В } & 7,30 & 34,78 & 16,23 & 0,47\end{array}$

$\begin{array}{llllll}0,33 & \text { ТЗВ } & 5,01 & 27,75 & 11,93 & 0,43\end{array}$

$\begin{array}{llllll}0,37 & \text { ТЗВ } & 4,20 & 24,87 & 12,25 & 0,49\end{array}$

$\begin{array}{llllll}0,38 & \text { ТЗВ } & 5,98 & 33,99 & 13,90 & 0,41\end{array}$

$\begin{array}{llllll}0,40 & \text { Т3В } & 4,86 & 27,25 & 12,74 & 0,47\end{array}$

$\begin{array}{lllllll}0,38 & \text { ТЗВ } & 4,76 & 27,60 & 10,84 & 0,39\end{array}$

$\begin{array}{llllll}0,37 & \text { ТЗВ } & 4,81 & 24,54 & 11,48 & 0,47\end{array}$

$\begin{array}{llllll}0,37 & \text { T3B } & 5,38 & 29,69 & 14,43 & 0,49\end{array}$

$\begin{array}{llllll}0,39 & \text { T3B } & 4,36 & 25,26 & 11,68 & 0,46\end{array}$

$\begin{array}{llllll}0,38 & \text { ТЗВ } & 5,51 & 27,49 & 13,24 & 0,48\end{array}$

$\begin{array}{llllll}0,47 & \text { T5A } & 1,44 & 3,48 & 1,30 & 0,37\end{array}$

$\begin{array}{llllll}0,34 & \text { T5A } & 1,38 & 6,61 & 2,36 & 0,36\end{array}$

$\begin{array}{llllll}0,29 & \text { T5A } & 1,31 & 6,23 & 3,07 & 0,49\end{array}$

$\begin{array}{llllll}0,45 & \text { T5A } & 1,25 & 5,56 & 2,92 & 0,53\end{array}$

$\begin{array}{llllll}0,49 & \text { T5A } & 1,36 & 3,36 & 1,50 & 0,45\end{array}$

$\begin{array}{llllll}0,38 & \text { T5A } & 0,78 & 3,61 & 1,71 & 0,47\end{array}$

$\begin{array}{llllll}0,42 & \text { T5A } & 1,34 & 5,37 & 2,37 & 0,44\end{array}$

$\begin{array}{llllll}0,36 & \text { T5A } & 1,4 & 6,19 & 2,33 & 0,38\end{array}$

$\begin{array}{llllll}0,38 & \text { T5A } & 1,11 & 3,52 & 1,56 & 0,44\end{array}$

$\begin{array}{llllll}0,37 & \text { T5A } & 1,06 & 3,07 & 1,54 & 0,50\end{array}$

$\begin{array}{llllll}0,51 & \text { T5A } & 1,19 & 3,9 & 2,14 & 0,55\end{array}$

$\begin{array}{llllll}0,41 & \text { T5A } & 1,13 & 3,6 & 1,61 & 0,45\end{array}$

$\begin{array}{llllll}0,35 & \text { T5A } & 1,12 & 4,14 & 1,47 & 0,36\end{array}$

$\begin{array}{llllll}0,36 & \text { T5A } & 1,16 & 3,82 & 1,75 & 0,46\end{array}$

$\begin{array}{llllll}0,46 & \text { T5A } & 1,23 & 4,59 & 1,76 & 0,38\end{array}$

$\begin{array}{llllll}0,43 & \text { T5A } & 1,13 & 3,43 & 1,68 & 0,49\end{array}$

$\begin{array}{llllll}0,34 & \text { T5A } & 1,23 & 3,83 & 1,77 & 0,46\end{array}$

$\begin{array}{llllll}0,40 & \text { T5A } & 1,36 & 3,78 & 1,67 & 0,44\end{array}$

$\begin{array}{llllll}0,56 & \text { T5A } & 1,23 & 3,96 & 1,73 & 0,44\end{array}$

$\begin{array}{llllll}0,45 & \text { T5A } & 0,79 & 5,26 & 1,55 & 0,29\end{array}$

$\begin{array}{llllll}0,44 & \text { T5A } & 1,46 & 4,6 & 2,00 & 0,43\end{array}$

$\begin{array}{llllll}0,48 & \text { T5A } & 1,17 & 3,98 & 1,78 & 0,45\end{array}$

$\begin{array}{llllll}0,50 & \text { T5A } & 1,38 & 4,4 & 1,62 & 0,37\end{array}$

$\begin{array}{llllll}0,31 & \text { T5A } & 0,8 & 2,79 & 1,36 & 0,49\end{array}$

$\begin{array}{llllll}0,40 & \text { T5A } & 1,35 & 3,66 & 1,35 & 0,37\end{array}$

$\begin{array}{llllll}0,46 & \text { T5A } & 1,23 & 3,77 & 1,68 & 0,45\end{array}$

$\begin{array}{llllll}0,46 & \text { T5A } & 1,22 & 3,61 & 1,55 & 0,43\end{array}$

$\begin{array}{llllll}0,50 & \text { T5A } & 1,28 & 3,35 & 1,43 & 0,43\end{array}$

$\begin{array}{llllll}0,48 & \text { T5A } & 1,55 & 4,15 & 2,03 & 0,49\end{array}$

$\begin{array}{llllll}0,47 & \text { T5A } & 1,45 & 4,05 & 1,75 & 0,43\end{array}$

$\begin{array}{llllll}0,37 & \text { T5A } & 0,99 & 3,87 & 1,89 & 0,49\end{array}$

$\begin{array}{llllll}0,47 & \text { T5A } & 1,67 & 5,4 & 2,62 & 0,49\end{array}$

$\begin{array}{llllll}0,40 & \text { T5A } & 1,15 & 2,94 & 1,59 & 0,54\end{array}$

$\begin{array}{llllll}0,36 & \text { T5A } & 1,25 & 6,14 & 1,79 & 0,29\end{array}$

$\begin{array}{llllll}0,41 & \text { T5A } & 1,21 & 4,03 & 2,00 & 0,50\end{array}$

$\begin{array}{llllll}0,56 & \text { T5A } & 1,35 & 4,49 & 1,84 & 0,41\end{array}$

$\begin{array}{llllll}0,52 & \text { T5A } & 1,08 & 3,41 & 1,33 & 0,39\end{array}$

continua 
continuação

$\begin{array}{llll}R a & R z & R p & R p / R z\end{array}$

$\begin{array}{llll}\text { T4A } & 1,07 & 3,65 & 1,53\end{array}$

T4A $\quad 1,15 \quad 4,65 \quad 2,1$

T4A $\quad 1,28 \quad 4,79 \quad 1,65$

$\begin{array}{llll}\text { T4A } & 1,25 & 4,76 & 2,38\end{array}$

$\begin{array}{llll}\text { T4A } & 1,23 & 4,68 & 1,39\end{array}$

T4A $0,93 \quad 3,75 \quad 1,5$

$\begin{array}{llll}\text { T4A } & 1,26 \quad 4,92 & 1,92\end{array}$

$\begin{array}{llll}\text { T4A } & 1,13 \quad 4,07 & 1,97\end{array}$

$\begin{array}{llll}\text { T4A } & 1,25 & 4,81 & 1,97\end{array}$

$\begin{array}{llll}\text { T4A } & 0,80 & 3,91 & 1,68\end{array}$

$\begin{array}{llll}\text { T4A } & 0,68 & 3,91 & 1,44\end{array}$

$\begin{array}{llll}\text { T4A } & 0,92 & 3,78 & 1,89\end{array}$

$\begin{array}{llll}\text { T4A } & 1,04 & 3,53 & 1,62\end{array}$

$\begin{array}{llll}\text { T4A } & 0,80 & 3,52 & 1,68\end{array}$

$\begin{array}{llll}\text { T4A } & 0,81 & 3,69 & 1,64\end{array}$

$\begin{array}{llll}\text { T4A } & 1,09 & 4,31 & 2,07\end{array}$

$\begin{array}{llll}\text { T4A } & 1,51 \quad 4,82 \quad 2,16\end{array}$

$\begin{array}{llll}\text { T4A } & 1,34 & 4,96 & 1,97\end{array}$

T4A $1,09 \quad 3,76 \quad 1,73$

T4A $1,53 \quad 5,34 \quad 2,4$

$\begin{array}{llll}\text { T4A } & 1,43 \quad 5,05 & 2,44\end{array}$

$\begin{array}{llll}\text { T4A } & 0,89 & 3,18 & 1,38\end{array}$

T4A $1,17 \quad 5,30 \quad 2,6$

$\begin{array}{llll}\text { T4A } & 1,45 \quad 5,44 & 2,48\end{array}$

$\begin{array}{llll}\text { T4A } & 1,24 & 5,38 & 2,27\end{array}$

$\begin{array}{llll}\text { T4A } & 1,16 & 4,89 & 2,11\end{array}$

$\begin{array}{llll}\text { T4A } & 1,34 \quad 4,67 & 2,18\end{array}$

T4A $1,42 \quad 5,16 \quad 2,02$

$\begin{array}{llll}\text { T4A } & 1,17 & 3,82 & 1,8\end{array}$

T4A $1,36 \quad 5,56 \quad 3,1$

$\begin{array}{llll}\text { T4A } & 1,26 & 3,89 & 1,77\end{array}$

T4A 1,05 4,23 1,45

$\begin{array}{llll}\text { T4A } & 0,94 \quad 4,28 & 1,68\end{array}$

T4A $\quad 0,93 \quad 3,24 \quad 1,55$

$\begin{array}{llll}\text { T4A } & 0,94 & 3,38 & 1,64\end{array}$

$\begin{array}{llll}\text { T4A } & 0,90 & 2,82 & 1,38\end{array}$

$\begin{array}{llll}\text { T4A } & 0,98 & 3,94 & 1,72\end{array}$

$\begin{array}{llll}\text { T4A } & 0,93 & 2,98 & 1,54\end{array}$

T4A $1,03 \quad 3,54 \quad 1,71$

T4A $1,05 \quad 4,16 \quad 1,89$

T4A $1,07 \quad 4,11 \quad 2,13$

$\begin{array}{llll}\text { T4A } & 1,02 & 3,98 & 1,34\end{array}$

T4A $\quad 0,87 \quad 3,51 \quad 1,7$

$\begin{array}{llll}\text { T4A } & 1,02 & 3,55 & 1,66\end{array}$

$\begin{array}{llll}\text { T4A } & 0,83 \quad 4,52 \quad 1,78\end{array}$

$\begin{array}{llll}\text { T4A } & 1,06 & 4,34 & 2,24\end{array}$

T4A $1,06 \quad 5,57 \quad 1,71$

$\begin{array}{llll}\text { T4A } & 0,76 \quad 2,85 & 1,31\end{array}$

$\begin{array}{llll}\text { T4A } & 1,25 & 3,91 & 1,62\end{array}$

T4A $1,24 \quad 4,33 \quad 2,16$

$\begin{array}{llll}\text { T4A } & 1,56 & 4,68 & 2,24\end{array}$
Rp/Rz $\quad$ Ra

$0,42 \quad$ T4B 1,11

$0,45 \quad$ T4B $\quad 1,15$

0,34 Т4В 1,04

$0,50 \quad$ T4B 1,03

$0,30 \quad$ T4B 1,03

$0,40 \quad$ T4B 1,22

0,39 T4B 0,8

$0,48 \quad$ T4B 1,05

$0,41 \quad$ T4B 1,06

$0,43 \quad$ T4B 1,16

$0,37 \quad$ T4B 1,03

$0,50 \quad$ T4B 1,28

$0,46 \quad$ T4B 1,24

$0,48 \quad$ T4B 1,16

$0,44 \quad$ Т4В 0,79

$0,48 \quad$ Т4В 0,85

$0,45 \quad$ Т4В 0,86

$0,40 \quad$ T4B $\quad 0,74$

$0,46 \quad$ T4B $\quad 0,65$

$\begin{array}{lll}0,45 & \text { T4B } & 0,87\end{array}$

$0,48 \quad$ T4B $\quad 0,85$

$0,43 \quad$ T4B $\quad 0,77$

$0,49 \quad$ T4B 0,67

$0,46 \quad$ Т4В 0,92

$0,42 \quad$ T4B $\quad 0,96$

$0,43 \quad$ Т4B $\quad 0,91$

$0,47 \quad$ Т4В 0,65

$0,39 \quad$ Т4В 0,84

$0,47 \quad$ Т4В 0,68

$0,56 \quad$ Т4В 0,68

$0,46 \quad$ Т4В 0,98

0,34 T4B 1,18

$0,39 \quad$ Т4В 1,2

0,48 T4B 1,19

0,49 T4B 1,23

0,49 T4B 1,23

$0,44 \quad$ T4B 1,33

0,52 T4B 1,33

$0,48 \quad$ T4B 1,18

$0,45 \quad$ T4B $\quad 0,93$

$0,52 \quad$ T4B $\quad 1,15$

$0,34 \quad$ T4B $\quad 1,12$

$0,48 \quad$ T4B $\quad 1,2$

$0,47 \quad$ Т4В 1,25

$0,39 \quad$ Т4В 1,11

$0,52 \quad$ T4B 1,21

$0,31 \quad$ T4B $\quad 1,1$

$0,46 \quad$ Т4В 1,28

$0,41 \quad$ Т4В 0,91

$0,50 \quad$ T4B 1,03

$0,48 \quad$ T4B 0,97
Rz Rp Rp/Rz

$\begin{array}{llll}0,47 & \mathbf{R a} & \mathbf{R}\end{array}$

$4,7 \quad 2,23$

$6,82 \quad 2,92$

0,43 T5A 0,82$$
\begin{array}{llllll}
0,52 & \text { T5A } & 1,09 & 4,09 & 1,79 & 0,44
\end{array}
$$

$\begin{array}{ll}4,91 & 2,56 \\ 4,57 & 2,31\end{array}$

$0,51 \quad$ T5A $\quad 0,75$

$5,19 \quad 2,23$

$6,05 \quad 2,73$$$
0,43
$$

$\begin{array}{lll}0,43 & \text { T5A } & 0,72 \\ 0,45 & \text { T5A } & 1,34\end{array}$

$3,53 \quad 1,69$

$0,48 \quad$ T5A $\quad 0,76$

$4,83 \quad 2,13$

$5,56 \quad 2,48$

$0,44 \quad$ T5A $\quad 0,57$

$6,73 \quad 2,43$

$0,45 \quad$ T5A $\quad 0,85$

$0,36 \quad T 5 A \quad 0,66$

$4,23 \quad 2,16$

$\begin{array}{llllll}0,51 & \text { T5A } & 0,88 & 3,56 & 1,75 & 0,49\end{array}$

$5,48 \quad 2,57$

$4,74 \quad 2,57$

$0,47 \quad$ T5A 1,33

$0,54 \quad$ T5A 1,25

$0,48 \quad$ T5A 1,56

$0,37 \quad$ T5A 1,35

$3,82 \quad 1,41$

$5,49 \quad 1,93$

$0,35 \quad$ T5A 1,42

$0,36 \quad$ T5A $\quad 0,67$

$0,30 \quad$ T5A $\quad 0,67$

$0,35 \quad$ T5A $\quad 0,55$

2,76

$0,36 \quad$ T5A $\quad 0,68 \quad 3,96$

$0,38 \quad$ T5A $\quad 0,65 \quad 3,43$

$0,37 \quad$ T5A $\quad 0,67 \quad 3,16$

$0,36 \quad$ T5A $1,15 \quad 4,57$

$\begin{array}{llll}0,37 & \text { T5A } & 1,5 & 5,41\end{array}$

$0,37 \quad$ T5A $\quad 1,08 \quad 5,21$

$0,43 \quad$ T5A $\quad 1,66$

$6,4 \quad 2,87$

$\begin{array}{lllll}0,36 & \text { T5A } & 1,68 & 5,1 & 2,06\end{array}$

$\begin{array}{lllll}0,39 & \text { T5A } & 1,41 & 4,32 & 2,06\end{array}$

$\begin{array}{lllll}0,35 & \text { T5A } & 1,65 & 5,37 & 2,19\end{array}$

$0,35 \quad$ T5A $\quad 1,65 \quad 5,44 \quad 2,22$

$\begin{array}{lllll}0,36 & \text { T5A } & 1,49 & 5,33 & 2,34\end{array}$

$\begin{array}{lllll}0,40 & \text { T5A } & 1,63 & 6,01 & 2,41\end{array}$

$0,50 \quad$ T5A $\quad 1,66 \quad 4,18 \quad 2,02$

$\begin{array}{rrrrr}0,34 & \text { T5A } & 1,6 & 4,85 & 2,21\end{array}$

$\begin{array}{rrrrr}0,39 & \text { T5A } & 0,6 & 2,59 & 1,09 \\ 0,43 & \text { T5A } & 1,12 & 2,76 & 1,28\end{array}$

$\begin{array}{lllll}0,41 & \text { T5A } & 1,55 & 4,51 & 2,36\end{array}$

$\begin{array}{lllll}0,38 & \text { T5A } & 1,63 & 4,73 & 2,42\end{array}$

$\begin{array}{lllll}0,39 & \text { T5A } & 0,93 & 5,65 & 1,41\end{array}$

$\begin{array}{lllll}0,44 & \text { T5A } & 1,5 & 3,9 & 1,89\end{array}$

$\begin{array}{lllll}0,45 & \text { T5A } & 0,57 & 3,01 & 1,29\end{array}$

$\begin{array}{lllll}0,46 & \text { T5A } & 1,43 & 4,2 & 1,85\end{array}$

$\begin{array}{lllll}0,52 & \text { T5A } & 0,84 & 6,28 & 1,98\end{array}$

$\begin{array}{lllll}0,42 & \text { T5A } & 0,94 & 4,05 & 1,77\end{array}$

$\begin{array}{lllll}0,43 & \text { T5A } & 0,51 & 2,5 & 1,02\end{array}$

$\begin{array}{lllll}0,46 & \text { T5A } & 0,97 & 3,25 & 1,45\end{array}$

$\begin{array}{lllll}0,48 & \text { T5A } & 1,54 & 4,46 & 2,37\end{array}$

$0,37 \quad$ T5A $\quad 0,92 \quad 2,68 \quad 1,22$

$\begin{array}{lllll}0,38 & \text { T5A } & 1,12 & 3,95 & 1,67\end{array}$

$\begin{array}{lllll}0,31 & \text { T5A } & 1,39 & 3,47 & 1,67\end{array}$

$\begin{array}{lllll}0,31 & \text { T5A } & 0,54 & 2,29 & 1,14\end{array}$
Rp/Rz

0,48

0,44

0,44

0,48

0,40

0,44

0,39

0,47

0,42

0,42

0,50

0,41

0,45

0,34

0,48

0,49

0,49

0,51

0,40

0,51

0,46

0,46

0,55

0,45

0,40

0,48

0,41

0,41

0,44

0,40

0,48

0,46

0,42

0,46

0,52

0,51

0,25

0,48

0,43

0,44

0,32

0,44

0,41

0,45

0,53

0,46

0,42

0,48

0,50

continua 
continuação

\begin{tabular}{|c|c|c|c|c|c|c|c|c|c|c|c|c|c|c|}
\hline & $\mathbf{R a}$ & Rz & Rp & Rp/Rz & & $\mathbf{R a}$ & Rz & Rp & Rp/Rz & & $\mathbf{R a}$ & Rz & Rp & Rp/Rz \\
\hline T4A & 0,83 & 4,16 & 1,83 & 0,44 & T4B & 0,99 & 4,48 & 1,86 & 0,42 & T5A & 1,32 & 3,3 & 1,45 & 0,44 \\
\hline $4 \mathrm{~A}$ & 0,86 & 2,91 & 1,16 & 0,40 & T4B & 0,99 & 3,98 & 1,66 & 0,42 & T5A & 0,7 & 2,75 & 1,32 & 0,48 \\
\hline$\Gamma 4 \mathrm{~A}$ & 1,18 & 4,99 & 1,82 & 0,36 & T4B & 1,08 & 4,88 & 2,18 & 0,45 & T5A & 0,89 & 3,8 & 1,18 & 0,31 \\
\hline $4 \mathrm{~A}$ & 0,69 & 4,71 & 1,5 & 0,32 & T4B & 1,01 & 5,11 & 1,65 & 0,32 & T5A & 1,47 & 3,46 & 1,70 & 0,49 \\
\hline T4A & 0,89 & 3,04 & 1,22 & 0,40 & T4B & 0,86 & 4,24 & 1,59 & 0,38 & T5A & 1,56 & 3,95 & 1,83 & 0,46 \\
\hline$\Gamma 4 \mathrm{~A}$ & 1,25 & 3,30 & 1,53 & 0,46 & T4B & 0,74 & 3,2 & 1,1 & 0,34 & T5A & 1 & 5,88 & 1,49 & 0,25 \\
\hline $4 \mathrm{~A}$ & 0,55 & 3,10 & 1,14 & 0,37 & T4B & 0,9 & 4,15 & 1,43 & 0,34 & T5A & 0,79 & 3,54 & 1,21 & 0,34 \\
\hline $4 \mathrm{~A}$ & 1,51 & 4,19 & 2,34 & 0,56 & T4B & 0,86 & 3,61 & 1,74 & 0,48 & T5A & 1,24 & 4,6 & 1,51 & 0,33 \\
\hline T4A & 0,89 & 3,30 & 1,33 & 0,40 & T4B & 0,85 & 4,69 & 2 & 0,43 & T5A & 1,12 & 3,61 & 1,68 & 0,47 \\
\hline T4A & 0,75 & 3,04 & 1,53 & 0,50 & T4B & 0,95 & 4,14 & 1,48 & 0,36 & T5A & 0,81 & 2,93 & 1,41 & 0,48 \\
\hline$\Gamma 4 \mathrm{~A}$ & 0,89 & 4,42 & 1,53 & 0,35 & T4B & 1,06 & 6,38 & 1,72 & 0,27 & T5A & 1,2 & 3,39 & 1,10 & 0,32 \\
\hline $4 \mathrm{~A}$ & 1,26 & 4,30 & 1,83 & 0,43 & T4B & 0,78 & 4,45 & 1,78 & 0,40 & T5A & 1,22 & 3,59 & 1,50 & 0,42 \\
\hline $4 \mathrm{~A}$ & 0,75 & 4,18 & 1,51 & 0,36 & T4B & 0,73 & 3,6 & 1,55 & 0,43 & T5A & 1,22 & 4,31 & 1,79 & 0,42 \\
\hline T4A & 1,51 & 5,05 & 2,05 & 0,41 & T4B & 1,04 & 5,13 & 1,82 & 0,35 & T5A & 0,91 & 3,79 & 1,55 & 0,41 \\
\hline T5B & 1,07 & 4,06 & 1,71 & 0,42 & T6A & 0,74 & 3,79 & 2,03 & 0,54 & T6B & 0,98 & 3,88 & 1,82 & 0,47 \\
\hline T5B & 0,97 & 3,69 & 1,47 & 0,40 & T6A & 0,81 & 3,3 & 1,63 & 0,49 & T6B & 0,82 & 3,48 & 1,46 & 0,42 \\
\hline $5 B$ & 1,27 & 6,11 & 1,87 & 0,31 & T6A & 0,52 & 2,46 & 1,07 & 0,43 & T6B & 0,9 & 3,67 & 1,79 & 0,49 \\
\hline T5B & 0,93 & 3,2 & 1,34 & 0,42 & T6A & 0,53 & 2,69 & 1,4 & 0,52 & T6B & 1,18 & 4,47 & 2,18 & 0,49 \\
\hline T5B & 1,12 & 4,34 & 1,6 & 0,37 & T6A & 0,72 & 3,19 & 1,73 & 0,54 & T6B & 0,94 & 3,44 & 1,7 & 0,49 \\
\hline T5B & 1,05 & 3,7 & 1,78 & 0,48 & T6A & 0,55 & 2,23 & 1,07 & 0,48 & T6B & 1,08 & 4,93 & 2,43 & 0,49 \\
\hline T5B & 0,92 & 3,47 & 1,15 & 0,33 & T6A & 0,59 & 2,58 & 1,17 & 0,45 & T6B & 0,78 & 3,59 & 1,52 & 0,42 \\
\hline T5B & 0,94 & 2,97 & 1,41 & 0,47 & T6A & 0,45 & 2,47 & 1,05 & 0,43 & T6B & 0,8 & 3,67 & 1,57 & 0,43 \\
\hline T5B & 0,9 & 2,96 & 1,23 & 0,42 & T6A & 0,92 & 3,47 & 1,76 & 0,51 & T6B & 1,07 & 3,61 & 1,61 & 0,45 \\
\hline T5B & 1,16 & 4,64 & 1,91 & 0,41 & T6A & 0,5 & 3,3 & 1,43 & 0,43 & T6B & 0,85 & 3,55 & 1,36 & 0,38 \\
\hline T5B & 1,14 & 3,18 & 1,56 & 0,49 & T6A & 0,9 & 4,27 & 2,03 & 0,48 & T6B & 1,09 & 3,69 & 1,69 & 0,46 \\
\hline T5B & 0,94 & 2,77 & 1,37 & 0,49 & T6A & 0,53 & 2,96 & 1,49 & 0,50 & T6B & 0,79 & 2,1 & 0,91 & 0,42 \\
\hline T5B & 1,17 & 4,43 & 1,83 & 0,41 & T6A & 0,51 & 2,66 & 1,07 & 0,40 & T6B & 0,62 & 2,41 & 0,9 & 0,37 \\
\hline T5B & 0,91 & 3,48 & 1,32 & 0,38 & T6A & 0,41 & 2,34 & 1,05 & 0,45 & T6B & 0,63 & 2,18 & 0,84 & 0,39 \\
\hline T5B & 1,17 & 3,18 & 1,35 & 0,42 & T6A & 0,39 & 2,37 & 1,03 & 0,43 & T6B & 0,76 & 3,14 & 1,05 & 0,33 \\
\hline T5B & 1,12 & 3,34 & 1,46 & 0,44 & T6A & 0,4 & 2,47 & & 0,45 & T6B & 0,78 & 2,5 & 1,15 & 0,45 \\
\hline T5B & 1,17 & 3,43 & 1,64 & 0,48 & T6A & 0,6 & 3,09 & 1,64 & 0,53 & T6B & 0,9 & & 1,3 & 0,43 \\
\hline T5B & 1,07 & 4,55 & 1,65 & 0,36 & T6A & 1,03 & 2,88 & 1,41 & 0,49 & T6B & 0,92 & 3,52 & 1,17 & 0,33 \\
\hline T5B & 1,06 & 3,77 & 1,43 & 0,38 & T6A & 1,1 & 3,44 & 1,45 & 0,42 & T6B & 0,97 & 4,02 & 1,55 & 0,39 \\
\hline T5B & 1,03 & 4,32 & 1,6 & 0,37 & T6A & 0,99 & 4,18 & 2,15 & 0,51 & T6B & 0,85 & 2,56 & 1,16 & 0,45 \\
\hline T5B & 0,97 & 4,26 & 1,61 & 0,38 & T6A & 0,9 & & & 0,44 & T6B & 0,74 & 3,0 & & 0,44 \\
\hline T5B & 0,99 & 4,31 & 1,64 & 0,38 & T6A & 1,13 & 3,51 & 1,69 & 0,48 & T6B & 0,79 & 2,6 & 1,3 & 0,50 \\
\hline T5B & 1,06 & 3,64 & 1,49 & 0,41 & T6A & 0,99 & 3,25 & 1,36 & 0,42 & T6B & 0,73 & 3,05 & 1,46 & 0,48 \\
\hline T5B & 1,27 & 4,56 & 1,81 & 0,40 & T6A & 1,08 & 4,42 & 1,93 & 0,44 & T6B & 0,67 & 2,83 & 1,49 & 0,53 \\
\hline T5B & 1,32 & 4,88 & 1,85 & 0,38 & T6A & 1,05 & 3,92 & 1,98 & 0,51 & T6B & 0,81 & 3,46 & & 0,30 \\
\hline T5B & 1,07 & 4,54 & 2,15 & 0,47 & T6A & 1,07 & 4,94 & 1,96 & 0,40 & T6B & 0,78 & 3,44 & & 0,36 \\
\hline T5B & 1,12 & 4,94 & 2,19 & 0,44 & T6A & 0,94 & 3,64 & 1,45 & 0,40 & T6B & 1,09 & 3,65 & 1,59 & 0,44 \\
\hline T5B & 1,31 & 4,58 & 2,1 & 0,46 & T6A & 1,15 & 3,16 & 1,57 & 0,50 & T6B & 0,76 & 4,27 & 1,19 & 0,28 \\
\hline T5B & 1,09 & 3,85 & 1,66 & 0,43 & T6A & 0,61 & 2,7 & 1,38 & 0,51 & T6B & 0,8 & 3,15 & 1,38 & 0,44 \\
\hline T5B & 1,29 & 4,66 & 2,58 & 0,55 & T6A & 0,97 & 4,46 & 1,63 & 0,37 & T6B & 0,74 & 3 & 1,19 & 0,40 \\
\hline T5B & 1,29 & 4,41 & 2,29 & 0,52 & T6A & 0,98 & 3,55 & 1,89 & 0,53 & T6B & 1,05 & 3,65 & 1,33 & 0,36 \\
\hline T5B & 1,07 & 4,76 & 2,24 & 0,47 & T6A & 0,92 & 3,73 & 1,87 & 0,50 & T6B & 0,76 & 3,01 & 1,23 & 0,41 \\
\hline T5B & 1,09 & 4,64 & 2,2 & 0,47 & T6A & 1,1 & 4,58 & 2,05 & 0,45 & T6B & 0,84 & 2,36 & 1,24 & 0,53 \\
\hline T5B & 1,27 & 4,21 & 2,17 & 0,52 & T6A & 0,85 & 3,83 & 1,93 & 0,50 & T6B & 0,83 & 3,08 & 1,18 & 0,38 \\
\hline T5B & 1,05 & 4,75 & 1,97 & 0,41 & T6A & 0,81 & 4,16 & 2,06 & 0,50 & T6B & 0,76 & 4,33 & 1,19 & 0,27 \\
\hline T5B & 0,98 & 4,03 & 1,71 & 0,42 & T6A & 0,87 & 4,24 & 2,02 & 0,48 & T6B & 0,89 & 3,64 & 1,34 & 0,37 \\
\hline
\end{tabular}


continuação

\begin{tabular}{|c|c|c|c|c|c|c|c|c|c|c|c|c|c|c|}
\hline & $\mathbf{R a}$ & Rz & Rp & Rp/Rz & & $\mathbf{R a}$ & Rz & Rp & Rp/Rz & & $\mathbf{R a}$ & Rz & Rp & Rp/Rz \\
\hline T5B & 1,19 & 4,43 & 2,05 & 0,46 & T6A & 0,93 & 3,81 & 1,6 & 0,42 & T6B & 1,09 & 3,12 & 1,47 & 0,47 \\
\hline $5 B$ & 0,96 & 4,26 & 1,7 & 0,40 & T6A & 1,03 & 2,96 & 1,63 & 0,55 & T6B & 1,07 & 3,46 & 1,63 & 0,47 \\
\hline $5 B$ & 1,02 & 4,18 & 1,54 & 0,37 & T6A & 0,98 & 3,74 & 1,68 & 0,45 & T6B & 0,77 & 2,73 & 1,33 & 0,49 \\
\hline $5 B$ & 0,98 & 3,92 & 1,64 & 0,42 & T6A & 1 & 2,98 & 1,53 & 0,51 & T6B & 0,76 & 2,42 & 1,16 & 0,48 \\
\hline $5 B$ & 0,73 & 3,77 & 1,53 & 0,41 & T6A & 0,87 & 3,23 & 1,56 & 0,48 & T6B & 0,74 & 3,11 & 1,35 & 0,43 \\
\hline $5 B$ & 1,03 & 4,22 & 1,44 & 0,34 & T6A & 0,96 & 2,89 & 1,47 & 0,51 & T6B & 0,8 & 5,51 & 1,28 & 0,23 \\
\hline $5 B$ & 1,1 & 4,65 & 1,44 & 0,31 & T6A & 0,83 & 3,98 & 1,73 & 0,43 & T6B & 1,02 & 4,24 & 1,61 & 0,38 \\
\hline $5 B$ & 0,98 & 4,25 & 1,38 & 0,32 & T6A & 0,79 & 3,76 & 1,91 & 0,51 & T6B & 0,86 & 2,78 & 1,46 & 0,53 \\
\hline $5 B$ & 0,82 & 4,17 & 1,37 & 0,33 & T6A & 0,6 & 2,52 & 1,18 & 0,47 & T6B & 0,75 & 2,89 & 1,33 & 0,46 \\
\hline $5 \mathrm{~B}$ & 0,7 & 3,56 & 1,32 & 0,37 & T6A & 0,86 & 2,96 & 1,46 & 0,49 & T6B & 0,74 & 2,84 & 1,02 & 0,36 \\
\hline T5B & 0,78 & 3,32 & 1,38 & 0,42 & T6A & 0,95 & 3,39 & 1,78 & 0,53 & T6B & 1,02 & 3,65 & 1,58 & 0,43 \\
\hline $5 \mathrm{~B}$ & 0,93 & 4,09 & 1,32 & 0,32 & T6A & 0,79 & 3,22 & 1,46 & 0,45 & T6B & 1,04 & 3,98 & 1,52 & 0,38 \\
\hline $5 B$ & 0,82 & 3,85 & 1,45 & 0,38 & T6A & 0,94 & 3,1 & 1,61 & 0,52 & T6B & 0,77 & 3,14 & 1,33 & 0,42 \\
\hline $5 \mathrm{~B}$ & 1,06 & 3,71 & 1,4 & 0,38 & T6A & 0,89 & 4,4 & 1,61 & 0,37 & T6B & 0,81 & 98 & 1,17 & 0,39 \\
\hline T5B & 1,03 & 4,55 & 1,76 & 0,39 & T6A & 0,8 & 2,93 & 1,23 & 0,42 & T6B & 0,79 & 2,46 & 0,97 & 0,39 \\
\hline T5B & 0,86 & 3,44 & 1,35 & 0,39 & T6A & 0,92 & 3,22 & 1,44 & 0,45 & T6B & 0,77 & 2,94 & 1,29 & 0,44 \\
\hline $5 B$ & 0,99 & 5,76 & 1,4 & 0,24 & T6A & 1,03 & 3,63 & 1,74 & 0,48 & T6B & 0,91 & 3,43 & 1,27 & 0,37 \\
\hline T5B & 1,02 & 3,64 & 1,39 & 0,38 & T6A & 0,84 & 3,12 & 1,6 & 0,51 & T6B & 0,81 & 2,6 & 1,14 & 0,44 \\
\hline T5B & 0,95 & 4,01 & 1,29 & 0,32 & T6A & 0,92 & 3,31 & 1,49 & 0,45 & T6B & 0,94 & 3,55 & 1,49 & 0,42 \\
\hline T5B & 1,16 & 5,72 & 1,61 & 0,28 & T6A & 0,86 & 2,99 & 1,64 & 0,55 & T6B & 0,78 & 3,39 & 1,33 & 0,39 \\
\hline $5 \mathrm{~B}$ & 0,96 & 5,1 & 1,63 & 0,32 & T6A & 0,85 & 3,27 & 1,51 & 0,46 & T6B & 0,89 & 2,46 & 1,02 & 0,41 \\
\hline T5B & 1,06 & 5,9 & 1,5 & 0,25 & T6A & 0,99 & 3,87 & 1,34 & ,35 & T6B & & & 1,26 & 0,33 \\
\hline T5B & 1,01 & 4,17 & 1,54 & 0,37 & T6A & 1,04 & 2,96 & 1,26 & 0,43 & T6B & 0,88 & 2,46 & 1,09 & 0,44 \\
\hline T5B & 0,77 & 3,93 & 1,25 & 0,32 & T6A & 1,04 & 3,04 & 1,27 & 0,42 & T6B & 0,9 & 2,47 & 1,26 & 0,51 \\
\hline T5B & 1,03 & 4,09 & 1,57 & 0,38 & T6A & 1,04 & 4,24 & 2,06 & 0,49 & T6B & 0,83 & 2,51 & 1,24 & 0,49 \\
\hline T5B & 1,02 & 4,29 & 1,46 & 0,34 & T6A & 1,01 & 3,51 & 1,72 & 0,49 & T6B & & & 1,28 & 0,32 \\
\hline T5B & 1,04 & 3,57 & 1,4 & 0,39 & T6A & 1,08 & 3,73 & 2 & 0,54 & T6B & 0,69 & 2,58 & 0,98 & 0,38 \\
\hline T5B & 0,71 & 3,87 & 1,35 & 0,35 & T6A & 1,05 & 4 & 1,94 & 0,49 & T6B & 1,02 & 2,49 & 1,08 & 0,43 \\
\hline T5B & 0,82 & 3,53 & 1,24 & 0,35 & T6A & 0,98 & 3,93 & 2 & 0,51 & T6B & 0,64 & 5,55 & 1,27 & 0,23 \\
\hline $5 \mathrm{~B}$ & 0,83 & 3,19 & 1,18 & 0,37 & T6A & 0,88 & 3 & 1,54 & 0,51 & T6B & 0,66 & 3,27 & 1 & 0,31 \\
\hline T5B & 0,79 & 4,62 & 1,41 & 0,31 & T6A & 0,85 & 2,96 & 1,54 & 0,52 & T6B & & & 1,15 & 0,36 \\
\hline T5B & 1,08 & 4,11 & 1,93 & 0,47 & T6A & 1,1 & 3,86 & 2,01 & 0,52 & T6B & 0,79 & 3,69 & 1,56 & 0,42 \\
\hline T5B & 1,31 & 4,24 & 1,81 & 0,43 & T6A & 0,93 & 3,22 & 1,66 & 0,52 & T6B & 0,66 & 2,57 & 1,11 & 0,43 \\
\hline $5 \mathrm{~B}$ & 1,01 & 4,11 & 1 & 0,41 & T6A & 0,87 & 2,91 & 1,46 & 0,50 & T6B & 1,03 & 3,84 & 1,66 & 0,43 \\
\hline T5B & 1,16 & 4,34 & 1,76 & 0,41 & T6A & 1 & 4 & 1,75 & 0,44 & T6B & & & & 0,38 \\
\hline T5B & 1,12 & 4,98 & 1,97 & 0,40 & T6A & 0,65 & 2,71 & 1,23 & 0,45 & T6B & 1,03 & 3,26 & 1,53 & 0,47 \\
\hline T5B & 0,98 & 4,14 & 1,48 & 0,36 & T6A & 0,96 & 4,13 & 2,31 & 0,56 & T6B & 0,69 & 3,43 & 1,41 & 0,41 \\
\hline T5B & 1,04 & 4,43 & 1,7 & 0,38 & T6A & 1,07 & 4,36 & 1,83 & 0,42 & T6B & 0,64 & 2,94 & 1,44 & 0,49 \\
\hline T5B & 1,04 & 2,6 & 1,22 & 0,47 & T6A & 0,9 & 3,13 & 1,52 & 0,49 & T6B & 0,68 & 3,15 & 1,32 & 0,42 \\
\hline T5B & 0,92 & 2,26 & 1,09 & 0,48 & T6A & 0,75 & 3,59 & 1,45 & 0,40 & T6B & 0,68 & 2,38 & 1,15 & 0,48 \\
\hline T5B & 0,82 & 2,88 & 0,94 & 0,33 & T6A & 0,74 & 2,85 & 1,44 & 0,51 & T6B & 0,98 & 3,6 & 1,64 & 0,46 \\
\hline T5B & 0,73 & 2,44 & 1,16 & 0,48 & T6A & 0,74 & 2,68 & 1,43 & 0,53 & T6B & 0,86 & 3,22 & 1,29 & 0,40 \\
\hline T5B & 1,02 & 4,67 & 1,95 & 0,42 & T6A & 0,84 & 3,75 & 1,46 & 0,39 & T6B & 0,98 & 2,8 & 1,37 & 0,49 \\
\hline T5B & 0,87 & 3,24 & 1,44 & 0,44 & T6A & 1,02 & 4,04 & 1,54 & 0,38 & T6B & 0,91 & 3,45 & 1,67 & 0,48 \\
\hline T5B & 0,87 & 4,82 & 1,37 & 0,28 & T6A & 0,57 & 2,94 & 1,38 & 0,47 & T6B & 0,95 & 4,07 & 2,07 & 0,51 \\
\hline T5B & 1,08 & 4,56 & 1,37 & 0,30 & T6A & 0,56 & 3,09 & 1,43 & 0,46 & T6B & 0,93 & 4,17 & 2,17 & 0,52 \\
\hline T5B & 0,83 & 3,59 & 1,73 & 0,48 & T6A & 1,12 & 4,24 & 1,84 & 0,43 & T6B & 0,95 & 3,67 & 1,91 & 0,52 \\
\hline T5B & 0,93 & 3,03 & 1,53 & 0,50 & T6A & 0,55 & 2,95 & 1,48 & 0,50 & T6B & 0,87 & 3,2 & 1,46 & 0,46 \\
\hline T5B & 0,98 & 4,6 & 1,06 & 0,23 & T6A & 0,51 & 2,91 & 1,34 & 0,46 & T6B & 0,67 & 3,06 & 1,53 & 0,50 \\
\hline T5B & 1,08 & 4,1 & 1,43 & 0,35 & T6A & 0,63 & 3,06 & 1,17 & 0,38 & T6B & 0,89 & 3,19 & 1,51 & 0,47 \\
\hline
\end{tabular}

continua 
conclusão

\begin{tabular}{|c|c|c|c|c|c|c|c|c|c|c|c|c|c|c|}
\hline & $\mathbf{R a}$ & Rz & Rp & Rp/Rz & & $\mathbf{R a}$ & Rz & Rp & Rp/Rz & & $\mathbf{R a}$ & Rz & Rp & $R p / R z$ \\
\hline T5B & 1,17 & 4,43 & 1,85 & 0,42 & T6A & 0,51 & 2,53 & 1,27 & 0,50 & T6B & 1,04 & 4,27 & 1,93 & 0,45 \\
\hline T5B & 1,28 & 4,52 & 2,26 & 0,50 & T6A & 0,8 & 2,65 & 1,21 & 0,46 & T6B & 0,82 & 3,21 & 1,43 & 0,45 \\
\hline T5B & 1,15 & 5,62 & 2,01 & 0,36 & T6A & 0,6 & 3,11 & 1,34 & 0,43 & T6B & 0,84 & 3,98 & 1,29 & 0,32 \\
\hline T5B & 1,39 & 4,77 & 2,43 & 0,51 & T6A & 0,88 & 4,51 & 1,66 & 0,37 & T6B & 0,8 & 3,32 & 1,3 & 0,39 \\
\hline T5B & 1,03 & 4,39 & 1,72 & 0,39 & T6A & 0,64 & 3,34 & 1,38 & 0,41 & T6B & 0,91 & 4,39 & 1,59 & 0,36 \\
\hline T5B & 1,06 & 3,56 & 1,78 & 0,50 & T6A & 0,6 & 3,24 & 1,48 & 0,46 & T6B & 0,82 & 3,39 & 1,2 & 0,35 \\
\hline T5B & 1,26 & 4,38 & 1,87 & 0,43 & T6A & 0,72 & 3,24 & 1,6 & 0,49 & T6B & 1,08 & 4,35 & 2,56 & 0,59 \\
\hline T5B & 1,25 & 3,45 & 1,57 & 0,46 & T6A & 0,71 & 2,51 & 1,17 & 0,47 & T6B & 0,76 & 3,78 & 1,36 & 0,36 \\
\hline T5B & 1,12 & 4,31 & 1,78 & 0,41 & T6A & 0,51 & 2,85 & 1,34 & 0,47 & T6B & 0,94 & 4,86 & 1,71 & 0,35 \\
\hline T5B & 0,88 & 3,14 & 1,43 & 0,46 & T6A & 0,52 & 3,01 & 1,4 & 0,47 & T6B & 1,08 & 3,85 & 1,77 & 0,46 \\
\hline T5B & 0,92 & 3,26 & 1,34 & 0,41 & T6A & 0,78 & 2,8 & 1,3 & 0,46 & T6B & 0,72 & 3,44 & 1,56 & 0,45 \\
\hline T5B & 0,95 & 2,93 & 1,02 & 0,35 & T6A & 0,8 & 2,95 & 1,34 & 0,45 & T6B & 0,6 & 2,9 & 1,61 & 0,56 \\
\hline T5B & 1,05 & 4,03 & 1,74 & 0,43 & T6A & 0,53 & 2,65 & 1,22 & 0,46 & T6B & 0,91 & 3,96 & 1,94 & 0,49 \\
\hline T5B & 1 & 5,07 & 1,6 & 0,32 & T6A & 0,59 & 3,09 & 1,31 & 0,42 & T6B & 0,91 & 3,69 & 2,07 & 0,56 \\
\hline T5B & 1,22 & 3,7 & 1,86 & 0,50 & T6A & 0,94 & 3,78 & 1,58 & 0,42 & T6B & 0,7 & 2,9 & 1,38 & 0,48 \\
\hline T5B & 1,07 & 3,91 & 1,53 & 0,39 & T6A & 0,51 & 2,6 & 1,28 & 0,49 & T6B & 0,87 & 3,86 & 1,59 & 0,41 \\
\hline
\end{tabular}

